\title{
Evaluation of the use of remotely sensed images to speciate mixed Appalachian forests
}

Doru Ioan Pacurari

West Virginia University

Follow this and additional works at: https://researchrepository.wvu.edu/etd

\section{Recommended Citation}

Pacurari, Doru loan, "Evaluation of the use of remotely sensed images to speciate mixed Appalachian forests" (2000). Graduate Theses, Dissertations, and Problem Reports. 1068.

https://researchrepository.wvu.edu/etd/1068

This Thesis is protected by copyright and/or related rights. It has been brought to you by the The Research Repository @ WVU with permission from the rights-holder(s). You are free to use this Thesis in any way that is permitted by the copyright and related rights legislation that applies to your use. For other uses you must obtain permission from the rights-holder(s) directly, unless additional rights are indicated by a Creative Commons license in the record and/ or on the work itself. This Thesis has been accepted for inclusion in WVU Graduate Theses, Dissertations, and Problem Reports collection by an authorized administrator of The Research Repository @ WVU. For more information, please contact researchrepository@mail.wvu.edu. 


\title{
Evaluation of the Use of Remotely Sensed Images to Speciate Mixed Appalachian Forests
}

\author{
Doru I. Pacurari
}

\author{
Thesis submitted to the College of \\ Agriculture, Forestry and Consumer Science \\ at West Virginia University \\ in partial fulfillment of the requirements \\ for the degree of \\ Master of Science \\ In \\ Forestry
}

\author{
Linda Gribko, Ph.D., Chair \\ Joe McNeel, Ph.D. \\ Timothy Warner, Ph.D. \\ Charlie Yuill, M.L.A. \\ Division of Forestry
}

Morgantown, West Virginia

2000

Keywords: Remote Sensing, Airborne Digital Images, Forest Management, Forest Trees Classification and Spatial Statistics 


\section{ABSTRACT}

\section{Evaluation of the use of remotely sensed images to speciate mixed Appalachian forests}

\section{Doru Pacurari}

Advancements in technology have led to development of various new sensors and platforms. Among them, the airborne digital camera has potential for use in detailed forest vegetation management. Digital cameras offer a number of advantages over conventional aerial photographs because they are generally lower in cost than 70-mm and other large format photographic cameras. Furthermore, there is no need for film development and subsequent scanning.

The aim of the study was to determine the ability to speciate mixed Appalachian hardwood forests using the Airborne Data Acquisition and Registration (ADAR) System 1000 , and to determine the optimal spatial resolution and the optimal scale of the acquired images. Digital images of a 200-ha area in west central West Virginia were acquired for the study. The first objective of the study was to determine the optimal spatial resolution of Central Appalachian hardwoods images through analysis of spatial autocorrelation and semivariance. The images used for this part of the study are of a very high spatial resolution, with a $0.18-\mathrm{m}$ pixel size. Spatial autocorrelation was measured using spatial profiles of the imagery. Semivariance was calculated using matrix files (images). As a control method, measurements were made in 182 field plots, each 400 square meters. The optimum value of spatial resolution based on autocorrelation measurements was 6.4 meters. The average value of the range of the semivariograms was 6.7 meters in the Rook case and 7 meters in the Bishop case. The relationship between diameter at breast height and tree crown diameter collected in the field suggested an average crown diameter of 6.9 meters.

Consequently, the optimal spatial resolution for these Appalachian Hardwoods plots is between 6 and 7 meters and corresponds to the average crown size. But, it is unlikely that a tree crown will be covered by a single pixel that is equal to the size of the tree crown. Hence, the next objective of the study was to determine the optimal scale of the acquired images, which represents the pixel size at which the classification accuracy was optimized. The images used for this part of the study were color-infrared with a pixel size of $0.44-\mathrm{m}$. A mosaicked image of the study was upscaled, and the upscaled images were classified using the Maximum Likelihood classifier. The species composition derived from classifications of increasingly upscaled images was compared with the species composition estimated from the ground data. The last upscaled image that produced correct species composition had 1.8-m resolution. So, the optimal scale of the acquire images was approximately $2 \mathrm{~m}$, or one-third the pixel size estimated by the semivariance and autocorrelation. 
The third objective of the study was to evaluate the ability to determine the species composition of the study area using the acquired images. Three sets of mosaicked images were used: color-infrared with $0.5-\mathrm{m}$ resolution, visible with $0.5-\mathrm{m}$ resolution and color-infrared with 1-m resolution. The images were classified using the Maximum Likelihood classifier. Accuracy assessment was conducted, the Kappa statistic and the species composition was determined for the whole study area and for six aspect-based subunits. The color-infrared image with $0.5-\mathrm{m}$ resolution produced the best results, with an overall accuracy of $73.1 \%$ and a Kappa statistic of 0.69 . The color-infrared image with 1-m resolution performed fairly well. The visible image was acquired on a dimly lit day and produced poor results. From the 0.5 -m color-infrared images, tree species could be correctly and accurately determined, and the compositions derived from the classifications of those mosaics were extremely close to the "true" ground estimated compositions. 


\section{DEDICATION}

This work is dedicated to God

and to my family. 


\section{AKNOWLEDGEMENTS}

First, thanks and glory to God, who freely and lovingly gave the strength, motivation, wisdom and encouragement to see me through the difficult times.

Were it not for the aid, support and encouragement of many people, this thesis would not be what it is. I would therefore like to formally recognize some of those who helped me along the way towards the realization of this goal at the West Virginia University.

Dr. Linda Gribko, my thesis supervisor, very generously contributed constructive feedback on many parts of the thesis. She suffered through many of the early drafts of the thesis, and helped me to organize the fieldwork.

I thank Dr. Joe McNeel, who helped me to come and study at West Virginia University, and also for the moments when he gave me moral support and encouragement.

Dr. Tim Warner is the prime source of most of the technical ideas that are the building blocks of the thesis. In the precious time we spent together I acquired esteem for his competence, trust, experience and talent for obtaining results. He deserves credit for allowing the work in the research laboratory of the Department of Geology and Geography, in which the work for the thesis was done. He even gave me comments by electronic mail during his sabbatical in France. For all that I am very grateful.

Professor Yuill very generously allowed me to use the ADAR 1000 System with which the digital images were acquired, and funded part of my research.

Many people deserve credit for assistance with the work of the thesis. I thank Dr. Chris Dean for the lively discussions on the use of the Kodak DCS460 digital camera that I am sure were mutually beneficial.

Last, but not least, I acknowledge my family who imparted in me the confidence to pursue my personal goals, even when this pursuit led us to a foreign land so far from home. 


\section{TABLE OF CONTENTS}

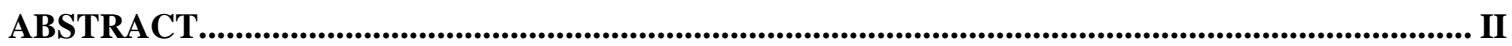

DEDICATION

AKNOWLEDGEMENTS ...........................................................................................................................

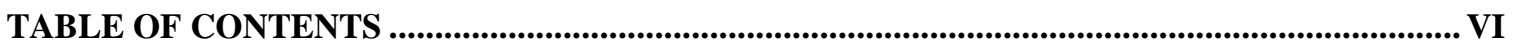

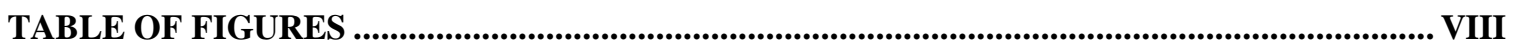

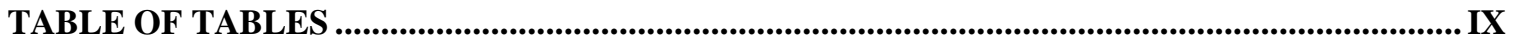

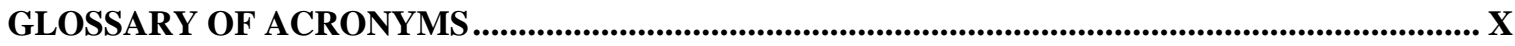

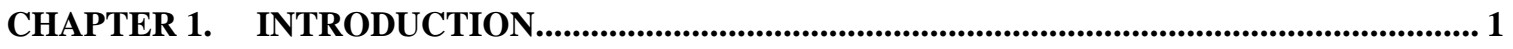

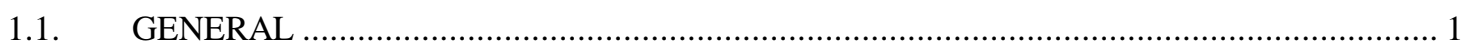

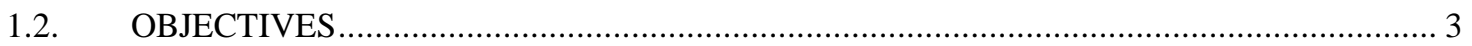

CHAPTER 2. AIRBORNE MULTISPECTRAL DIGITAL CAMERAS: LITERATURE REVIEW OF SYSTEM DESIGN AND APPLICATIONS ............................................................................. 5

2.1. SHORT HISTORY OF AIRBORNE DIGITAL CAMERA REMOTE SENSING .................. 5

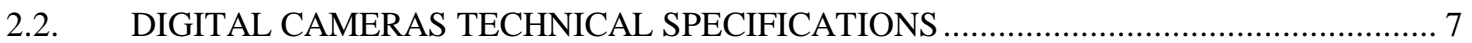

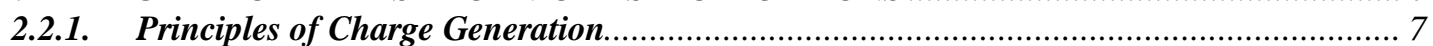

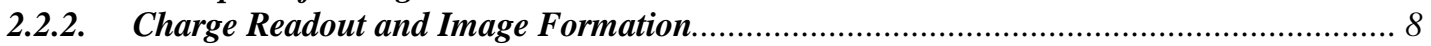

2.2.3. Spectral Response and Spatial Resolution..................................................................... 9

2.2.4. Computer Controlled versus Manual or Autonomous Imagers .................................... 11

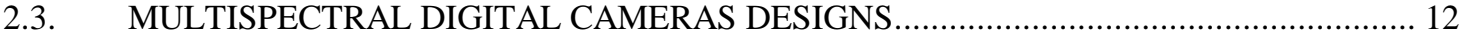

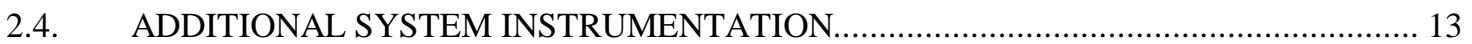

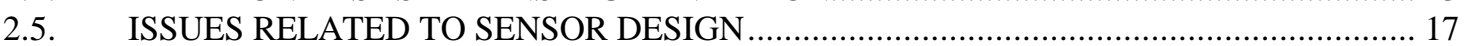

2.5.1. Issues related to sensor size, lens focal length and view angle ................................... 17

2.5.2. Issues related to photo-site size, exposure time and image motion.................................. 19

CHAPTER 3. CURRENT AND POTENTIAL APPLICATIONS OF AIRBORNE

MULTISPECTRAL DIGITAL CAMERA REMOTE SENSING....................................................... 20

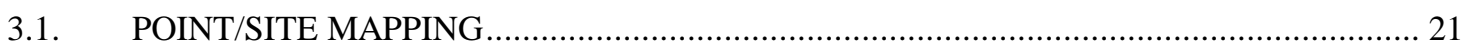

3.2. LINE AND TRANSECT MAPPING

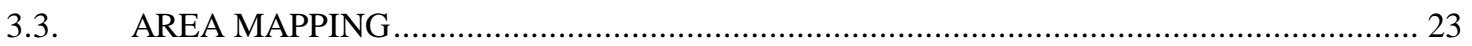

3.4. SOME POTENTIAL APPLICATIONS OF DIGITAL AIRBORNE IMAGES ...................... 25

CHAPTER 4. GENERAL METHODOLOGY .................................................................................. 29

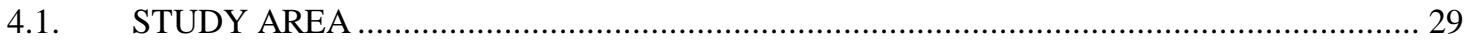

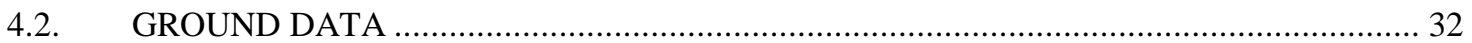

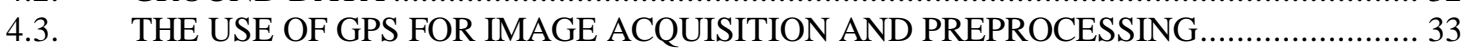

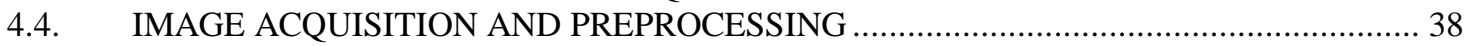

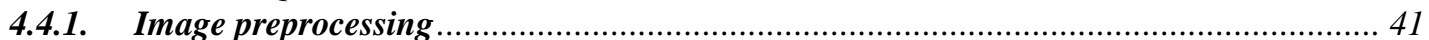

4.4.1.1. The Correction of Vignetting and Fall-Off Of The Images.................................................42

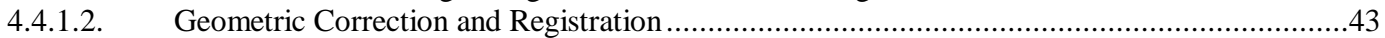

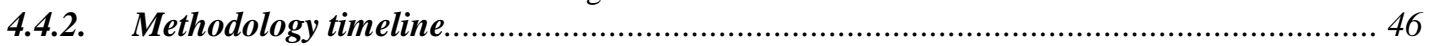


CHAPTER 5. OPTIMAL SPATIAL RESOLUTION AND OPTIMAL SCALE FOR CENTRAL APPALACHIAN HARDWOOD FOREST IMAGES ................................................................... 47

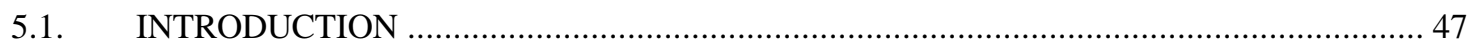

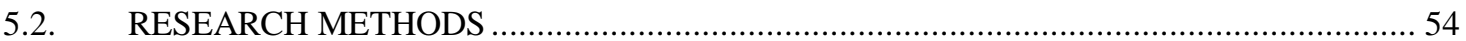

5.2.1. Objective 1 - Determination of Optimal Spatial Resolution of Acquired Images ............ 55

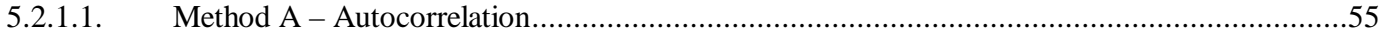

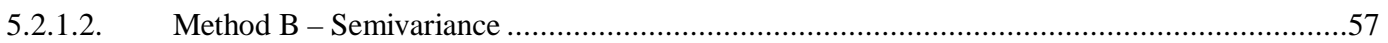

5.2.1.3. Method C (Control method) - Statistical analysis of field measurements ..............................57

5.2.2. Objective 2 - Determination of Optimal Scale for Classification .............................. 58

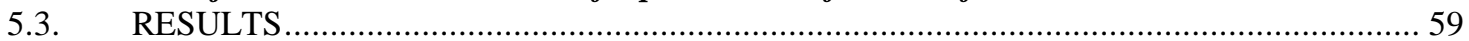

5.3.1. Objective 1 - Determination of Optimal Spatial Resolution of Acquired Imagery........... 59

5.3.2. Objective 2 - Determination of Optimal Scale of Acquired Images................................ 65

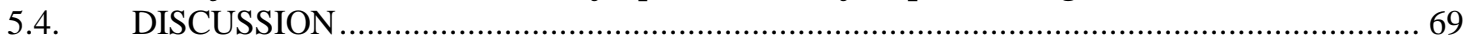

5.4.1. Objective 1 - Determination of Optimal Spatial Resolution of Acquired Images ............ 69

5.4.2. Objective 2 - Determination of Optimal Scale of Acquired Images............................. 70

CHAPTER 6. SPECIATION OF A CENTRAL APPALACHIAN HARDWOOD FOREST USING

AIRBORNE REMOTELY SENSED DIGITAL IMAGES ........................................................... 75

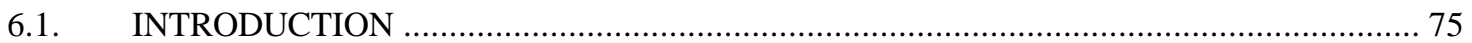

6.2. TRAINING DATA AND SPECTRAL SIGNATURES ACQUISITION .......................... 77

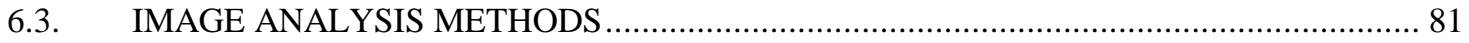

6.3.1. Accuracy assessment of classified images .......................................................... 81

6.3.2. Comparison between the species composition derived from ground sampling and the

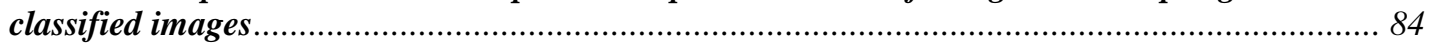

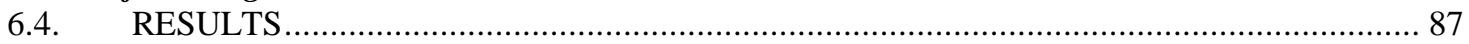

6.4.1. CIR 0.5-m resolution imagery classification ...................................................... 87

6.4.2. VIS 0.5-m resolution imagery classification .................................................... 91

6.4.3. CIR 1-m resolution imagery classification ..................................................... 95

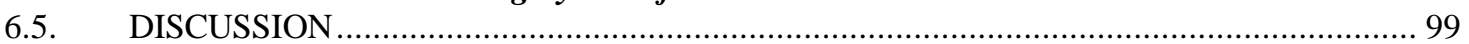

CHAPTER 7. CONCLUSION .......................................................................................114

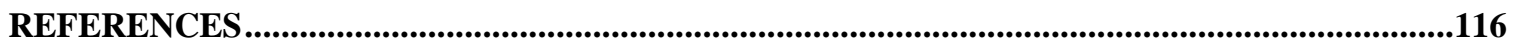

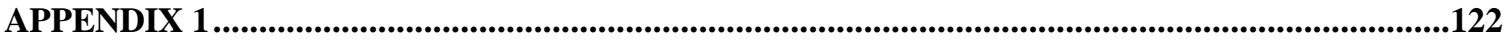

RECOMMENDATIONS...................................................................................................122

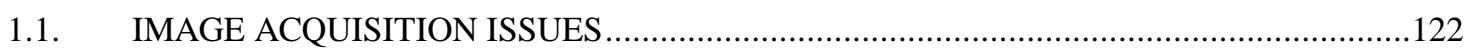

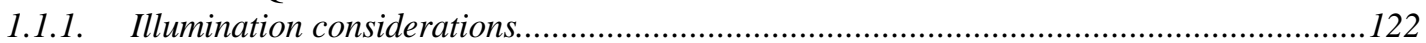

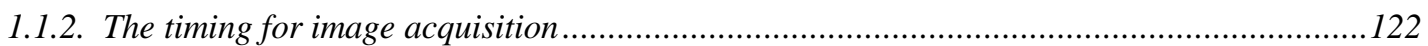

1.1.3. Mosaicking and geometric correction.............................................................. 123

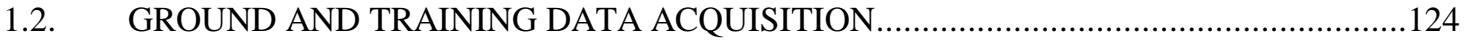




\section{TABLE OF FIGURES}

Figure 2.1- The transmission spectra for the 20-mm lenses used with ADAR 1000 system................ 10

Figure 4.1- Westvaco Wildlife and Ecosystem Research Forest Study Area...................................... 30

Figure 4.2- Draped CIR 0.5-m image over the 15-m resolution DEM .............................................. 31

Figure 4.3- Distribution of ground plots in the study area ................................................................ 36

Figure 4.4- Image of the ADAR 1000 system inside the plane ................................................... 38

Figure 4.5- The Piper Apache aircraft used for image acquisition ................................................. 39

Figure 4.6 - Sensor element (pixel) arrangement in the CCD array used in the Kodak DCS460 digital

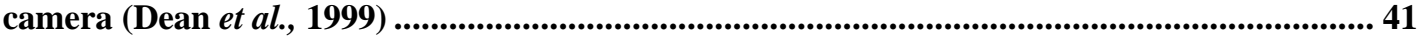

Figure 5.1- Lags of 1, 2 and 3 pixels along transect .......................................................................5 51

Figure 5.2- The parameters of the semivariogram (from Curran, 1988) ........................................ 51

Figure 5.3- Example of spatial profile generated in ERDAS Imagine..............................................5 56

Figure 5.4- Sample of autocorrelation plot used for determination of optimal spatial resolution (1) 60

Figure 5.5- Sample of autocorrelation plot used for determination of optimal spatial resolution (2) 61

Figure 5.6- Semivariance plot sample for the Rook case (measurements along pixels axes)............... 62

Figure 5.7- Semivariance plot sample for the Bishop case (measurements along pixels diagonals).... 63

Figure 5.8- Plot of crown data observations and the fitted line .................................................64

Figure 5.9 - Plot of Kappa Hat statistic for upscaled images ..........................................................65

Figure 6.1- Sample plot of mean values of all the species spectral signatures used for the classification of CIR 0.5-m imagery

Figure 6.2- Aspect-based subunits of the study area (no data were collected in part of the southern end of the study area that was scheduled for clearcutting in 1998) ....................................... 85

Figure 6.3- Plot of signatures used for the classification of the CIR 0.5-m imagery .......................... 88

Figure 6.4- Plot of signatures used for the classification of the VIS 0.5-m imagery ............................ 92

Figure 6.5- Plot of signatures used for the classification of the CIR 1-m imagery ........................... 96

Figure 6.6- Total study area species composition derived from various sources.................................102

Figure 6.7- Classified image of the entire study area derived from CIR $0.5-\mathrm{m}$ resolution imagery ..103

Figure 6.8- Classified image of the entire study derived from VIS 0.5-m resolution imagery ............104

Figure 6.9- Classified image of the entire study derived from CIR 1-m resolution imagery $\ldots . . . . . . . . .105$

Figure 6.10- NE-1 subunit species composition derived from various sources..................................106

Figure 6.11- NE-1 subunit classification derived from different images ............................................107

Figure 6.12- NE-2 subunit species composition derived from various sources...................................108

Figure 6.13- Partial Cut subunit species composition derived from various sources.........................109

Figure 6.14- SE-1 subunit species composition derived from various sources ....................................110

Figure 6.15- SE-2 subunit species composition derived from various sources ....................................111

Figure 6.16- SW subunit species composition derived from various sources ...................................112

Figure 6.17- SW subunit classification derived from different images...............................................113 


\section{TABLE OF TABLES}

Table 4.1- Description of soil types found in the study area (from McNab and Avers, 1994) ............ 30

Table 4.2- Differences in differentially corrected plot center positions using two different GPS units

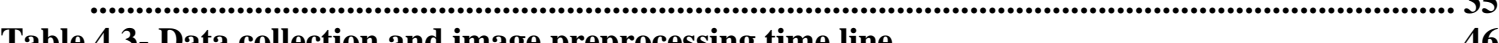

Table 5.1- Classified image statistics and the species composition derived from the aggregated CIR

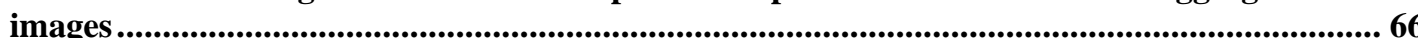

Table 5.2- Research methods results ................................................................................................................. 70

Table 5.3- Percentage of area occupied by species from the classification of original and upscaled

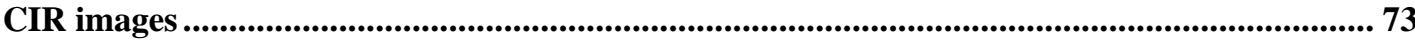

Table 5.4- Contingency table for classification of CIR - 0.44-m image using Maximum Likelihood

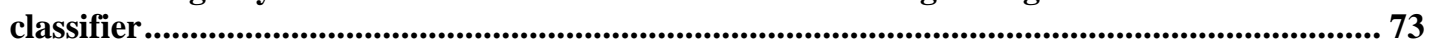

Table 5.5- Contingency table for classification of aggregated image with 1.8-m pixel resolution using

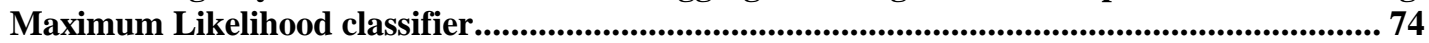

Table 5.6- Contingency table for classification of aggregated image with 3.1-m pixel resolution using Maximum Likelihood classifier

Table 6.1- Leaf colors and leaf area indices (LAI) for the principal forest species identified in the

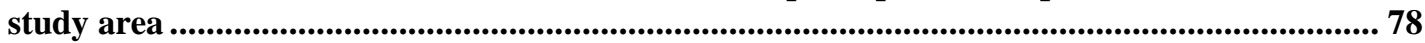

Table 6.2- Estimated error in determination of basal area.......................................................................... 86

Table 6.3- Signature separability for the CIR 0.5-m imagery based on the Jefferies-Matusita distance. Colored blocks indicate pairs with low separability ......................................................... 89

Table 6.4- Contingency table for classification of the CIR 0.5-m imagery using the Maximum Likelihood classifier ................................................................................................................................ 90

Table 6.5- Classification accuracy assessment report for the CIR 0.5-m resolution imagery .............. 90

Table 6.6- Signature separability for the VIS 0.5-m imagery based on the Jefferies-Matusita distance. Colored blocks indicate pairs with low separability .....................................................93

Table 6.7-Contingency table for classification of the VIS 0.5-m imagery using Maximum Likelihood classifier

Table 6.8- Classification accuracy assessment report for VIS 0.5-m resolution imagery ................... 94

Table 6.9- Signature separability for the CIR 1-m imagery based on the Jefferies-Matusita distance. Colored blocks indicate pairs with low separability ................................................................. 97

Table 6.10- Contingency table for classification the of CIR 1-m imagery using the Maximum

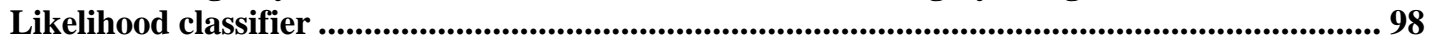

Table 6.11- Classification accuracy assessment report for the CIR 1-m resolution imagery.............. 98

Table 6.12 - Statistical results of the image classification ........................................................................ 99 


\section{GLOSSARY OF ACRONYMS}

$\mathrm{AB}$

ADAR

BAS

BC

$\mathrm{CC}$

CCD

CIR

DBH

DEM

DGPS

DN

DTM

ERDAS

GCP

GIS

GPS

LAI

MTF

NRO

OTH

P CUT

RM

RMS

SB

SM

TIFF

USDA

UTM

VIS

YB

YP
American beech (Fagus grandifolia)

Airborne Data Acquisition and Registration

American basswood (Tilia americana)

Black cherry (Prunus serotina)

Clearcut

Charged Coupled Device

Imagery acquired in the color infrared spectrum $(500-800 \mathrm{~nm})$

Diameter at breast height

Digital Elevation Model

Differential Global Positioning System

Digital number

Digital Terrain Model

Earth Resources Data Analysis System

Ground Control Point

Geographic Information Systems

Global Positioning System

Leaf Area Index

Modulation Transfer Function

Northern red oak (Quercus rubra)

Other species, i.e. white ash, chestnut oak, white oak, cucumber tree, fraser magnolia, black locust, eastern hemlock.

Partial cut

Red maple (Acer rubrum)

Root Mean Square Error

Sweet birch (Betula lenta)

Sugar maple (Acer saccharum)

Tagged Image File Format

United States Department of Agriculture

Universal Transverse Mercator

Imagery acquired in the visible spectrum (400-700 nm)

Yellow birch (Betula alleghanensis)

Yellow-poplar (Liriodendron tulipifera) 


\section{CHAPTER 1. INTRODUCTION}

\subsection{GENERAL}

The importance of North American forests to industry, society and in natural processes requires sound management for sustainability and ecological enhancement. The use of remote sensing in forestry applications is well documented (Pitt et al., 1997). Numerous optical and microwave sensors providing imagery at a variety of scales have proven useful in various decision-making processes. The advancements in technology have led to development of various new sensors and platforms, and among them, a sensor that has potential for use in detailed forest vegetation management is the airborne camera. The digital cameras offer a number of advantages over conventional aerial cameras. First, because they are generally lower in cost than $70 \mathrm{~mm}$ and other large format photographic cameras. Furthermore, there is no need for film developing and subsequent scanning, which is necessary for computerized analysis. Digital cameras also offer the capability for in-flight viewing of acquired images, automated control of exposure levels and linear response to radiance (King, 1995). The aircraft used to acquire such imagery can fly under clouds and appear almost anywhere and anytime as required, and obtain images with a finer spatial resolution than commercial satellite-borne sensors. In addition, the digital images are based on frame charge coupled devices (CCD), and they are more similar to the frame format of photography than are line scanners, thus providing more potential for integration into forest management activities compared to aerial photography (Haddow et al., 1999). 
The focus of this study is to determine the ability of the Airborne Data Acquisition and Registration (ADAR) System 1000 (produced by Positive Systems, Montana, USA), which is based on a Kodak Digital Science 460 color infrared camera to speciate mixed hardwood forests.

The major areas of emphasis were:

1) to determine the optimal spatial resolution of images of Central Appalachian hardwood forests;

2) to produce low resolution images obtained by aggregating the pixels in the original imagery, to classify them, and to evaluate their accuracy relative to their spatial resolution;

3) to evaluate the capacity to speciate Central Appalachian hardwood forests.

The study area was a part (200 ha/ 494 acres) of the Westvaco Wildlife and Ecosystem Research Forest, located in Randolph County, in west-central West Virginia. The imagery processing and analysis was conducted on a UNIX SunOS 5.6 workstation at the Department of Geology and Geography of WVU, using the Earth Resources Data Analysis System (ERDAS ${ }^{1}$ ) Imagine version 8.3 image processing and geographic information system software.

\footnotetext{
${ }^{1}$ ERDAS Imagine is a trademark of ERDAS Inc, Atlanta, Georgia.
} 


\subsection{OBJECTIVES}

The investigation is a three-part study to determine the spatial resolution of Central Appalachian hardwoods remotely sensed images and to evaluate their use in the speciation of forest trees.

The first part of the study focused on determining the optimal spatial resolution for individual tree classification through analysis of the spatial autocorrelation and the semivariance of optical remote sensing images of Central Appalachian Hardwoods acquired with Airborne Multispectral Digital Camera Systems (ADAR 1000). The images used for this part of the research were acquired at a very high spatial resolution, with a 0.18-m ground pixel size. The methods applied consist of measurements of spatial autocorrelation made on spatial profiles of the imagery and of measurements of semivariance made on matrix files (images). For control, ground-based measurements were made in 182 plots, each 400 square meters, where tree diameter at breast height $(\mathrm{DBH})$ and crown diameter were measured.

The second portion of the study deals with the aggregation of the original data into images with bigger pixel sizes, and applying the Maximum Likelihood classifier to compare the classification results with the ground data. The aim of this part of the study was to establish the optimal scale of the imagery for classification purposes, namely to establish the threshold where the composition derived from the image classification was different than the one derived from the ground data. 
The final part of the study concentrated on the comparison of forest composition derived from the classification of ADAR 1000 images acquired in the fall of 1998 with the composition estimated from the ground data. Three data sets were acquired for classification purposes, two of them having a spatial resolution of $0.5 \mathrm{~m}$, and the last one having 1-m spatial resolution. The high-resolution images were acquired both in the visible spectrum (VIS) and in the color-infrared (CIR), whereas the imagery with 1-m resolution was acquired in CIR. Each set of images was geographically corrected and mosaicked. Ground and control plot data were collected and used to classify the imagery using the Maximum Likelihood classifier. For each of the image data sets, the accuracy of the classification was determined. As a control method, the classified mosaics were cut into subunits based on the different topographic aspects of the study area, and for each such subunit a comparison was made between the forest composition produced by the Maximum Likelihood classifier and the composition estimated from the ground data. 


\section{CHAPTER 2. AIRBORNE MULTISPECTRAL DIGITAL CAMERAS: LITERATURE REVIEW OF SYSTEM DESIGN AND APPLICATIONS}

\subsection{SHORT HISTORY OF AIRBORNE DIGITAL CAMERA REMOTE SENSING}

In the last ten years, the use of digital cameras in remote sensing has developed rapidly from individual research to very large research groups and commercial applications with hundreds of users. The first large contract involving multispectral remote sensing was awarded in 1994 by the U.S. Army Corps of Engineers for a project to map land cover in a large area of Mississippi by using multispectral airborne digital camera imagery as a primary source of data (King, 1995). Some authors claimed that the low cost of digital cameras and the advances in technology that allow construction of a multispectral digital camera sensor comparable with the multispectral scanners will become in the near future the standard consumer-imaging device.

King (1995) conducted research to determine the most appropriate sensor configuration to be used by a non-government environmental organization in monitoring and mapping a variety of resource industry activities. One of the optimal solutions was the use of airborne digital cameras incorporating simplified techniques adapted from 
more sophisticated sensors. However, the author considers that the data has a lower quality than one would expect from an expensive government-sponsored sensor.

Early attempts made in the 1970's to develop multispectral airborne sensors demonstrated that such analog electronic imaging systems were feasible, but the equipment was large and fragile. In the early 1980's, the first solid-state cameras and video-based sensors became available. The earliest solid-state sensor developed for airborne remote sensing incorporated a 100 by 100 CCD imager (Hodgson et al., 1981). Such systems using multiple CCD camera multispectral sensors were later developed at the University of Toronto, USDA-Weslaco Research Station, TX and the University of Minnesota.

Since the early 1990's, developments in low-cost digital airborne imagery have been promoted in three primary domains:

- integration of Global Positioning System (GPS);

- development of radiometric calibration capabilities; and

- development of digital camera sensors.

Some results of the various researchers and operational organizations will be referenced in the chapter dedicated to applications of airborne multispectral digital cameras, and they all demonstrate the level of expertise and sophistication that currently exists and the direction this technique is heading in the near future. 


\subsection{DIGITAL CAMERAS TECHNICAL SPECIFICATIONS}

\subsubsection{Principles of Charge Generation}

The digital camera imaging sensors consist of wafers (chips) with specific composition that absorb incident protons into their internal structure and that release a proportionate amount of free charge carriers (Slater, 1980). The basic mechanism of charge generation consists of photons arriving at individual potential wells or photo-sites, which are arranged in a two-dimensional (raster) array, where a certain proportion of them are absorbed. The absorbed photons cause electrons in the chip material to become excited and jump to outer shells. Once they jump in the outer shells, the electrons are less bounded to the atomic nuclei and can be held in electrons embedded in the substrate by application of a potential voltage. They can then be transferred from electrode to electrode to the side of the chip (or points within the chip) by varying the potential at each electrode. This potential is gated or timed, so that the sensor chip can be exposed to incident energy for a given interval, and the generated free charge carriers can be drawn off to form an analog electric signal.

Currently, there is no purely digital camera with a binary output signal from the photo-sites. Instead, analog signals are converted to digital within the camera. Other systems use a frame-grabbing device exterior to the camera (King, 1995). 


\subsubsection{Charge Readout and Image Formation}

There exist different techniques of charge accumulation in the sensor chip, and they are incorporated into various types of sensors. The most common and least costly is the $\mathrm{CCD}$, and it is used in most commercial and research digital systems. This is the sensor used in the ADAR 1000 system. There are also several types of charge transfer techniques out of the photo-sites, and the most common use an 'interline' technique, where the photo-sites do not touch each other in the raster grid but have column or row spaces between them. The charge from each photo-site is read off and to the adjacent space (called a shift register) and then down the spaces to the edge of the chip.

The output signal from a digital-camera sensor has a non-interlaced image scan format, which means that each image is read row-by-row. This type of imagery is also called full-frame, non-interlaced or progressive scan imaging.

The analog output signal from the sensor is usually a low specific voltage (0 to1 V), with the maximum and the minimum voltage representing, respectively, the photo-site saturation and no incident radiation (the black level). This analog voltage can be displayed directly, but usually it is sampled digitally at a given spatial frequency to produce a digital image. The digitization is conducted at the same number of rows and columns as are present on the chip. Digital cameras with more than 1024x1024 photosites utilize an internal A/D converter, but the signal must still be formed into a raster grid for subsequent computer display. In the case of the ADAR 1000 system, the sensor chip has 3060 x 2036 pixels, and these sensors are considered common alternatives to 35 $\mathrm{mm}$ film. The most important gain in the increased number of photo-sites in future digital 
cameras will probably be through the development of sensors with enough photo-sites and angle of view to match the resolution of standard large-format $(23 \times 23 \mathrm{~cm})$ aerial photography (Slater, 1980).

Radiometrically, digital sampling has commonly been 8-bit, with a number of 256 possible gray levels. There exist digital cameras with more than 8-bit digitization, but they are very costly.

\subsubsection{Spectral Response and Spatial Resolution}

The materials used in CCD sensors have different spectral sensitivities, with the most common chip material being silicon. For CCDs, the quantum efficiency is typically about $10 \%$ in the blue $(380-430 \mathrm{~nm})$, about $40-60 \%$ in the far red/beginning of nearinfrared (680-800nm), and then about $10 \%$ in the near-infrared (900-1000nm) (Slater, 1980). The shape of the response curve is almost Gaussian. An important point is that almost one half of the response is in the near-infrared, providing excellent potential for color infrared (CIR) composite imaging and vegetation studies, but blue response is very poor (Slater, 1980).

The transmission spectra of the lens used with the ADAR 1000 system are shown in figure 2.1. Data were collected using an Analytical Spectral Devices (ASD) Full Range Spectrometer, covering the region 400-2500 nm (Dean et al., 1999). The amplitudes were not normalized for the unit area of incident light (sunlight) on the front of the lens, and consequently the curves are relative. The graphs show that there are non-transmission wavelengths for both lenses. The VIS lens has an IR filter and transmits fairly evenly 
across the red (around $630 \mathrm{~nm}$ ), green (around $510 \mathrm{~nm}$ ) and blue (around $450 \mathrm{~nm}$ ) regions, but with a little less blue being transmitted. The CIR lens and filter combination does not transmit blue light, it transmits fairly evenly across the red and green, but the transmission slowly decreases in the near-IR part of the spectrum (Dean et al., 1999).

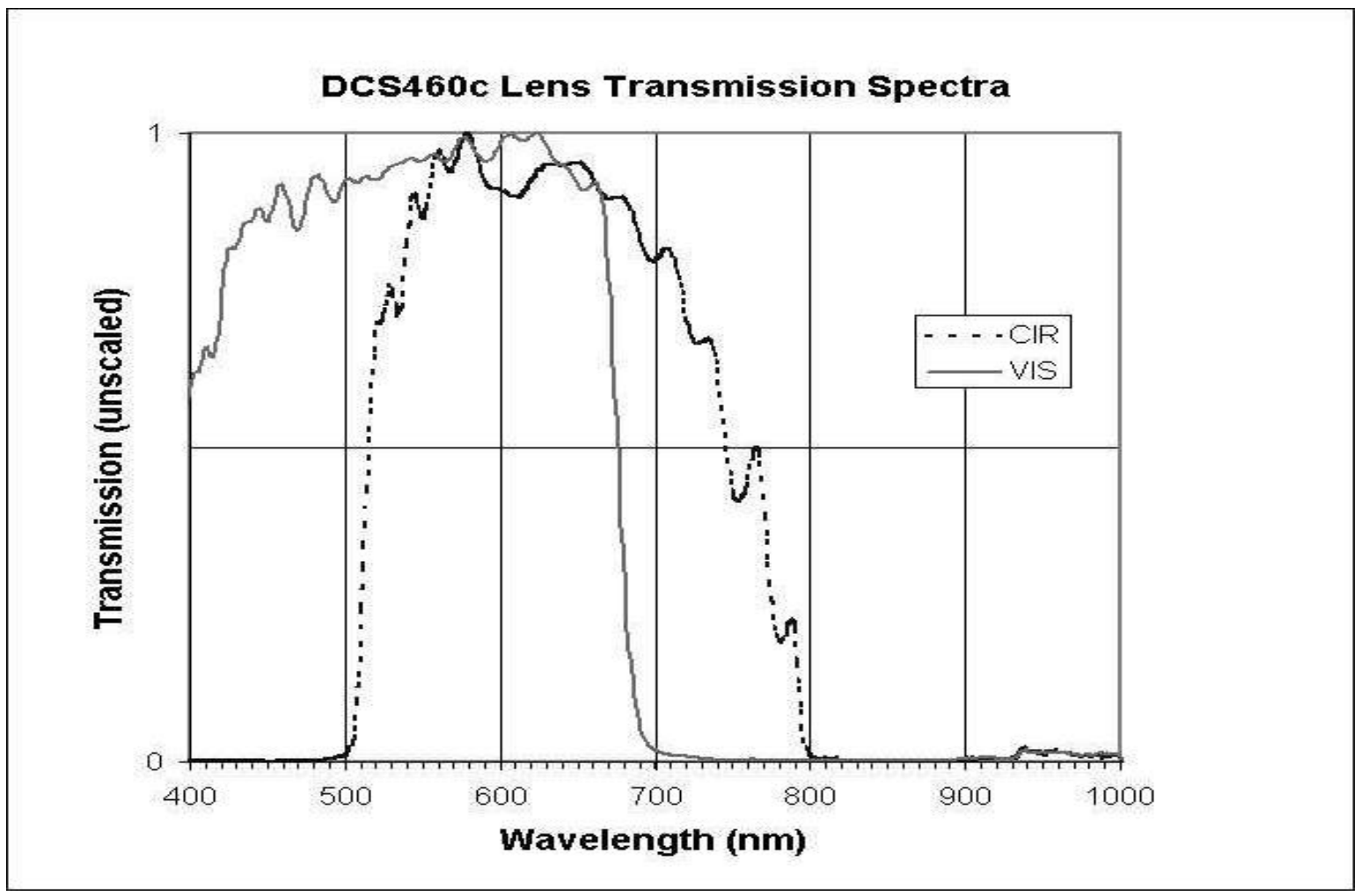

Figure 2.1- The transmission spectra for the 20-mm lenses used with ADAR 1000 system (Dean et al., 1999).

The spatial resolution can be summarized in the common units of line pairs per millimeter on the sensor surface, but also can be used the more rigorous Modulation Transfer Function (MTF) also can be used as a measure of optical-electronic image 
formation capability. The silicon-based CCD sensors have variable spatial resolution depending on the number and size of the photo-sites on the sensor chip. Some authors (King, 1995, Mason et al., 1997) noted that the spatial resolution of digital images is lower than the resolution of $35 \mathrm{~mm}$ film photos.

Also evident in the research on spatial resolution was that specification of the nominal ground pixel size as the defining resolution element is convenient, but useful only for generalized applications, because it overestimates, by a significant amount, the size of an object that can be resolved (detected, identified and measured). The spatial resolution measure of line pairs per millimeter from empirical tests is much more accurate in flight planning related to object detection (King, 1995).

\subsubsection{Computer Controlled versus Manual or Autonomous Imagers}

There exist digital cameras and video cameras designed to operate remotely and autonomously. Such systems have a general aperture setting when the camera is positioned and the shutter speed is allowed to vary automatically in response to varied illumination or target brightness. Even though automatic exposure control optimizes the overall image contrast and brightness, it presents problems if used in continuous airborne imaging where feature image brightness from scene to scene may vary because of internal camera adjustments. Consequently, most sensor developers disable the Automatic Gain Control (AGC) (Mao et al., 1994). This is also the case with the ADAR 1000 system, which was used for the acquisition of all imagery for the project. During the image gathering, the aperture setting was typically at 2.8 (the widest possible), the 
shutter speed was established manually, and the exposure time used was 1/500 second (Positive Systems, 1998).

Thus, the whole system was controlled manually, but probably in the future it will be possible to use a computer controlled shutter speed, or even develop complete computer control over the camera. This should allow flexibility in camera shuttering, by viewing images/histograms of each spectral band in-flight to be used for optimum exposure time determination. A complete computer control should allow a complete communication between computer and the sensor, but the system we used is far from such possibilities.

\subsection{MULTISPECTRAL DIGITAL CAMERAS DESIGNS}

Multispectral digital camera sensor development has generally been based on perceived needs for four spectral bands situated between blue and near infrared. Studies conducted by King and Vlcek (1990) that used imagery of diverse land cover types (forest, soil, grass, road) have proven that the bands contributing the most to the data variance are the blue-green (430-470 nm), green-yellow $(530-570 \mathrm{~nm})$, deep red (680$720 \mathrm{~nm})$, and near infrared (780-820 nm). However, correlation analysis showed adjacent bands to be very highly correlated, so a smaller number of bands can be used for certain applications. Most system allow changing of the filter, and this is the case with the ADAR 1000 system, where the operator could use the two filters provided, one for the blue, green and red bands, and the other for green, red and near infrared bands. 
One common digital camera design is the multiple camera system. One requirement of such a system is a sturdy mount constructed of rigid material that can minimize vibrations. In a multiple camera system, the cameras must be synchronized so that they acquire images of the same area at the same time. Currently, there are differences in the filter mounting in multi-camera systems, and some systems have the filters mounted in front of the lens and others with the filter behind the lens. Also, it is necessary to conduct post-flight band registration (Neale and Crowther, 1994). The cost of a multiple camera system is higher than the single camera system because of the extra cameras, lenses, synchronization electronics, and larger mounts.

A lower cost alternative to the multiple camera system is the single camera system capable of spectral filter changing, and this is the type of camera used by the ADAR 1000 system. The camera, a Kodak DCS 460, has two different interchangeable filters, as mentioned earlier, one for the visible part of the spectrum (RGB) and another one for blue, green and near infrared. The principal advantage of a single camera system is that it has one optical axis. Consequently, no pre-flight alignment is necessary and optical problems such as differential spatial illumination are simplified (Mason et al., 1997).

\subsection{ADDITIONAL SYSTEM INSTRUMENTATION}

Some of the newer digital camera systems incorporate additional components for specific applications. The most common instruments incorporated in such systems are Global Positioning Systems (GPS), radiometric measurement instrumentation, and laser altimetry instrumentation. 
Global Positioning System (GPS) is a system of satellites implemented by the United States government to provide accurate positioning information worldwide to ground observers by means of portable receivers. The official name for these satellites is NAVSTAR (Navigation Satellite Timing and Ranging). The GPS satellites continuously transmit highly accurate timing and orbital information from which the range (distance) between the user and the satellite can be calculated. With this range information, a receiver can calculate its location very quickly and accurately.

The global positioning system is a dual-purpose system:

i) to provide the U.S. military with accurate positional information to assist military operations; and

ii) to provide civilians worldwide with position information for such purposes as navigation, map making and surveying with accuracies that could not be achieved otherwise except at great expense.

The global positioning system is a passive receiver positioning system. The satellites transmit to ground users, but do not receive information back from ground users. This means that the satellites do not serve for two-way communication between user and user's base station. This also means that there are no subscriber or access fees to use GPS signals, and no limits to the number of users simultaneously using GPS (Hofmann-Wellenhoff et al., 1994). Positioning information is provided on the open access (civilian) signal at all times. There is one limitation of the civilian signal, because the military has reserved the right to degrade the performance of the GPS on the civilian signal by introducing errors up to 100 meters. This is performed by intentional degradation of the timing and orbital information 
and is known as Selective Availability (SA). In the absence of Selective Availability, the inaccuracies on the civilian signal are typically in the 5-meter to 15-meter range (Liu, 1993, Deckert and Bolstad, 1995, D’Eon, 1996, McDonald, 1999). Most of the residual error is the result of ionospheric propagation group delay effects and of receiver noise errors. The delay effects vary considerably depending on the time of day, season of year and the activity state of the 11-year solar cycle. The receiver noise errors are caused by the equipment accuracy, and the most important factor is the number of GPS receiver channels or the maximum number spacecraft that can be tracked simultaneously (Hofmann-Wellenhoff et al., 1994, McDonald, 1999).

In order to improve position accuracy by correcting for SA, as well as most environmental errors, GPS can be used in a differential GPS (DGPS) mode in which known navigation data at a reference point are compared (or differenced) with GPS measured data at the same point and time. The corrections from this process are then applied at the same time to the GPS measured data taken at a remote point. For real-time operation, a datalink between the receiver and the remote receiver is normally used to communicate the corrections (real-time DGPS). The method used for this thesis involved the storing of field data and then applying the corrections, a method known as postprocessing.

GPS has become a standard additional instrument used with digital cameras, and is also incorporated into the ADAR 1000 system. A single GPS is used alongside the digital camera system, and the GPS time code is matched post-flight to an encoded time on the imagery in a separate text file. This type of system is considered very precise, but 
the main disadvantage is that the operator does not have any control over roll, pitch, and yaw of the plane, and consequently the position recorded by the GPS cannot be precisely located on the image. Another disadvantage is the fact that the GPS file is provided in a text format instead of a .SSF format that is specific to Trimble Pathfinder ${ }^{2}$ software, that facilitates differential correction of the positions and production of a more precise and accurate location of the center of each image.

Another use of the GPS is in an integrated flight planning and navigation system, implemented on Geolink $5.6^{3}$ software. Geolink software connects the GPS technology with Geographic Information System (GIS) and provides real-time map display and navigation (Geolink, 1997). The system uses a Trimble GeoExplorer GPS unit that collects the signal throughout flight. The flight lines can be plotted on a digital map, and the output file can be used to navigate the aircraft using a moving map display, which greatly improves the accuracy of image acquisition. The usefulness of the system resides in its high operability and practicability. For example, for the acquisition of the imagery, the pilot could use the navigation system and even signal the digital camera operator when to begin and when to stop the image acquisition along a flight line. Also, the system allows incorporation of a small airplane icon on the navigation screen, which can be easily followed by the pilot while navigating the aircraft.

In the future, such a navigation system could be used to trigger the camera at the pre-specified image centers. Also, through the use of real-time differential GPS, the next phase will be to use the distortion information and aircraft attitude measurements to aid in

\footnotetext{
${ }^{2}$ Pathfinder is a trademark of Trimble Navigation Limited, Sunnyvale, CA.

${ }^{3}$ Geolink is a trademark of GeoResearch, Inc., Billings, MT
} 
positioning the principal point and in selecting other control points, eliminating the need for field surveyed points (Holm et al., 1999).

\subsection{ISSUES RELATED TO SENSOR DESIGN}

Some of the important options of a digital camera system that affect the quality of the acquired data are: sensor chip size, photo-site size on the chip, exposure time and lens focal length. All are usually selected in relation to the view angle and ground pixel size.

\subsubsection{Issues related to sensor size, lens focal length and view angle}

For area-base mapping, large sensors with small focal length lenses are best. For a given lens, the sensor size increases the view angle. The sensor used for the Kodak DCS 460 camera that is employed by the ADAR 1000 system has a sensor comprised of an array of 3060 x 2036 pixels, and dimensions of about $28 \times 18 \mathrm{~mm}$. The angle of view is very close to that for $35 \mathrm{~mm}$ photography, and the lenses commonly used have a focal length of $20 \mathrm{~mm}$ (Positive Systems, 1998).

There are some view angle effects on radiometric quality of digital imagery. As view angle increases, the radiation incident to the sensor surface decreases theoretically as a function of $\cos ^{4}$ or $\cos ^{3}$ of the view angle (Benkelman et al., 1996). This is called 'shading', and for many modern lenses is less than the above value, maybe in the order of $\cos ^{1}$ (Pellika, 1994.). Another radiometric effect is caused by the absorption and blocking 
of radiation by the lens walls, and it is called 'vignetting'. Vignetting greatly affects the images acquired with the ADAR 1000 system. Vignetting and shading together produce significantly decreased image brightness toward the corners of images (Lillesand and Kiefer, 1994).

Some authors (Thom and Jurvillier, 1994) used radiometric calibration methods, which involves determining the relationship between image brightness as measured in digital image units (called digital numbers-DN) and the actual radiance or reflectance of the target. By studying the spatial non-uniformity in response (shading, vignetting), some authors developed methods of correcting such effects, some of them based on outdoor targets (King, 1995), and others based on lab measurements (Benkelman et al., 1996). Probably the more precise, but also more costly method, is during-the-flight acquisition of radiometric calibration data, which requires a field staff, a portable spectrometer and targets large enough to occupy several image pixels (Mao et al., 1994).

Currently, have been few attempts to reduce spatial variations in image brightness due to topography. Pellika (1994) used Digital Elevation Models (DEM) to generate an iradiance surface for the given sun illumination angle at the time of imaging for both the actual pixel orientation and a flat plane at the same elevation. The ratio of these was applied to remove the effects of topography on image brightness. 


\subsubsection{Issues related to photo-site size, exposure time and image motion}

As the sensor increases, the photo-site size tends to be larger. Photo-sites typically have sizes ranging from about 7 micrometers to 21 micrometers. The primary limitation of large photo-sites is reduced spatial resolution, while the primary benefit is increased radiometric sensitivity. The photo-site size for the camera used by the ADAR 1000 system is 9 micrometers (Positive Systems, 1998).

In applications and flight planning, there is a trade-off between image motion and spectral bandwidth. For a given ground pixel size and a given aircraft velocity, a shutter speed capable of producing the most $1 / 2$ pixel size image motion can be calculated (Pellika, 1994) (this is considered the common upper limit on acceptable image motion). This shutter speed may pose a limit on the bandwidth, especially for the blue region. However, shutter speeds in the range of $1 / 500$ second to $1 / 1000$ second are required for small ground pixel size imaging, and the standard shutter speed used is in the ADAR 1000 system is $1 / 500$ second. 


\section{CHAPTER 3. CURRENT AND POTENTIAL APPLICATIONS OF AIRBORNE MULTISPECTRAL DIGITAL CAMERA REMOTE SENSING}

Applications of Airborne Multispectral Digital Camera Remote Sensing are very diverse. There are currently applications in forestry, rangeland, agriculture, water resources, geology, and a variety of environmental studies, as well as in urban and demographic analysis. In recent years, some users have begun to carry out larger government mapping projects (King, 1997). The most common analysis is the visual interpretation of color and color infrared imagery; usually the features are identified by eye and the analyst transfers the information into a database. The next level of sophistication of multispectral digital camera imagery is the use of several spectral bands to identify one best band for mapping the feature of interest. This is usually done by statistical means. More sophisticated analysis has made use of multiple spectral bands, and classifications using such standard techniques as Maximum Likelihood or band ratioing are now very common. An analytical domain that also should receive more attention is the extraction of spatial information contained in the high-resolution digital camera imagery, and the ADAR 1000 digital camera system is very suitable for such applications (King, 1997). The airborne multispectral digital camera imagery is wellsuited to a variety of specific studies, but they can be divided into point/site specific mapping, corridor and site specific mapping, and area and regional thematic mapping. 


\subsection{POINT/SITE MAPPING}

Airborne multispectral digital camera images are especially well-suited for point and site mapping because the coverage of individual frames is limited but the area must be imaged at a very high resolution, usually less than 2-3 meters per pixel. The small sensors in digital cameras provide view angles that are less than those using photography, but the specific advantage is that they allow for faster exposure times because of the greater sensibility of the CCD. Therefore, low-altitude imaging with small pixel sizes can be conducted without noticeable image motion effects during sensor exposure.

Some of the most successful applications of airborne multispectral digital camera imagery are in forestry, and some authors have been studying the spectral and textural characteristics of individual deciduous trees (King, 1997). Levesque and King (1995) have studied the textural and spectral characteristics of deciduous trees with varying amounts of pollution related damages. They produced methods to assess the damage with a higher accuracy than possible during field assessment because much of the damage symptoms are exhibited in the upper parts of the crown that cannot be seen easily from the ground.

There is also high potential for the use of digital images in regeneration assessment. Haddow et al. (1999) used very high-resolution airborne imagery, with a pixel size of $2.5 \mathrm{~cm}$, to discriminate conifer species from vegetative competition at various densities using classification of spectral and textural image information. Haddow et al. (1999) developed models relating vegetation structure parameters to image spectral and textural information. The results indicated a very strong potential for classification 
and counting of conifer seedlings when competition is low or not visible to the sensor. Systematic decreases in class separability and conifer count accuracy were observed with an increase in density of competitive vegetation (Haddow et al., 1999). Another interesting aspect of this research is the capability of digital cameras to acquire data at very high resolution, while other systems currently employed such as aerial photographs, do not have this capability.

There is an increasing number of remote sensing companies that are using multispectral images for commercial purposes, namely for the evaluation of crops. Midstate Laboratory of San Joachin Valley, CA, which uses point/site mapping for commercial purposes, offers monitoring of crops using true color and CIR images to successfully manage crops such as grapes, citrus, almonds, potatoes and strawberries. The ADAR 5500 system images are collected throughout the growing season and provide a detailed picture of the crop during the season, allowing early warning so that action can be taken for production maximization and to measure damages induced by various factors (Midstate Laboratory, 1999).

\subsection{LINE AND TRANSECT MAPPING}

The airborne digital camera is well-suited to the acquisition of images and mapping linear and curvilinear features or transects, because the system is able to collect images continuously. This allows an overlap between the images of $50 \%$ or even greater. Line and transect mapping require coverage of narrow areas with one or very few adjacent flight lines. In mapping curvilinear targets, it is necessary to overlay many short, 
straight flight lines that cover the whole area, or even to acquire the images along a curved transect that allows the aircraft to "follow" the desired locations.

The current and potential applications are data acquisition along transects or corridors, such as rivers, coasts, hydro right-of-ways, and transportation routes. One current application of corridor mapping is the acquisition of images over Muskingum Island, which is part of the Ohio River Islands National Wildlife Refuge (Yuill, 1999).

\subsection{AREA MAPPING}

The large number of images required to conduct regional mapping projects can sometimes be cost prohibitive. Progress has been made in addressing the problems of area based-mapping through development of automated mosaicking procedures that can handle a large number of camera frames. For example, an airborne digital camera and mosaic creation system for large areas was produced and is operated by the Remote Sensing Group of the Technical Research Centre of Finland. The system uses a single digital camera (Minolta 3 CCD-sensor RD-175), a differential GPS and a laptop computer that controls the imagery acquisition via NavCam navigation software. The images are captured automatically and stored on PCMCIA disks. The system uses the photogrammetric bundle block adjustment method to produce image mosaics. The method is based on the approximate image positions, and only a few, if any, ground control points are needed. The bundle block adjustment method uses a specific parameter set for each image to restore precisely the original location and rotation of the image at the moment of exposure. These parameter sets are exploited to transform three- 
dimensionally the image pixels into the final mosaic. To improve the mosaic quality, the system can integrate a digital terrain model (DTM) and atmospheric corrections. The system was extensively used for various applications in Finland, the Netherlands, Indonesia, Malaysia, Kenya, Venezuela and Argentina, and currently more than two million hectares have been processed into mosaic images (Holm et al., 1999).

Seed et al. (1999) used low cost airborne digital CIR imagery with a ground pixel size of $25 \mathrm{~cm}$ and multivariate statistics to develop a series of empirical models to estimate forest canopy structure in deciduous and mixed-woods stands. Using the linear combination of spectral, textural and structural information, models were developed for predicting leaf area index (the ratio of the total area of all leaves on the trees to the area of ground covered by the trees), basal area, crown closure and within crown structural damage. The results suggested that image spectral and textural information were important for modeling the mixed-wood stands and within-crown structural damage in the deciduous stand. The study demonstrated that low cost digital camera CIR imagery could be effective data sources for canopy biophysical structure models (Seed et al., 1999).

Other researches have simply decreased the precision of class attributes to provide suitable thematic map accuracy. Monday et al. (1994) mapped 280 four-band scenes of 1m ground pixel size using ADAR 5500 imagery over a $25.7 \mathrm{~km}^{2}$ test area. The Normalized Difference Vegetation Index (NDVI) was used to classify impermeable versus permeable surfaces for use in run-off determination within each ownership land parcel for compliance with US water quality management guidelines. The images were rectified and an orthoimage mosaic was produced. The result of classification correlated 
very well with expected values, and the project was completed three times earlier than expected if aerial photography had been used. The costs were one-third higher, but the digital multispectral database was used in many other urban management applications.

\subsection{SOME POTENTIAL APPLICATIONS OF DIGITAL AIRBORNE IMAGES}

Probably the most important application of the digital airborne camera will be in positional mapping. As digital camera technology advances and resolution approaches, and even surpasses, that of photography, most topographic mapping will be based on digital imagery. Collecting images is much simpler than using an analog camera because scanning of photography is eliminated and computer control of the digital camera provides additional flexibility and accuracy in data acquisition. King et al. (1995) have evaluated a 1280x1024 digital camera in elevation modeling in a remote area of the Canadian Shield using standard adjustment techniques to determine a three-dimensional terrain surface. The authors found that DEM precision was in the range of pixel size, even without camera calibration. The DEM precision decreased where few control points were available, but the precision of the DEM was comparable to that of a DEM of the same area derived from scanned aerial photography.

Mason et al. (1997) reported on investigations into the use of the Kodak DCS 460 digital camera for mapping the Marconi Beam informal settlement in Cape Town, South Africa. Stereopairs of DCS 460 images at 1:18,500 scale (0.15-0.2 m ground pixel size) yielded accuracies in the order of $0.2 \mathrm{~m}$ in planimetry and $0.6 \mathrm{~m}$ in elevation. The authors 
found that while these accuracies are sufficient for many mapping exercises, the limited format size of the camera and slow image download times economically restrict applications of the camera to the mapping of small areas. Thus, for small area mapping the accuracies obtained are suitable and permit a good use of the imagery for positional mapping.

Bobbe (1997) documented the use of a Kodak DCS 420 airborne for natural resource management applications. The digital camera was successfully used for forest fire burn area assessments. The USDA Forest Service used the CIR digital camera in 1996 to acquire images with 3-m ground pixel resolution over a 12,150-ha (30,000 acres) watershed burned on the Mendacino National Forest in California. The images were mosaicked and georeferenced. A burn intensity map with three classes of burn intensity was produced. The burn intensity was determined visually, and the derived map (together with other thematic layers) was used in a GIS to determine areas requiring various erosion control measures. The Pacific Southwest Region of the USDA Forest Service is now contracting for services using CIR digital camera imagery for producing burn intensity map products.

CIR digital cameras were used by USDA Forest Service for riparian mapping and monitoring (Bobbe, 1997). The surveys were conducted on the Inyo National Forest in California, Flathead and Payette National Forests in Idaho and Deerlodge National Forest in Montana. The images were enhanced in order to highlight vegetation types and were used to successfully identify various vegetation types, including sagebrush, conifers, willows and grasses. The imagery also provided information to help determine the channel condition, to locate and map abandoned channels, and to understand the causes 
of habitat change and monitor changes over time. The georeferenced images were mosaicked and used to digitize GIS vector data and display where vegetation types or stream channel locations have changed. Overlaying periodic GIS layers can help fisheries biologists and hydrologists determine trends in hydrologic changes and identify potential mitigation measures.

Another very important current and possible application of the digital cameras is for forest pest and disease detection and monitoring. The usefulness of CIR digital cameras has been evaluated by several USDA Forest Health Protection field operation offices as a tool to complement aerial sketch mapping (Bobbe, 1997). The CIR digital camera was used to survey forest insect disease sites on the Boise, Vinta, and Dixie National Forests. The camera was held to acquire oblique imagery at relatively low flying heights (less than $600 \mathrm{~m}$ ), and the effects of the following forest insect and disease agents were imaged: western pine beetle (Dendroctonus brevicormis), Douglas-fir beetle (Dendroctonus pseudotsugae), fir engraver beetle (Scolytus ventralis), Douglas tussock moth (Orgyia pseudotsugata) and dwarf mistletoe (Arceuthobium sp). CIR digital imagery is considered useful for highlighting currently infested, recently killed and previously killed trees, but in this application the imagery was useful for quantifying dispersed mortality and highlighting subtle spectral signatures of infested trees. A potential application of the digital cameras would involve collecting imagery over small project areas on a frequent basis.

The usefulness of CIR digital cameras was also documented in a change detection project on the island of Korsae in Micronesia (Bobbe, 1997). The purpose of the project was to acquire current imagery over the entire island to document urban development and 
agricultural impact on the natural forest environment. Previous efforts to obtain aerial photography were not successful because of poor weather conditions and continuous cloud cover typical for tropical islands near the equator. The CIR digital camera performed very well given the adverse lighting and humid tropical environment, and the imagery was excellent even when the plane was flown under a dense cloud cover with extremely dim lighting conditions (Bobbe, 1997). 


\section{CHAPTER 4. GENERAL METHODOLOGY}

\subsection{STUDY AREA}

The study was conducted on a part of the 3413-ha (8430 acres) Westvaco Wildlife and Ecosystem Research Forest, located in Randolph County, West Virginia. The study area extends over 200 ha (494 acres), and is positioned in the middle western part of the forest (figure 4.1). Almost the whole area is classified as sugar maple (Acer saccharum)beech (Fagus grandifolia)-yellow birch (Betula alleghanensis) SAF type (Soc. Am. For., 1980); associated species include white ash (Fraxinus americana), American basswood (Tilia americana), black cherry (Prunus serotina), yellow-poplar (Liriodendron tulipifera) and northern red oak (Quercus rubra). 


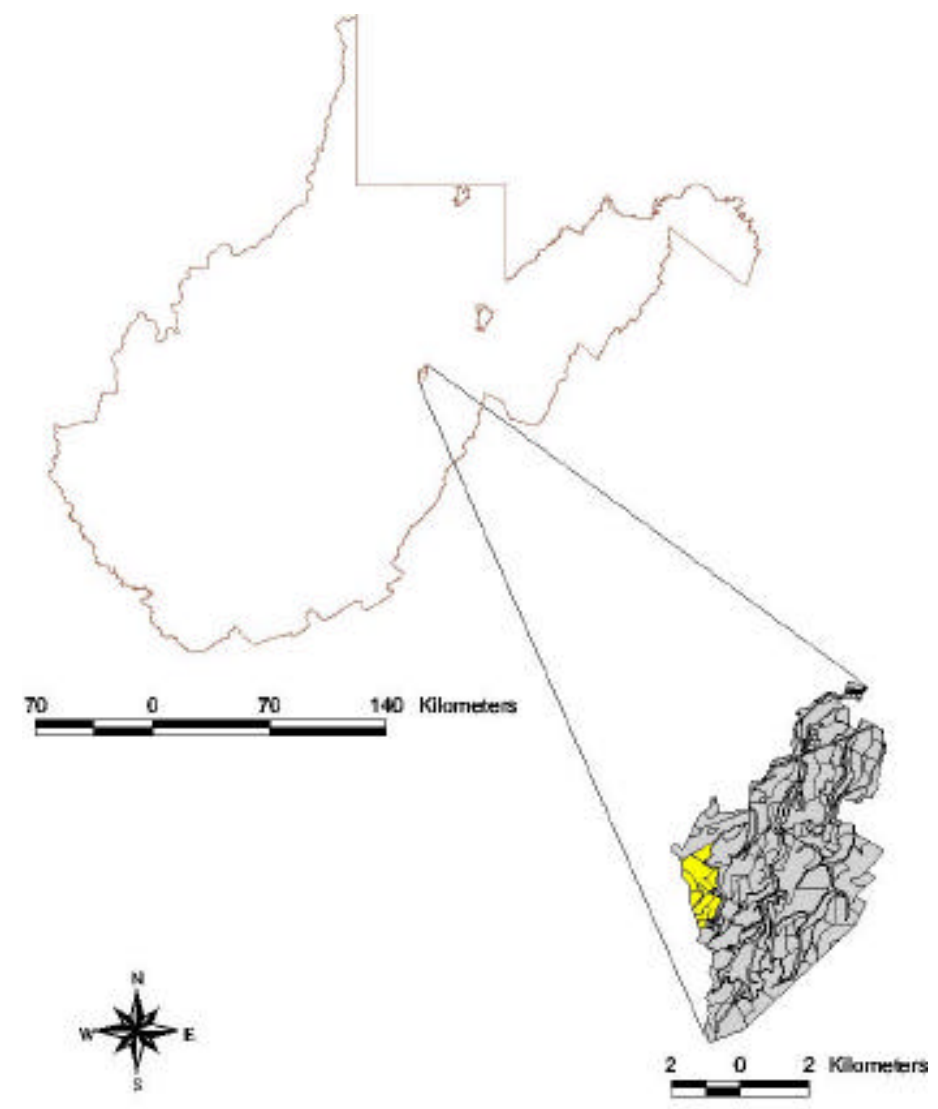

Figure 4.1- Westvaco Wildlife and Ecosystem Research Forest Study Area

The ecological land type of the study area is the Allegheny Mountains of the Central Appalachian Broadleaf Forest (McNab and Avers, 1994). The soils of the study area are part of the Gilpin-Dekalb-Buchanan soils association, and their description can be seen in table 4.1 .

Table 4.1- Description of soil types found in the study area (from McNab and Avers, 1994)

\begin{tabular}{|l|l|l|l|}
\hline $\begin{array}{l}\text { Map } \\
\text { Unit }\end{array}$ & \multicolumn{1}{|c|}{ Description } & Location & $\begin{array}{c}\text { Estimated } \\
\text { percent }\end{array}$ \\
\hline GkE & $\begin{array}{l}\text { Gilpin - Dekalb stony complex, moist 15 to 35 percent } \\
\text { slopes }\end{array}$ & Slopes & $70 \%$ \\
\hline GkF & $\begin{array}{l}\text { Gilpin - Dekalb stony complex, moist 35 to 70 percent } \\
\text { slopes }\end{array}$ & $\begin{array}{l}\text { Steep } \\
\text { slopes }\end{array}$ & $4 \%$ \\
\hline DbC & Dekalb channery loam, moist, 8 to 15 percent slopes & $\begin{array}{l}\text { Low } \\
\text { slopes }\end{array}$ & $6 \%$ \\
\hline BtC & Buchanan and Ernest stony soils, 3 to 15 percent slopes & Coves & $20 \%$ \\
\hline BtE & Buchanan and Ernest stony soils, 15 to 35 percent slopes & & \\
\hline
\end{tabular}


The soils of the study area are moderately well-drained, acid soils, and are formed in material weathered from sandstone and some interbeded siltstone and shale. The soils are dark brown to brown, channery, medium-textured surface layer and a yellowish brown, channery, moderately coarse textured subsoil (U.S. Dept. of Agr., 1982).

The research area is dominated by 60 to 70 -year-old stands of mature timber, being almost entirely covered by closed-canopy second-growth hardwood forest. Site quality varies between 62 and 80, with an average of 70, at base age 50 .

The study area consists of broad ridgetops and steep hillsides, with elevations ranging from $928 \mathrm{~m}$ to $1048 \mathrm{~m}$. The average elevation of the study area is $967 \mathrm{~m}$. A draped image of the study area over a 15-m resolution DEM can is shown in figure 4.2.

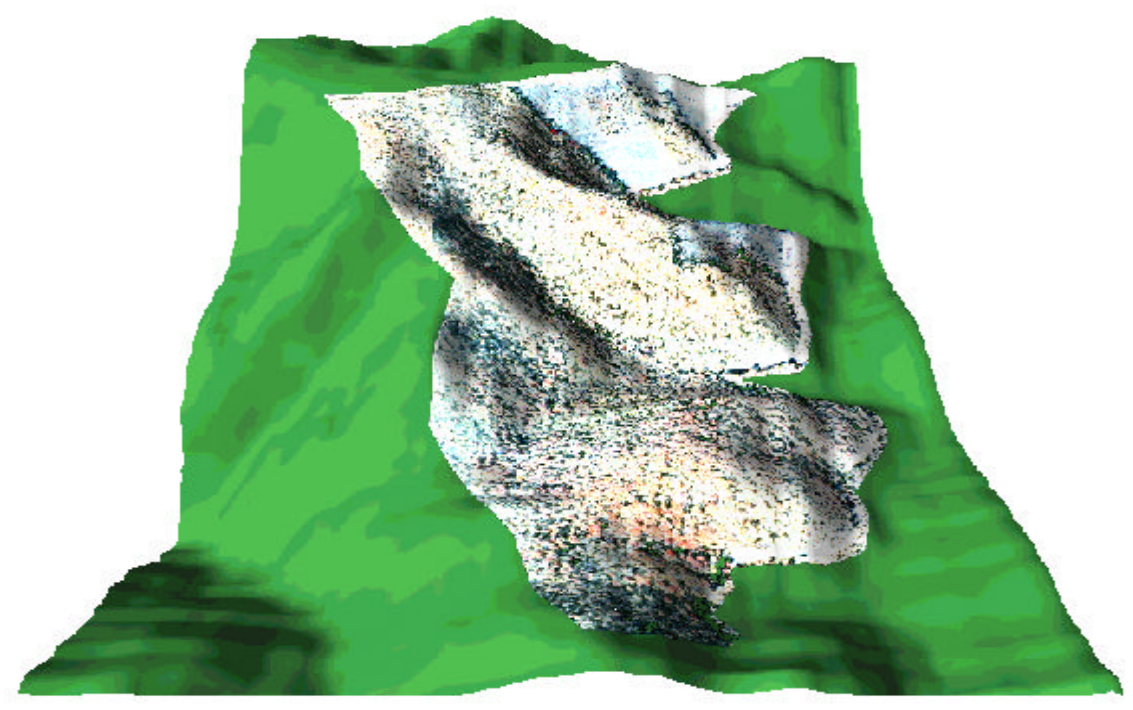

Figure 4.2- Draped CIR 0.5-m image over the 15-m resolution DEM 


\subsection{GROUND DATA}

The study area was sampled in the summer of 1998 (table 4.3), using systematic sampling because the field plots are easily located on the ground and they covered the entire area. The ground plots were established along transects oriented N-S, and they encompassed any potential vegetative variability or change in topography.

The plots were circular with an area of $400 \mathrm{~m}^{2}$, or 0.10 acre. Each plot was located at the center of a 0.8 -ha (2 acre) square grid cell. A sampling intensity formula was used to determine the number of plots required in the study area. This ensured that the systematic sampling was statistically efficient and the number of plots in the study area was sufficient to capture local variability (Avery and Burkhart, 1994).

The formula used was:

$$
n=\frac{t^{2} * C V^{2}}{A^{2}}
$$

$n=$ the required number of plots;

$t=$ the Student's t-value at 5\% level of confidence;

$C V=$ coefficient of variation;

$A=$ allowable error, expressed as a percentage (10\%).

Initially, the study area was divided into two administrative subunits, and for each one of them the formula's projected $n$ was compared to the original number of sample plots. The total number of plots was 182. 
Each ground plot was sampled to determine the species composition and basal area. One fifth of all ground plots were sampled to determine crown diameters, and the measurements were used for establishing the optimal spatial resolution. On each plot, diameter at breast height (DBH at $1.3 \mathrm{~m}$ or $4.5 \mathrm{ft}$ above ground), crown class (dominant, codominant, intermediate and suppressed), position of the tree's crown (overstory or understory) and crown closure were measured. No trees were cored, however, Westvaco Corporation provided site indices.

All trees in the suppressed crown class or situated in the understory, together with dead trees, were removed from the data set. Basal area $\left(\mathrm{ft}^{2} / \mathrm{acre}\right)$ and species percentages were determined for dominant, codominant and intermediate tree species in each plot, in the study area as a whole and in each aspect-based subunit. For the determination of the aspect-based subunits, a DEM with 15-m resolution provided by Westvaco Corporation was used.

\subsection{THE USE OF GPS FOR IMAGE ACQUISITION AND PREPROCESSING}

GPS was used heavily for both image acquisition and for image preprocessing. For image acquisition, a Trimble Geoexplorer was connected to a Dell Latitude laptop computer that was running the Geolink software and used for navigation. The data from each flight were saved in a specific Trimble format. Naturally, during each flight the Selective Availability was running, but we did not see any errors in the acquisition of the images and the ground areas of interest were totally covered by the acquired images. 
However, the Trimble Geoexplorer is not a high-end GPS product, and the number of GPS receiver channels is low (only 4). That created some problems during the flights; namely, at some point the GPS data could not be used by the navigation software and we had to rely on the airplane instruments.

Another GPS is incorporated into the ADAR 1000 operator console, and is used for post flight preprocessing by correlating GPS data collected in a current GPS log file with the acquired imagery. The correlation between the images collected and the GPS log file is done after the flight to actually identify the moment when the image was collected to the nearest second, and records the latitude and longitude of the point. Because the GPS can acquire positions every second, the precision of the position recorded for each image ranges of $\pm 44 \mathrm{~m}$ for an airplane speed of $160 \mathrm{~km} / \mathrm{hour}$. Consequently, the lack of precision precludes the use of such data for automated mosaicking.

The use of GPS for image preprocessing was an important part of the research. First, the GPS was used for collecting the position of each of the ground plots; the center of each plot was determined using a Trimble Geoexplorer unit (table 4.3). At each plot center, 180 satellite positions were collected and later were differentially corrected. The ground data were mainly used to determine the composition of the species in the subunits of the study area. Second, the GPS was used to collect a large number of ground control points (GCP) in the summer of 1998, using a Trimble Geoexplorer unit (table 4.3).

The initial intention to use some of the ground plots for training, especially the plots that included only two to three species, was precluded by the big differences in plot locations recorded using two different GPS units. In the fall of 1999, some of the ground plot locations were measured again using a Trimble Pathfinder ProXL GPS unit, and 
large differences between the original recorded locations and the control locations were noted (table 4.2).

Table 4.2- Differences in differentially corrected plot center positions using two different GPS units

\begin{tabular}{|l|c|}
\hline Plot Number & $\begin{array}{c}\text { Differences in position of } \\
\text { plot location recorded } \\
\text { with Trimble } \\
\text { GeoExplorer and Trimble } \\
\text { Pathfinder ProXL } \\
\text { (meters) }\end{array}$ \\
\hline 27A & 17.95 \\
\hline 12A & 8.25 \\
\hline $86 \mathrm{~B}$ & 13.75 \\
\hline $45 \mathrm{~A}$ & 15.25 \\
\hline $39 \mathrm{~B}$ & 4.75 \\
\hline 10B & 6.00 \\
\hline $15 \mathrm{~B}$ & 4.75 \\
\hline $71 \mathrm{~B}$ & 9.75 \\
\hline $34 \mathrm{~B}$ & 12.00 \\
\hline $102 \mathrm{~B}$ & 1.25 \\
\hline 134B & 4.25 \\
\hline 130B & 4.75 \\
\hline
\end{tabular}

Because of such large differences, the plots could not be correctly located on the mosaicked images, and it was necessary to locate different training areas, which were measured using a very accurate GPS unit, the Trimble Pathfinder ProXL. The positions of the field plots can be seen in figure 4.3 . 


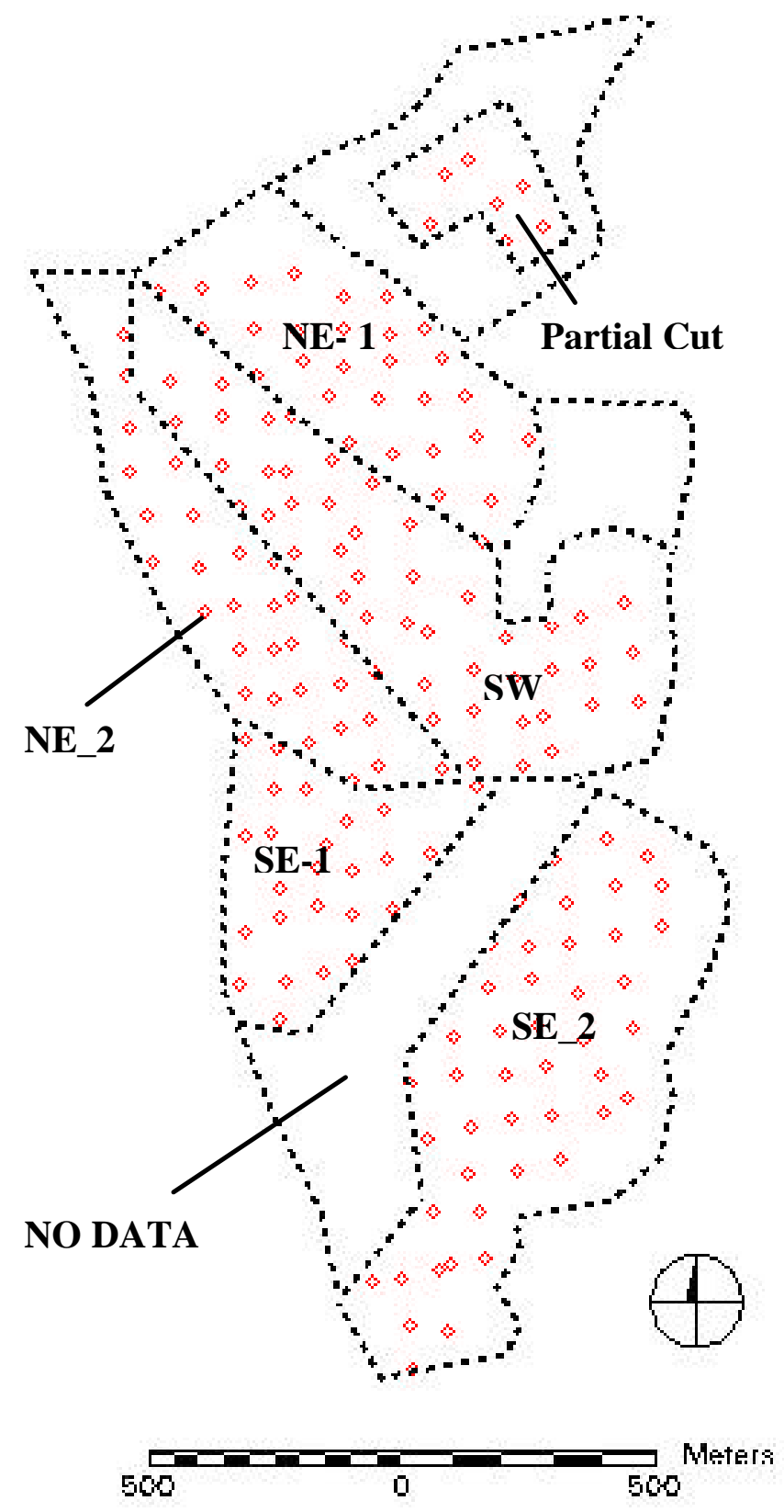

Figure 4.3- Distribution of ground plots in the study area

Fifteen ground control points (GCP) were located along Rocky Run Road for rectification purposes. For each, 500 satellite positions using the Trimble Geoexplorer unit were collected. The GCP locations were chosen to be easily identified on the imagery, such as road intersections, edges of forests that are close to the road and sharp 
curves. Also, in the summer of 1998, a large number of GCPs situated on the western side of the study area were located, but very few of them could be identified in the images.

After the images were acquired in the fall of 1998 (table 4.3), and the fieldwork was finished, it appeared that the number of ground control points should be increased in order to make it possible to apply second degree polynomial correction for each of the images. It was necessary to collect at least 6 GCPs for each of the images using a Trimble Pathfinder ProXL receiver. The GCPs were first identified on the images and then their positions were measured on the ground. Color printouts of all the images were used to determine well-defined and easily recognizable features that could be located accurately in the field. The data, consisting of 50 GCPs, were collected in February 1999 (table 4.3) and were differentially corrected.

The same Trimble Pathfinder ProXL receiver was used to collect more than 60 training and control points in the fall of 1999. We also checked some of the positions collected with the Trimble Geoexplorer units (table 4.2). All these data were differentially corrected using the Trimble Pathfinder software, and all the data were projected in the UTM coordinate system, using the NAD 27 datum. This coordinate system and datum were chosen to match the base data provided by Westvaco Corporation. The collected points were then exported as shapefiles using the Trimble Pathfinder utility, and later imported as Arc/Info coverage into ERDAS Imagine. The points were overlaid on the digital images and used for correcting the images geometrically, to select the ground plots situated in each subunit, to clip the mosaic of the 
images and for defining the study area and identifying the training and control areas for the image classification.

\subsection{IMAGE ACQUISITION AND PREPROCESSING}

The imagery was acquired on three different dates in the fall of 1998 (table 4.3), using the ADAR 1000 system built by Positive Systems Inc. The main part of the system is a digital Kodak DCS460c camera with two interchangeable 20-mm lenses, one lens for visual color (VIS) and the second one for color infrared (CIR). The other parts of the system are a laptop computer (system console) on which is installed the software that controls the image acquisition during the flight, and the power distribution unit (figure 4.4).

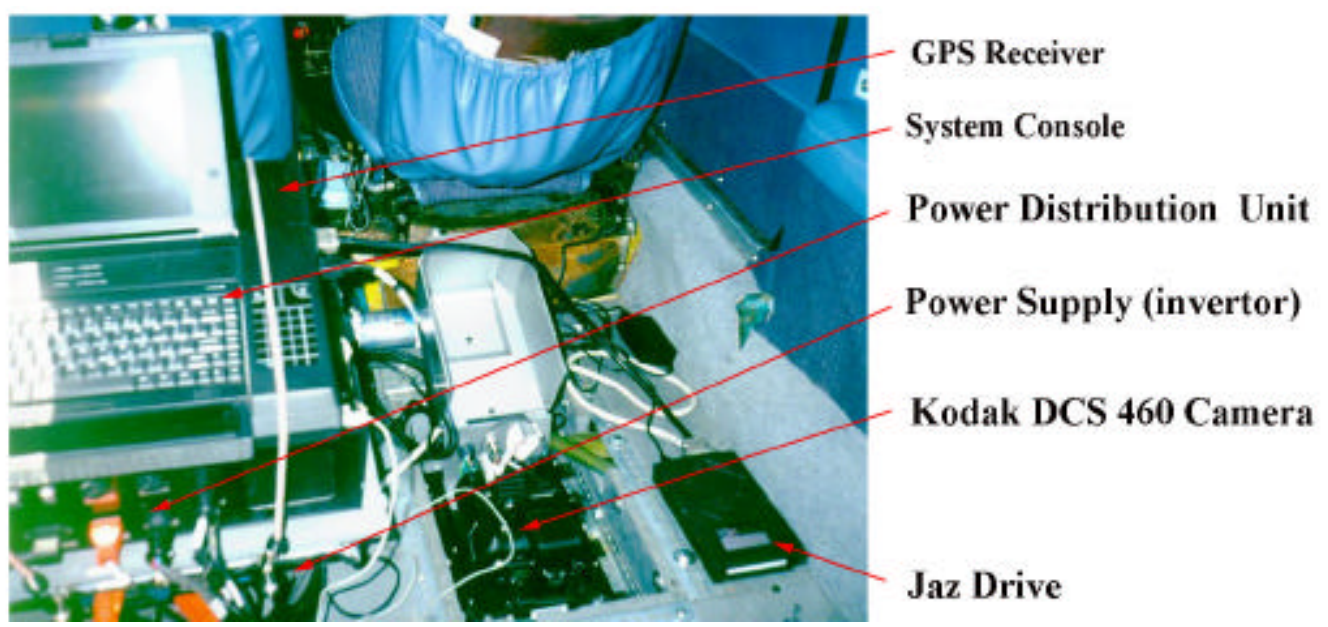

Figure 4.4- Image of the ADAR 1000 system inside the plane 
The whole system was mounted in a Piper Apache airplane (figure 4.5), with the camera bolted to a belly mount. The airplane generator produced the power necessary for the system, and it was inverted to alternative current (AC) and distributed throughout the power distribution unit (figure 4.4). A navigation system that made use of a Dell Latitude laptop computer running Geolink software, which had been connected to a Trimble Geoexplorer GPS, was used for all the flights.

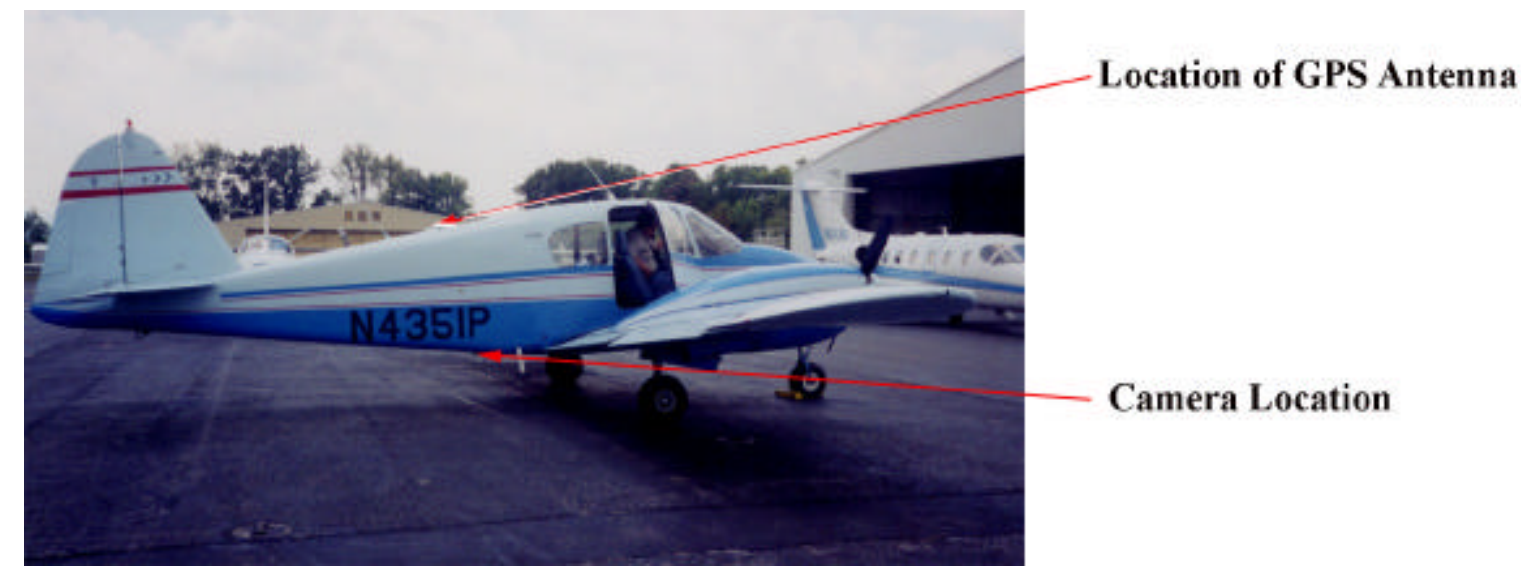

Figure 4.5- The Piper Apache aircraft used for image acquisition

The first set of images was acquired on October 12, 1998. We made a double flight, and the imagery was acquired both in visible (VIS) and color infrared (CIR). That was the first flight executed using the ADAR 1000 system, and was primarily a pilot flight. The images were acquired from a height of $500 \mathrm{~m}$ (1500 feet) above ground, and the camera was set with an aperture of 2.8 and a shutter speed of 1/500 sec. The ground pixel resolution was $0.18-\mathrm{m}$, but unfortunately there were large gaps between consecutive images, which precluded the possibility of mosaicking them in a whole image of the 
study area. The flight conditions were excellent, with high ceiling and no clouds. The plane speed was $160 \mathrm{~km} /$ hour (100 miles/hour). These images were used to determine the optimal spatial resolution of acquired images.

A second set of normal visible (VIS) images was acquired on October 21, 1998. The height of flight was $900 \mathrm{~m}$ (3000 feet) above ground, and the camera was set with an aperture of 2.8 (the widest possible) and a shutter speed of 1/500 sec. The flight conditions were far from ideal because the ceiling was low and the sky was completely covered with clouds. The images were darker than normal and the effect of radiance falloff toward the edges of the images was apparent. Twenty-two images with ground pixel resolution of 0.44-m were acquired along three different flight lines. The plane speed was $160 \mathrm{~km} /$ hour (100 miles/hour). The overlap of the images varied between $20 \%$ and $40 \%$ and the sidelap was close to $40 \%$. These images were used for classification purposes. In the present and the 7th chapter, these images will be considered to have 0.5 -m ground pixel resolution, and will be labeled as VIS 0.5-m images.

The second set of color infrared images was acquired on October 23, 1998. The height of flight was again $900 \mathrm{~m}$ (3000 feet) above ground, with a camera aperture of 2.8 and a shutter speed of 1/500. The flight conditions were normal, with unlimited ceiling and no clouds. Forty images with ground pixel resolutions of $0.44-\mathrm{m}$ were acquired along three different flight lines. The plane speed was $160 \mathrm{~km} / \mathrm{hour}$ (100 miles/hour). The overlap of the images varied between $20 \%$ and $50 \%$, and the sidelap was close to $50 \%$. These images were use for classification purposes and to determine the optimal scale of the images. In the present and the 7th chapter, these images will be considered to have 0.5-m ground pixel resolution, and will be labeled as CIR 0.5-m images. 
On the same date images were acquired for the whole Westvaco Wildlife and Ecosystem Research Forest, with a ground pixel resolution of $1 \mathrm{~m}$. Those images were acquired from $2000 \mathrm{~m}$ (7000 feet) above ground, with an overlap of 50\% and a sidelap of $40 \%$. In the present and the 7 th chapter, these images will be considered to have $0.5-\mathrm{m}$ ground pixel resolution, and will be labeled as CIR 1-m images. All these images were use for classification purposes.

\subsubsection{Image preprocessing}

The images were saved on the ADAR 1000 operator's console in a Kodak TIFF format (each image having 6 Mbytes in size), and then the images were imported to "normal" TIFF format using DCS Access Kodak software. The CCD array in the Kodak DCS460 digital camera has twice as many green pixels as red or blue (or color-infrared for CIR imagery) pixels, and the layout of the pixels is shown in figure 4.6.

\begin{tabular}{|l|l|l|l|l|l|}
\hline $\mathrm{g}$ & $\mathrm{r}$ & $\mathrm{g}$ & $\mathrm{r}$ & $\mathrm{g}$ & $\mathrm{r}$ \\
\hline $\mathrm{b}$ & $\mathrm{g}$ & $\mathrm{b}$ & $\mathrm{g}$ & $\mathrm{b}$ & $\mathrm{g}$ \\
\hline $\mathrm{g}$ & $\mathrm{r}$ & $\mathrm{g}$ & $\mathrm{r}$ & $\mathrm{g}$ & $\mathrm{r}$ \\
\hline $\mathrm{b}$ & $\mathrm{g}$ & $\mathrm{b}$ & $\mathrm{g}$ & $\mathrm{b}$ & $\mathrm{g}$ \\
\hline $\mathrm{g}$ & $\mathrm{r}$ & $\mathrm{g}$ & $\mathrm{r}$ & $\mathrm{g}$ & $\mathrm{r}$ \\
\hline $\mathrm{b}$ & $\mathrm{g}$ & $\mathrm{b}$ & $\mathrm{g}$ & $\mathrm{b}$ & $\mathrm{g}$ \\
\hline
\end{tabular}

Figure 4.6 - Sensor element (pixel) arrangement in the CCD array used in the Kodak DCS460 digital camera (Dean et al., 1999) 
One half of the pixels coded with the information from the green band, and one quarter of the pixels coded with the information from each of the red and blue (or color infrared) bands are used in "active interpolation" of the data (Eastman Kodak Company, 1995). Neighboring pixels are used to determine the colors for the remaining pixels in each band. Thus, the interpolated pixels consist of half of the green pixels, and three quarters of the pixels for each of the red and blue (color infrared) bands. Production of the three-band TIFF image resulted in expansion of the size of the imagse from 6 Mbytes to 18 Mbytes. The TIFF images were imported into the ERDAS Imagine format.

\subsubsection{The Correction of Vignetting and Fall-Off Of The Images}

The strongest artifact in the acquired imagery was a decrease in brightness toward the corners of the images. The radial reduction of light intensity was caused partly by the increasing obliquity in the view away from the nadir axis and partly by vignetting effects from the lenses and their internal geometry (Dean et al., 1999). From now on, the brightness fall-off will be referred to as "vignette effects", even though it also includes view angle obliquity effects.

Vignette effect correction of the CIR 0.5-m imagery was accomplished using "flat-field imagery" from a white panel to produce vignette effect images (Stow, 1996). Positive Systems, Inc. produced two such "flat-field" images using the camera from our ADAR 1000 system, one for VIS and one for CIR. The "flat-field" images were inverted and multiplied with all subsequent imagery. 
Even though good results were obtained through application of the vignette correction model, only the centers of the CIR 0.5 -m resolution images were used in mosaicking. The centers of the VIS 0.5-m resolution and the CIR 1-m resolution images were used in mosaicking without applying the vignette correction model.

\subsubsection{Geometric Correction and Registration}

The transformation of a remotely sensed image so that it has the scale and projection properties of a map is called geometric correction (Lillesand and Kiefer, 1994, Bannari et al., 1996). A related technique called registration is the fitting of the coordinate system of one image to that of a second image in the same area. Only after applying adequate geometric correction do many applications and uses of high spatial resolution digital images become possible.

The sources of geometric error in the ADAR 1000 digital imagery were:

i) lens artifact;

ii) panoramic distortion; and

iii) platform instability.

The geometric correction of our images involved the use of GCPs measured in the field and the identification of the GCPs on the images. At least 6 GCPs were identified on each image to allow the use of a second-order polynomial correction. On some of the images more than 10 GCPs were identified, and they were used as a "backbone" for the mosaic. A problematic high root mean square error (RMS) in the GCP positions was found in the rectified images. RMS error is the distance between the field-measured 
locations of the GCPs, and the retransformed location for the same GCPs. RMS error is calculated with a distance equation:

$$
\text { RMS error }=\sqrt{\left(x_{r}-x_{i}\right)^{2}+\left(y_{r}-y_{i}\right)^{2}}
$$

where:

$x_{i}$ and $y_{i}$ are the input (GPS) source coordinates;

$x_{r}$ and $y_{r}$ are the retransformed coordinates.

RMS error is expressed in the source coordinate system. If data file coordinates are the source coordinates, then the RMS error is a distance in pixel widths. After applying the geometric correction for every image, the RMS error was within 10 to 20 pixels, or 4.5 to $9 \mathrm{~m}$ for a pixel size of $0.44 \mathrm{~m}$ (the size of the pixels in the mosaicked CIR imagery).

This error is caused by the use of GPS for the acquisition of GCPs. The inherent error in point locations is between 5 to $10 \mathrm{~m}$, and even higher under the forest canopy (Deckert and Bolstad, 1995). The error probably could have been halved if there were more GCPs on each of the images, and the GPS unit used for the acquisition of the GCPs was more accurate.

The nearest neighbor resampling method was used during the geometric correction process. Nearest neighbor is the simplest and in the same time the fastest correction method. Its most important advantage is that it ensures that the pixel values in the output image are "real", in that they are copied directly from the input image. The values of the pixels were not interpolated using an algorithm such as bilinear interpolation or cubic convolution. The images were georeferenced by projecting the 
GCPs positions in the Universal Traverse Mercator (UTM) coordinate system, zone 17 North, using the NAD 27 datum.

After correction and georeferencing, the images were used to produce a mosaic of the study area. The centers of all the images where the effect of vignetting and fall-off was not apparent were visually selected and mosaicked together. The "no matching" function, which preserves the original values of the digital numbers (DN) and does not interpolate the DNs in the output images, was used.

Finally, the study area was buffered with a buffer zone of $10 \mathrm{~m}$ and clipped from the raw mosaicked images, using an overlaid vector image of the GCPs situated on the borders of the study area to produce the clip vector layer. 


\subsubsection{Methodology timeline}

A time line of the fieldwork, digital image acquisition, GPS data collection and image preprocessing can be seen in table 4.3.

Table 4.3- Data collection and image preprocessing time line

\begin{tabular}{|c|c|c|c|c|c|c|c|c|c|c|c|c|c|c|c|c|c|c|}
\hline Activity & & 1 & 9 & 9 & 8 & & & & & & & 9 & 9 & & & & & \\
\hline & \begin{tabular}{l|ll}
$\mathbf{J}$ & $\mathbf{J}$ \\
\end{tabular} & $\mathbf{A}$ & $\mathbf{S}$ & $\mathbf{O}$ & $\mathbf{N}$ & D & J & $\mathbf{F}$ & & A & $\mathbf{M}$ & & $\mathbf{J}$ & $\mathbf{A}$ & $\mathbf{S}$ & $\mathbf{O}$ & & D \\
\hline FIELD WORK & & & & & & & & & & & & & & & & & & \\
\hline Ground plot measurements & * & * & & & & & & & & & & & & & & & & \\
\hline Training site measurements & & * & & & & & & & & & & & & * & * & & & \\
\hline DIGITAL IMAGES ACQUISITION & & & & & & & & & & & & & & & & & & \\
\hline VIS \& CIR, 0.18-m resolution & & & & $*$ & & & & & & & & & & & & & & \\
\hline VIS, $0.5-\mathrm{m}$ resolution & & & & * & & & & & & & & & & & & & & \\
\hline CIR, $0.5-\mathrm{m}$ resolution & & & & * & & & & & & & & & & & & & & \\
\hline CIR, 1 m resolution & & & & * & & & & & & & & & & & & & & \\
\hline GPS DATA COLLECTION & & & & & & & & & & & & & & & & & & \\
\hline Ground plot location & * $\mid * \begin{array}{ll}* \\
\end{array}$ & $*$ & & & & & & & & & & & & & & & & \\
\hline $\begin{array}{l}\text { GCP collection - Trimble Geoexplorer } \\
\text { GCP collection - Trimble ProXL }\end{array}$ & & * & & & & & & $*$ & & & & & & & & & & \\
\hline $\begin{array}{c}\text { Training site } \& \text { control point location } \\
\text { IMAGE PREPROCESSING }\end{array}$ & & & & & & & & & & & & & & & * & & & \\
\hline Digital image preprocessing & & & & & * & * & s & & * & * & $*$ & * & * & * & * & & & \\
\hline
\end{tabular}




\section{CHAPTER 5. OPTIMAL SPATIAL RESOLUTION AND OPTIMAL SCALE FOR CENTRAL APPALACHIAN HARDWOOD FOREST IMAGES}

\subsection{INTRODUCTION}

One of the fundamental characteristics of a remotely sensed image is spatial resolution, or the size of the area on the ground from which the measurements that comprise the image are derived (Woodcock and Strahler 1987, Bian 1997, Cao and Lam 1997, Franklin and Woodcock 1997, Walsh et al., 1997). In this sense, spatial resolution is analogous to the scale of the observations. However, when using remotely sensed imagery from space borne sensors, users are limited to specific scales of observation. Until recently, this date choice was limited, and one of the most commonly used data sets was Landsat Thematic Mapper (TM) imagery, with its 30-m ground resolution.

To select an appropriate scale of data, one must understand the spatial structure of images. In particular, the manner in which the images of a scene change as a function of spatial resolution is important. According to Townshend (1980), there are four criteria for the selection of the spatial resolution of an imaging system:

i) the geometrical properties of the system;

ii) the ability to separate point targets;

iii) the ability to measure periodicity of repetitive targets; and, 
iv) the ability to measure spectral properties of small targets.

When the pixel size is larger than the objects information is lost because the spatial resolution of images is low (Woodcock and Strahler, 1987). On the contrary, when very high-resolution images are used adjacent pixels give the same information because it is highly probable that they are from the same object. Another drawback of high resolution is that the amount of data soon becomes too large to compute. The worst case is when the use of unsuitable resolution results in erroneous supervised image classification because of the spatial autocorrelation of the neighboring pixels. Spatial autocorrelation is the interdependence between measurements in neighboring locations. Spatial autocorrelation violates the assumption of independence between residuals of adjacent observations.

In the context of remote sensing, Jupp, Strahler and Woodcock studied spatial autocorrelation in a series of papers published in 1988 and 1989 (Jupp et al., 1988, 1989). They assumed that in many applications of remote sensing and digital image processing it is reasonable to regard a scene as a spatial arrangement of two or three-dimensioned objects imposed upon a background. In such a case, it is possible to consider a discreteobject scene model as an appropriate abstraction of the scene. In this type of model, the scene includes one or more classes of objects, each of which has a set of unique properties or parameters that characterize it. For example, an agricultural region could be regarded as a two-dimensional patchwork of rectangular fields of some different basic sizes. Another example would be a winter scene of a conifer forest with one species, that could be modeled 3-dimensionaly as a series of green cones of constant shape, but 
varying size, scattered randomly on a snow-covered plane and that cast shadows on a snowy background as well as on other cones.

The spatial structure of real scenes induces a measurable spatial structure of real scenes in the images derived from them. This occurs because distinguishable objects tend to be spectrally homogenous and separable from other objects and background. Adjacent points in a scene are consequently more similar spectrally than might be expected on average and the mean distance at which this spatial autocorrelation disappears is related to the size, spacing and shape of the objects in the scene. The induced spatial structure depends greatly on the spatial resolution of the sensor as compared to the objects that are being imaged.

If the resolution of cells (pixels) is small with respect to the objects, an $\mathrm{H}$ resolution case exists. In this case it is possible to identify the size and shape of each object as well as to examine the brightness values within them. On the other hand, an Lresolution case might exist in which the resolution cell is larger than the objects of interest within the scene. In such a case, each digital value represents brightness for a combination of objects and background (Woodcock and Strahler, 1987).

Thus, the spatial structure and statistics of digital images will be greatly influenced by:

i) the shape, size and density of objects in the scene; and

ii) the relationship between the size of the objects and the size of the cells in the digital image of the scene.

Jupp et al. (1988) have related an image to the theory of regionalized variables by considering the output of a scanned scene as a set of measurements associated with a 
spatial position. These measurements can be considered values of a "regionalized variable" with brightness a function of the integrated brightness over the specified area. At the same time, the authors adopted a stochastic view of the scene and its spatial structure, and considered that such statistics characterize the properties of the underlying spatial random function adopted. Second-order statistics, such as the spatial covariance and the variogram, were appropriate for characterizing the spatial random function (Jupp et al., 1988).

Curran (1988) emphasized that the near-ideal tool when using the regionalized variable theory is the semivariogram. The semivariogram is a function that relates semivariance to sampling lag, and is a useful measure of dissimilarity between spatially separate pixels. The average semivariance for an image is:

$$
\overline{S^{2}}=\frac{1}{2 m} \sum_{i=1}^{m}\left[z\left(x_{i}\right)-z\left(x_{i}+h\right)\right]^{2}
$$

where:

$\overline{S^{2}}=$ the average semivariance;

$m=$ pairs of observations separated by the same lag;

$z=$ digital numbers $(\mathrm{DN})$ of pixels;

$x_{i}=$ the pixels in the image;

$h=$ lag, or distance between sampling pairs (figure 5.1). 


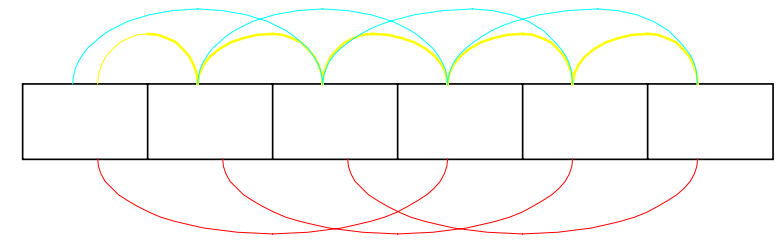

Lag $\mathrm{h}=1 ; \quad$ Lag $\mathrm{h}=2 ; \quad \ldots \quad \operatorname{Lag} \mathrm{h}=3$.

Figure 5.1- Lags of 1, 2 and 3 pixels along transect

The semivariogram and its graph have the following set of parameters: support (size and spacing of the sample points or ground resolution elements); lag (described above); sill (the maximum value of semivariance); range (the lag at which the sill is reached); nugget variance (represents spatially independent variance and is the limit of the semivariogram function at a lag of 0 ).

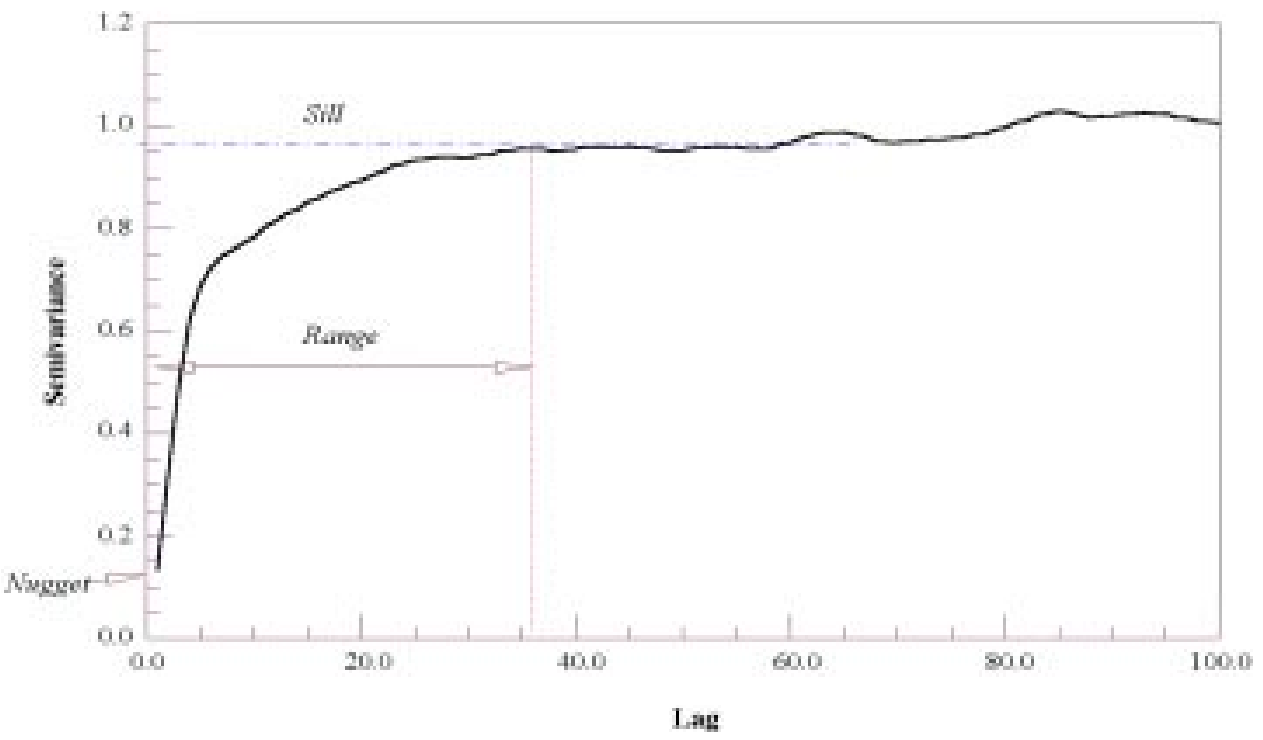

Figure 5.2- The parameters of the semivariogram (from Curran 1988) 
Curran (1988) stressed the use of semivariogram for the selection of spatial resolution. Although we are inclined to use a high spatial resolution, such data are expensive and difficult to process. Analytically, autocorrelation is used to eliminate unnecessary intraparcel variability by using variograms of different wavebands and directions.

There is no single pixel size that would give the best interpretation result for all land use classes (Marceau et al., 1994). Instead, there is an optimal pixel size for each land use class. However, seldom has any consideration been given to suitable spatial resolution and spatial autocorrelation of pixels. Considerable improvements in image interpretation accuracy could be achieved if there is prior knowledge about the optimal spatial resolution for remote sensing based inventory. The intended application and the spatial characteristics of the forest must be considered when determining the appropriate scale of the remotely sensed data.

As has been previously emphasized, a fundamental characteristic of a remotely sensed image is the support or the size of the area on the ground from which the measurements that compose the image area derived. In this sense, the support is analogous to the scale of observations (Woodcock and Strahler, 1987).

Scale-variance analysis was initially applied to image processing by Woodcock and Strahler (1987), and their work emphasized the effects increasing ground pixel size had on the spectral variance levels of the image. Recently, Marceau et al. (1994a, b, c), refined this approach and addressed the image classification issues in order to identify the ground pixel size at which classification accuracy was optimized. Their objectives were to estimate the optimal spatial resolution for detection and discrimination of coniferous 
classes in a temperate forested environment. Their approach was to aggregate data acquired from a fine spatial sampling grid and to apply an optimization criterion, the intraclass variance, to the series of spatially aggregated data. Marceau et al. (1994b, c) used the airborne MEIS-II data, acquired at 0.5 -m resolution. For all coniferous classes and for the eight spectral bands considered in the study, there was a minimum intraclass variance that indicated an optimal spatial resolution for each class that varied between 2.5 $\mathrm{m}$ and $21.5 \mathrm{~m}$. Their study emphasized the intricate link between the definition and the measurement of geographical entities, and it confirmed the necessity of selecting the appropriate scale of measurement in studies involving the manipulation of geographical data.

Hay et al. (1997) investigated the need for a multiscale approach to feature extraction and the appropriate upscaling techniques to be used for such an approach. Their analysis of original and modeled datasets suggested that appropriately upscaled imagery represented a more accurate scene-model than an image obtained at the upscaled resolution. However, they used a CASI scene with $1.5-\mathrm{m}$ spatial resolution, which can be considered a low start-up resolution, from which were produced images with 3-m, 5-m and 10-m resolution. These were compared to a CASI scene acquired at 10-m resolution.

Hay et al. (1997) suggested that by sampling image-objects under iteratively growing object-specific kernels (matrices), unique optimal scales could be defined for each object. The authors emphasized that common upscaling algorithms, such as nearest neighbor, bilinear interpolation and cubic convolution, are not suitable for upscaling remotely sensed data to a coarser spatial resolution, especially when the upscale factor is greater than 5. Bian and Butler (1999) evaluated three different methods for scaling-up 
remotely sensed data: averaging, central-pixel resampling and median. The authors emphasized that even though data aggregation could cause information loss, some of the methods can retain statistical characteristics of the original data better then others. The averaging method performed the best, retaining the mean and median values. The averaging method also produces aggregated data and aggregation errors with the most statistically and spatially predictable behavior, and the magnitude and range of errors are affected by the spatial autocorrelation present in the data.

\subsection{RESEARCH METHODS}

Determining the optimal spatial resolution for applications in mixed species deciduous forests of Central Appalachia was the first objective of this part of the present study. The methods used to determine the optimal spatial resolution were an analysis of autocorrelation and the semivariance of the imagery. The trees sampled in the ground plots were used to quantify the relationship between the crown diameter and the DBH, and the results can be used to estimate the tree diameters from remotely sensed images.

The second objective of the present study was to determine the optimal scale of the Central Appalachian hardwoods images by comparing the species composition derived from the ground plots (control) to the species composition derived from scaledup CIR imagery.

The study was conducted on a part of the 3413-ha (8430-acre) Westvaco Wildlife and Ecosystem Research Forest, located in Randolph County, West Virginia. The study 
area is extended over 200 ha (494 acres), and is positioned in the middle western part of the forest.

To meet the first objective, the ADAR System 1000 imagery of October 12, 1998, was used. The visible (VIS) and color infrared (CIR) images have a ground pixel size of $0.18 \mathrm{~m}$.

To meet the second objective, the ADAR System 1000 digital imagery of October 23, 1998, was used. The CIR images have a ground pixel size of $0.44 \mathrm{~m}$.

\subsubsection{Objective 1 - Determination of Optimal Spatial Resolution of Acquired Images}

\subsubsection{Method A - Autocorrelation}

Spatial autocorrelation is a measure of the influence of neighboring regions on each other. In the presence of positive spatial autocorrelation, similar values of the variable are clustered in space. In the presence of negative spatial autocorrelation, dissimilar values of the variable are clustered in space. Lack of spatial autocorrelation indicates a pattern of random values in space (Davis, 1996).

It is known that the information provided by the spatial autocorrelation could help in determining the optimal resolution (Hyppanen, 1996). The optimal spatial resolution was defined as a spatial resolution maximizing the classification of the individual tree species. Measurements of the first minimum value on autocorrelation plots generated from spatial profiles obtained from the acquired images were examined as a means of 
defining optimal resolution. The results from these measurements were compared with the statistics from the ground, and they suggested that the determined spatial resolution represents the average crown size of the trees for the study area. The spatial profiles were generated in ERDAS Imagine using the spatial profile tool. They were produced in different directions (E-W, N-S, SW-NE, and NW-SE) with lengths of 80 to 100 meters. An example of a N-S spatial profile can be seen in figure 5.3. The figure shows a cyclical occurrence of relatively low digital number values, which correspond to the spaces between the trees crowns, associated with shade. The average periodicity of the low digital numbers indicate the size of the tree crowns, approximately 35 pixels or 6.3 meters.

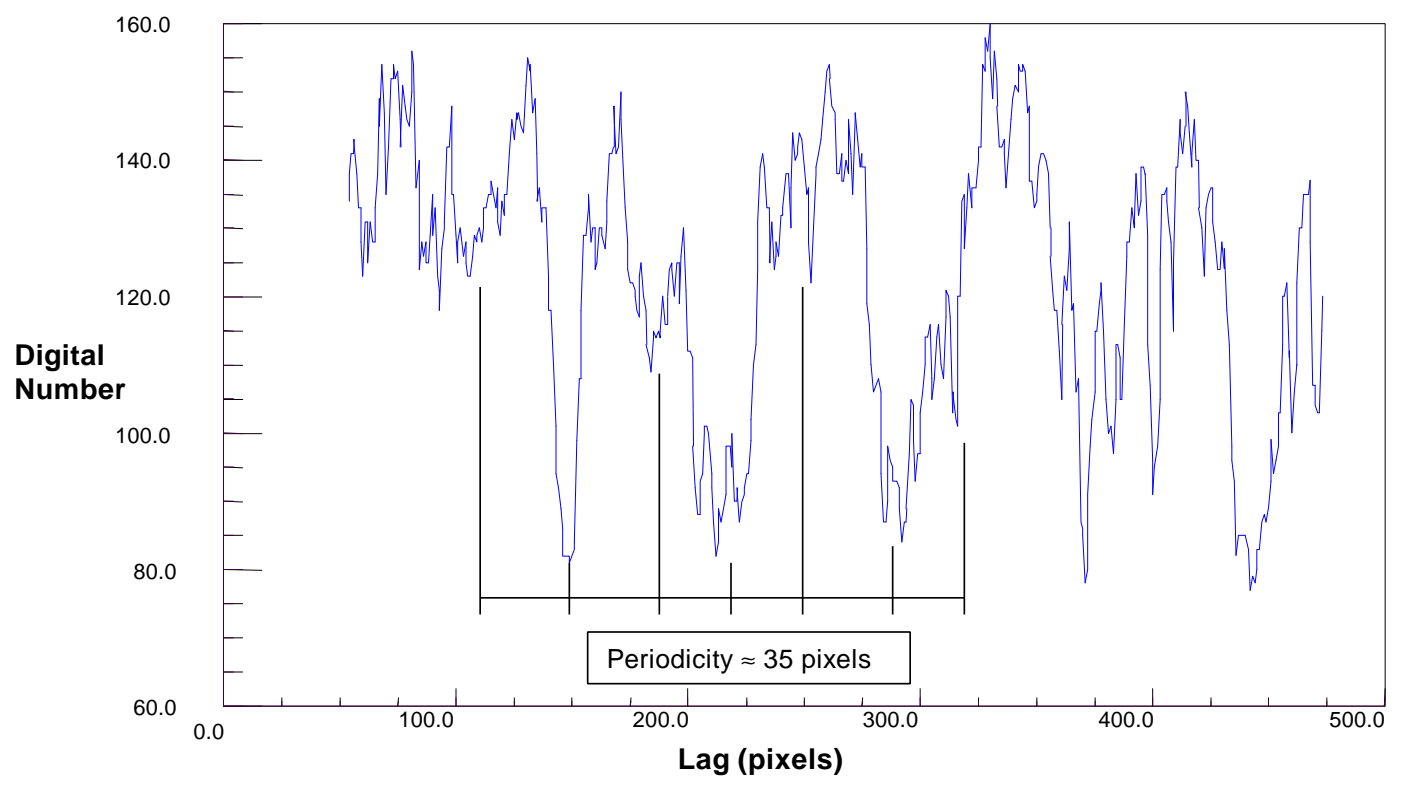

Figure 5.3- Example of spatial profile generated in ERDAS Imagine 


\subsubsection{Method B - Semivariance}

Semivariance is a measure of degree of spatial dependence between samples along a specific support. Variography is a method of measuring, presenting and modeling the variation between spatial objects, originally developed for geological and mining purposes, and recently applied in remote sensing (Curran 1988, Cohen et al., 1990, Jupp et al., 1988). The semivariograms were generated using Spatial Analyst software, on matrix files (subsets of images). Neighborhood associations in two directions were considered, one with a lag oriented along the image axes (Rook case), and the second oriented at 45 degrees (Bishop case).

\subsubsection{Method C (Control method) - Statistical analysis of field measurements}

Circular ground plots were located by using a systematic sampling design. Each plot had an area of $400 \mathrm{~m}^{2}$, or 0.10 acre, and was located in the center of a 0.8 -ha (2-acre). square grid cell. The total number of plots was 182, and the total number of sampled trees was 2820. Each plot center was geolocated with a Trimble GeoExplorer GPS unit. Inside each plot, the tree species, the DBH (in inches) and the crown position were determined 
for each tree. Also, heights for 3-5 trees and the canopy closure were determined for each plot. In 47 plots, the trees crown diameters (in feet) were measured.The edges of each crown were located from below and two perpendicular diameters were measured using a measuring tape; their average was considered to be the tree crown diameter. Average diameter at breast height (DBH) for all trees was calculated. A regression equation was developed to quantify the relationship between crown diameter and tree DBH.

\subsubsection{Objective 2 - Determination of Optimal Scale for Classification}

The CIR mosaicked image with 0.44-m ground pixel size was progressively resampled using the ERDAS Imagine averaging scaling-up routine DEGRADE. The images were scaled-up using window sizes of $2 \times 2,3 \times 3$, up to $7 \times 7$ pixels. After scalingup, the image produced was classified to determine the species composition by using the Maximum Likelihood classifier. For each classification, the same training sites and classification validation data were used. The classification accuracy of each image was determined using the same set of ground control points used for the original CIR image, and the general species composition for the entire study area was determined.

The classification accuracies were compared with the accuracy of the classified CIR 0.44-m resolution image. Species composition for the entire study area was compared with the species composition estimated from the ground data, and presented in graphical and tabular formats. This empirical method allowed determination of optimal scale of imagery for multispectral classification. 
The Kappa Hat $\left(\mathrm{K}^{\wedge}\right)$ statistic was used to assess and compare the actual agreement between reference data and an automated classifier and the chance of agreement between the reference data and a random classifier. The Kappa Hat statistic is defined as:

$$
\mathrm{K}^{\wedge}=\frac{\text { observed accuracy }- \text { chance agreement }}{1-\text { chance agreement }}
$$

A Kappa Hat value of 1.00 indicates a perfect agreement between the control data and the statistics used in the Maximum Likelihood classifier.

\subsection{RESULTS}

\subsubsection{Objective 1 - Determination of Optimal Spatial Resolution of Acquired Imagery}

Spatial profiles were generated from areas of the image that visually represented a high heterogeneity of species and, thus, of signal. Autocorrelation was calculated using a program called AUTO. The output was used to generate plots in PSI-Plot. For each of the 18 plots, the location of the first minimum value of the autocorrelation was measured (figures 5.4 and 5.5). An average lag of 6.4 meters was calculated form the 18 plots, and the standard error was 0.29 . The plots shown in figures 5.4 and 5.5 represent samples of the autocorrelation plots. It is important to note the values for the first minimum value, 
and also that the autocorrelation coefficient never exceeds a value of 0.4 after the first minimum, which strengthens the conclusion that the first minimum represents the optimal resolution of the sampled trees.

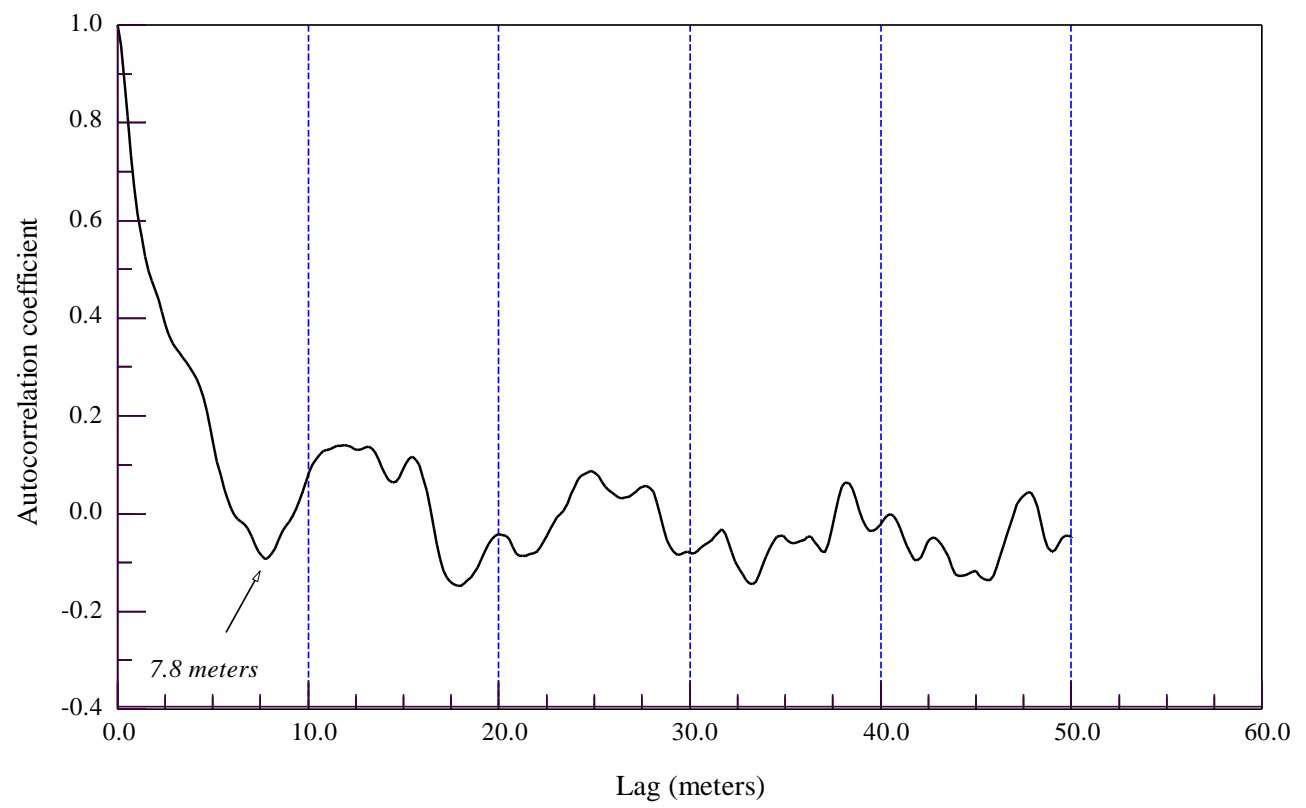

Figure 5.4- Sample of autocorrelation plot used for determination of optimal spatial resolution (1) 


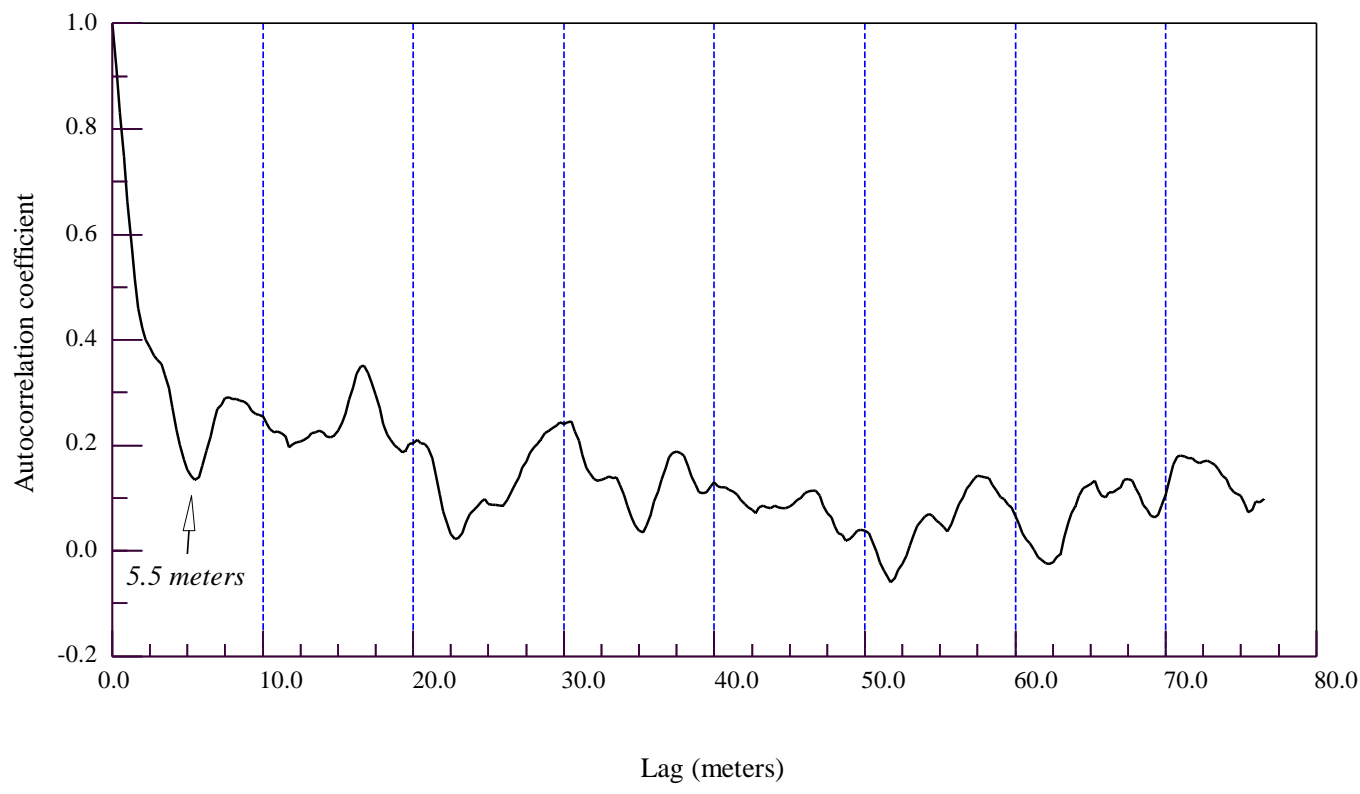

Figure 5.5- Sample of autocorrelation plot used for determination of optimal spatial resolution (2)

Semivariograms were generated for 15 matrix images. The maximum lag spacing used was between 50 and 80 pixels, and the models were generated automatically. In the Rook case, the mean range was 37 pixels, and the confidence level (95\%) was 1.36. The average nugget value for all the plots was close to 0 . The semivariance calculation was made along the pixels' axes, and, thus, the pixel size is 0.18 meters. So, the average range is 6.7 meters. 


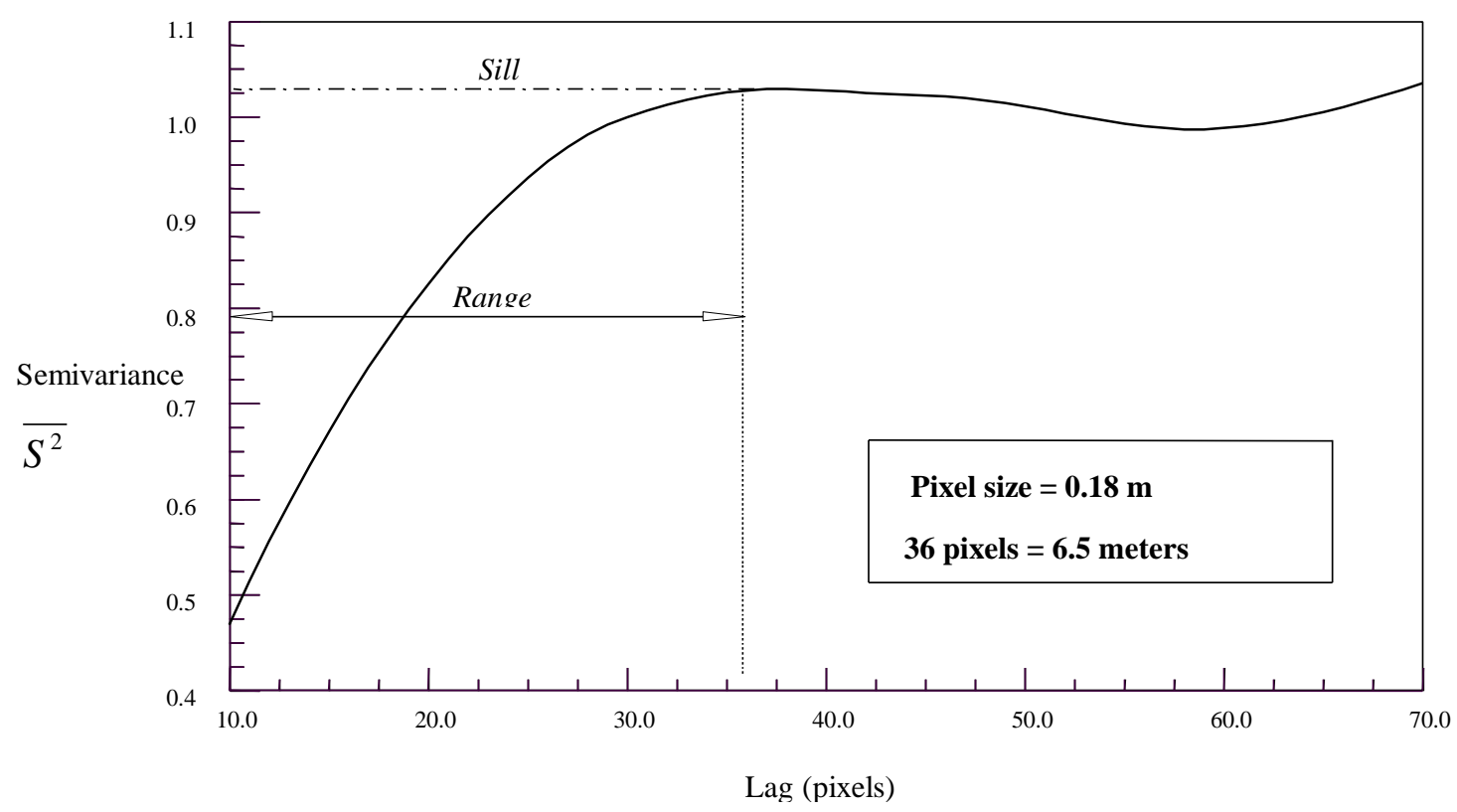

Figure 5.6- Semivariance plot sample for the Rook case (measurements along pixels axes)

In the Bishop case, the average range was 24 pixels, and the confidence level (95\%) was 1.07 . The average nugget value for all the plots was close to 0 . The semivariance calculation was made along the pixels' diagonals, and in this case the pixel size was 0.25 meters per pixel. So, the average range is approximately 7 meters.

In both Rook and Bishop cases, the sill value was approximately equal and close to a value of 1.0 . 


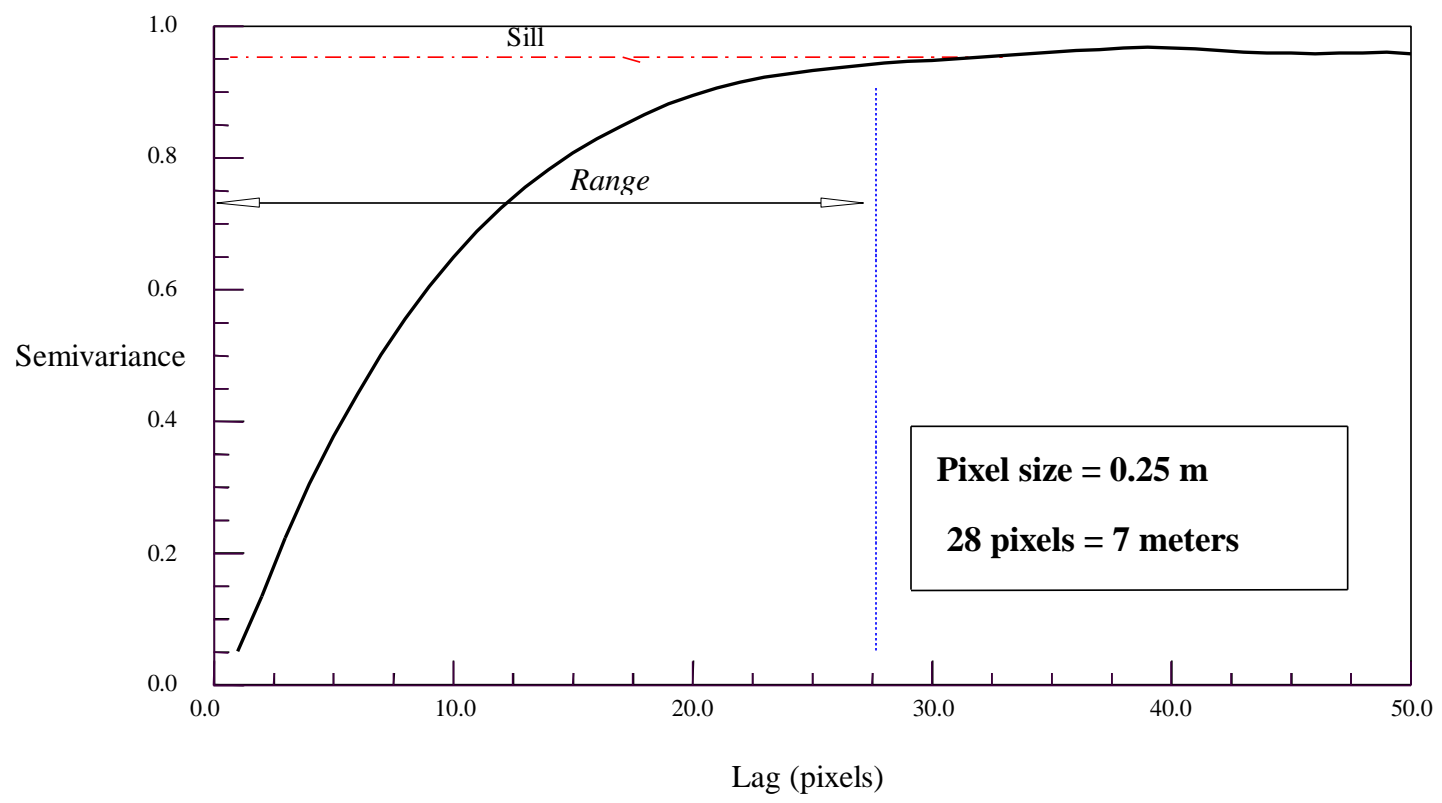

Figure 5.7- Semivariance plot sample for the Bishop case (measurements along pixels diagonals)

The field statistics were based only on the trees situated in the overstory (dominant, codominant and intermediate crown classes), which can be remotely sensed. The mean diameter of the 1874 trees was 13.56 inches $(34.6 \mathrm{~cm})$, and the standard error was 0.085 . Since the DBH and the crown diameter were measured in inches and feet, respectively, the units of the estimated regression equation are feet and inches.

The estimated regression parameters were:

$$
\text { Crown diameter }(\text { feet })=14.9645+0.5916 * \text { DBH }(\text { inches })
$$

Substituting the average DBH of 13.65 inches the estimated average crown diameter is approximately 23 feet $(6.9 \mathrm{~m})$. A total of 579 trees, for which the crown diameters were measured, were used for the regression statistics. The standard error of the intercept was 
0.74 and the standard error of the slope was 0.051 . However, the regression coefficient of determination $\mathrm{R}^{2}$ is low (0.183), indicating that the relationship between $\mathrm{DBH}$ and crown diameter is weak (figure 5.8). That resulted because all tree species were used to determine the regression parameters. If I determined the same type of relationship for each single species, the coefficient of determination $R^{2}$ surely would be higher.

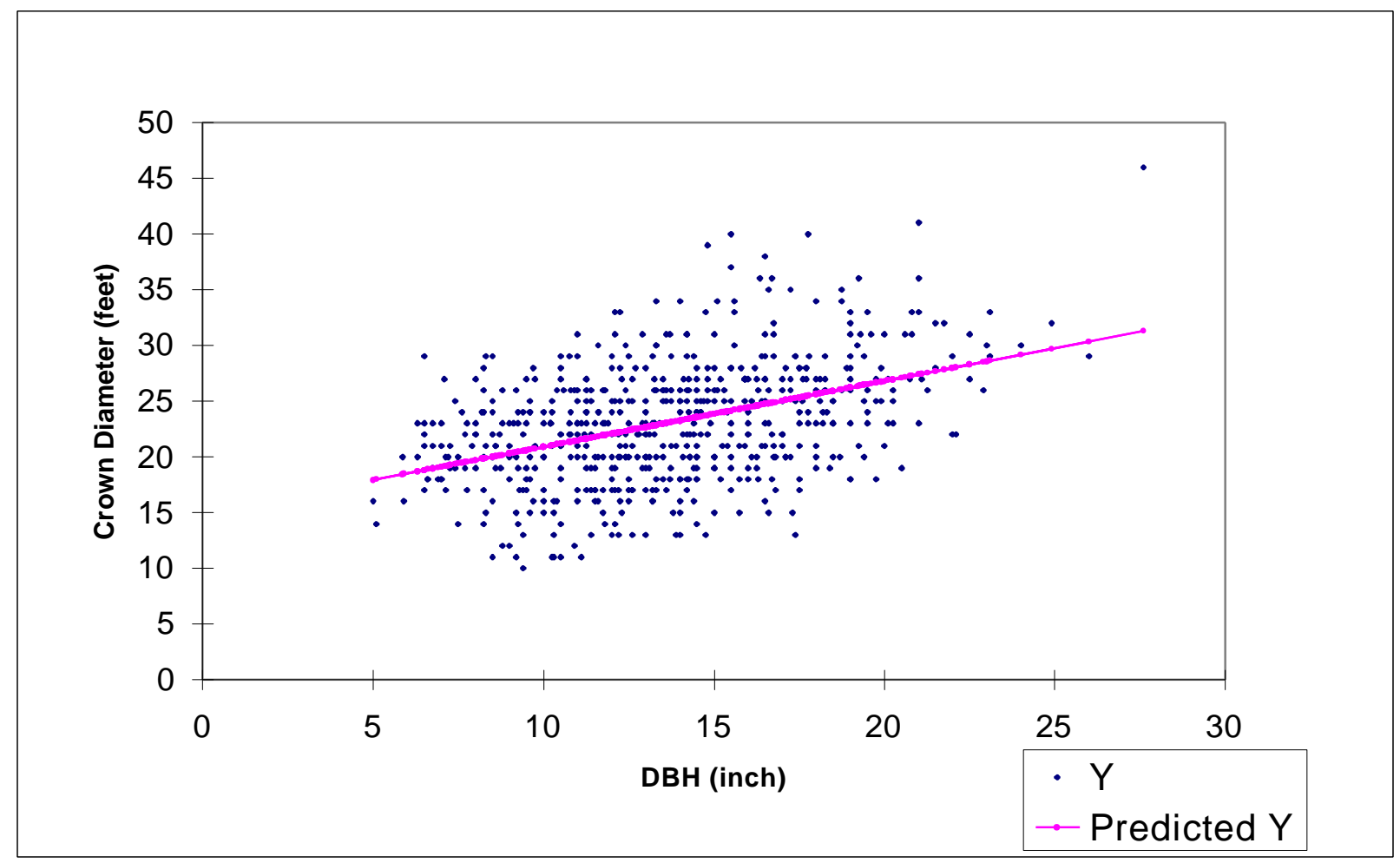

Figure 5.8- Plot of crown data observations and the fitted line 


\subsubsection{Objective 2 - Determination of Optimal Scale of Acquired Images}

The results of the aggregation (DEGRADE) routine are displayed in table 5.1. The highest classification accuracy was obtained for the original CIR 0.44-m resolution imagery, with an overall accuracy of $73.1 \%$ and an overall Kappa statistic of 0.69 . The classification accuracy and the Kappa statistic decreased steadily and the number of species correctly identified stayed the same until a pixel size of 1.8-m (corresponding to a $4 \times 4$ aggregating window) was reached. For this image, the classification accuracy was 50\% and the overall Kappa statistic was 0.41 (table 5.1 and figure 5.9).

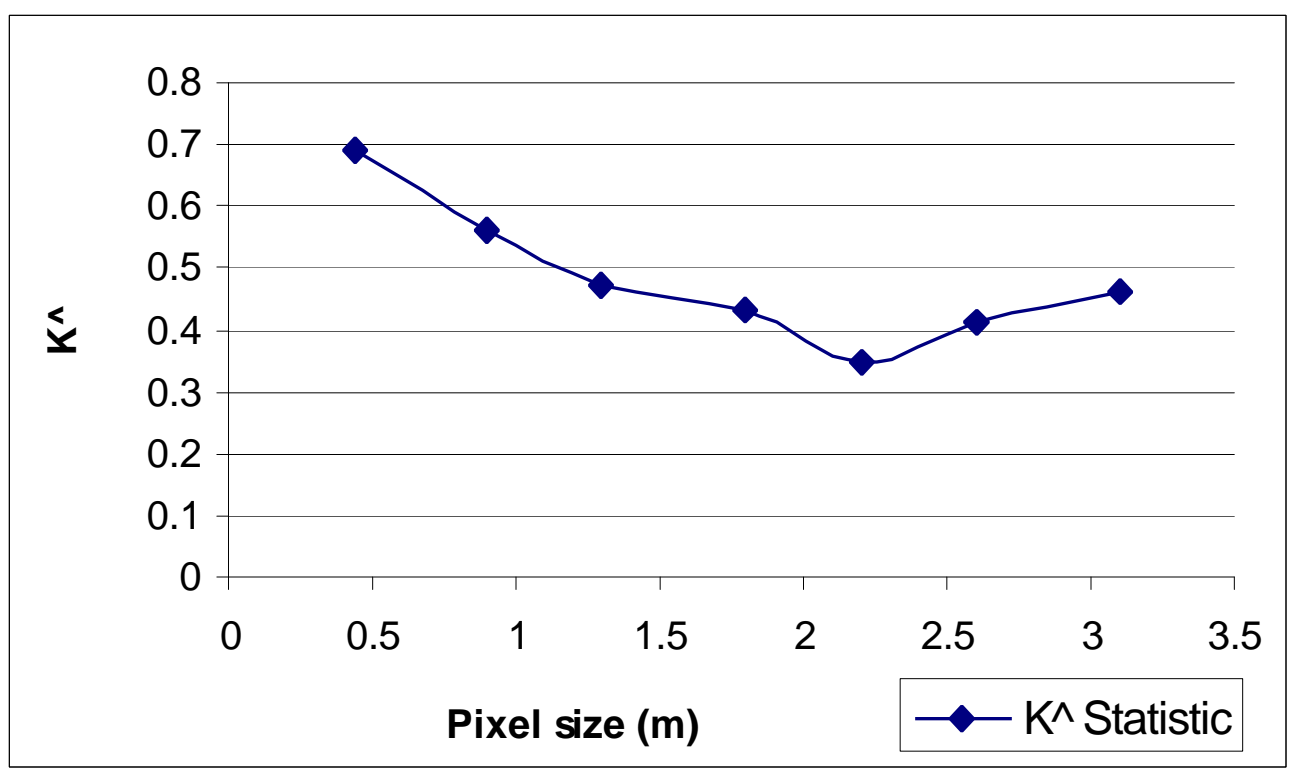

Figure 5.9 - Plot of Kappa Hat statistic for upscaled images 
Table 5.1- Classified image statistics and the species composition derived from the aggregated CIR images

\begin{tabular}{|c|c|c|c|c|c|c|}
\hline $\begin{array}{l}\text { Pixel } \\
\text { size } \\
(\mathrm{m})\end{array}$ & $\begin{array}{c}\text { DEGRADE } \\
\text { window } \\
\text { size }\end{array}$ & $\begin{array}{c}\text { Overall } \\
\text { Accuracy } \\
\%\end{array}$ & $\begin{array}{c}\text { Kappa } \\
\text { Hat } \\
\text { statistic }\end{array}$ & $\begin{array}{l}\text { Image } \\
\text { size } \\
(\mathrm{MB})\end{array}$ & $\begin{array}{c}\text { Chart of the species composition (\%) } \\
\text { derived from: }\end{array}$ & Comments \\
\hline--- & --- & --- & --- & --- & 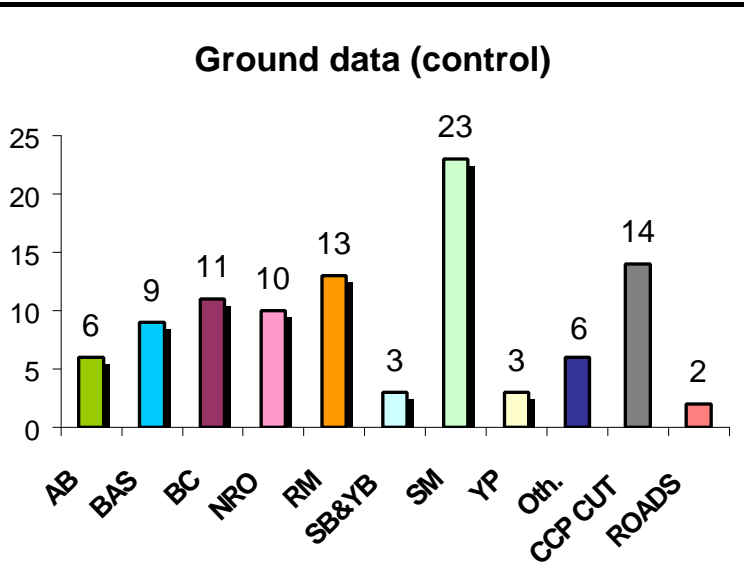 & $\begin{array}{l}\text { Reference } \\
\text { (control) } \\
\text { Composition }\end{array}$ \\
\hline $\begin{array}{l}\text { Orig } \\
\text { inal } \\
\text { Data } \\
\\
0.44\end{array}$ & $1 \mathrm{x} 1$ & 73.1 & 0.69 & 80 & 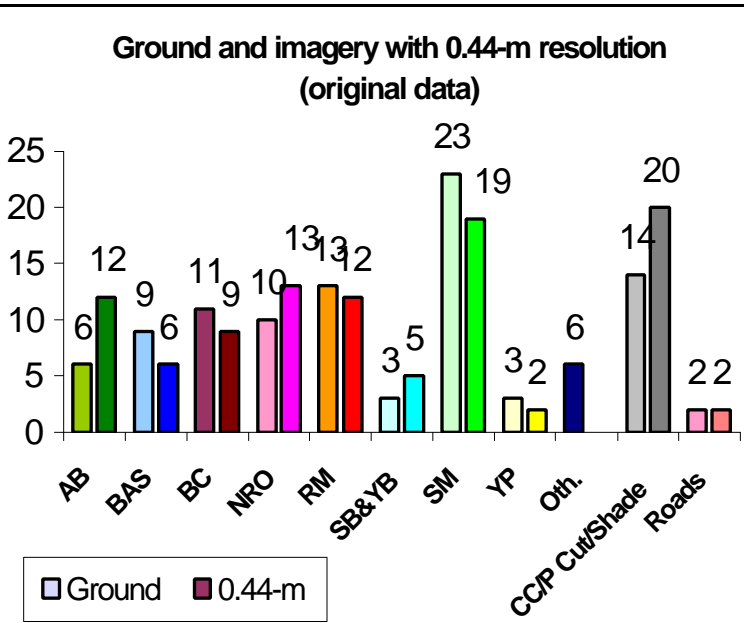 & $\begin{array}{l}\text { Highest } \\
\text { overall } \\
\text { accuracy }\end{array}$ \\
\hline 0.9 & $2 \times 2$ & 61.5 & 0.56 & 27 & $\begin{array}{l}\text { Ground and imagery with } 0.9 m \text { resolution } \\
\text { पGround }=0.9 \mathrm{~m}\end{array}$ & \\
\hline
\end{tabular}




\begin{tabular}{|c|c|c|c|c|c|c|}
\hline $\begin{array}{l}\text { Pixel } \\
\text { size } \\
(\mathrm{m})\end{array}$ & $\begin{array}{c}\text { DEGRADE } \\
\text { window } \\
\text { size }\end{array}$ & $\begin{array}{c}\text { Overall } \\
\text { Accuracy } \\
\%\end{array}$ & $\begin{array}{c}\text { Kappa } \\
\text { Hat } \\
\text { statistic }\end{array}$ & $\begin{array}{l}\text { Image } \\
\text { size } \\
(\mathrm{MB})\end{array}$ & $\begin{array}{c}\text { Chart of the species composition (\%) derived } \\
\text { from: }\end{array}$ & Comments \\
\hline 1.3 & $3 \times 3$ & 53.9 & 0.47 & 9 & $\begin{array}{l}\text { Ground and imagery with 1.3-m resolution } \\
\text { G Ground } \\
\text { Q1.3-m }\end{array}$ & \\
\hline 1.8 & $4 \times 4$ & 50.0 & 0.43 & 4.5 & $\begin{array}{l}\text { Ground and and imagery with 1.8m resolution } \\
\text { Ground } \\
1.8-m\end{array}$ & $\begin{array}{l}\text { Statistics } \\
\text { very close } \\
\text { to the } \\
\text { classified } \\
\text { image of } \\
\text { CIR-1m } \\
\text { imagery }\end{array}$ \\
\hline 2.2 & $5 \times 5$ & 42.3 & 0.35 & 3.7 & $\begin{array}{c}\text { Ground and imagery with 2.2-m } \\
\text { resolution } \\
25 \\
20 \\
25 \\
\text { पGround }\end{array}$ & $\begin{array}{l}\text { Only } 5 \\
\text { species were } \\
\text { accurately } \\
\text { identified: } \\
\text { AB, BAS, } \\
\text { NRO, RM } \\
\text { and SM }\end{array}$ \\
\hline
\end{tabular}




\begin{tabular}{|c|c|c|c|c|c|c|}
\hline $\begin{array}{l}\text { Pixel } \\
\text { size } \\
(\mathrm{m})\end{array}$ & $\begin{array}{c}\text { DEGRADE } \\
\text { window } \\
\text { size }\end{array}$ & $\begin{array}{c}\text { Overall } \\
\text { Accuracy } \\
\%\end{array}$ & $\begin{array}{l}\text { Kappa } \\
\text { Hat } \\
\text { statistic }\end{array}$ & $\begin{array}{l}\text { Image } \\
\text { size } \\
(\mathrm{MB})\end{array}$ & $\begin{array}{c}\text { Chart of the species composition }(\%) \\
\text { derived from: }\end{array}$ & Comments \\
\hline 2.6 & $6 \times 6$ & 50.0 & 0.41 & 2.5 & 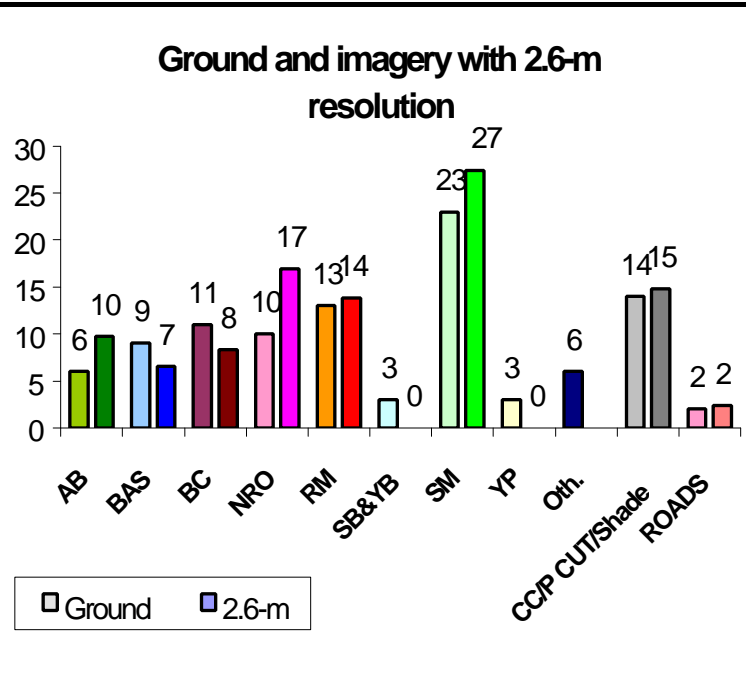 & $\begin{array}{l}\text { Only } 5 \\
\text { species } \\
\text { accurately } \\
\text { classified: } \\
\text { BAS, BC, } \\
\text { NRO, RM } \\
\text { and SM. } \\
\text { Species } \\
\text { eliminated } \\
\text { from } \\
\text { classification: } \\
\text { YP and } \\
\text { SB\&YB }\end{array}$ \\
\hline 3.1 & $7 \times 7$ & 55.0 & 0.46 & 1.9 & 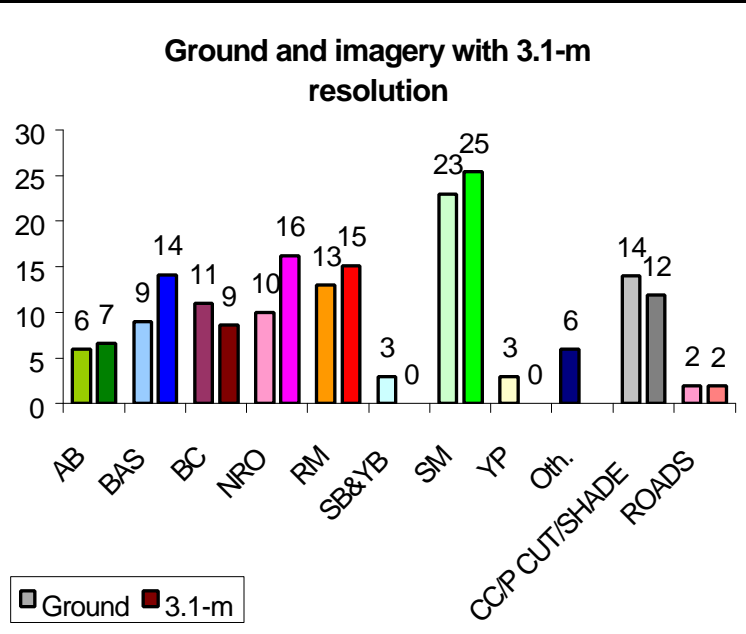 & $\begin{array}{l}\text { Difficult to } \\
\text { identify the } \\
\text { tree species. } \\
\text { Only } 4 \\
\text { species were } \\
\text { correctly } \\
\text { identified: } \\
\text { BAS, NRO, } \\
\text { RM and SM }\end{array}$ \\
\hline
\end{tabular}

Key for the abbreviations:

AB - American beech (Fagus grandifolia)

BAS - American basswood (Tilia americana)

BC - Black cherry (Prunus serotina)

NRO - Northern red oak (Quercus rubra)

$\mathrm{RM}$ - Red maple (Acer rubrum)

SB - Sweet birch (Betula lenta)

SM - Sugar maple (Acer saccharum)

YB - Yellow birch (Betula alleghanensis)

YP - Yellow poplar (Liriodendron tulipifera)

OTH. - Other species, i.e. white ash, chestnut oak, white oak, cucumber tree, fraser magnolia, black locust, eastern hemlock.

$\mathrm{CC}$ - Clearcut.

P CUT - Partial cut. 
When pixel size was further scaled-up, the number of species correctly identified decreased, and some species were no longer detected. At pixel sizes of 2.6 and 3.1, the overall percent accuracy and the Kappa statistic increased slightly, but less prevalent species including sweet birch, yellow birch, yellow-poplar and black cherry were no longer detected. The Kappa statistic and the overall accuracy increases were produced by using a reduced number of training sites, and most training sites that included less prevalent species were no longer used for classification.

\subsection{DISCUSSION}

\subsubsection{Objective 1 - Determination of Optimal Spatial Resolution of Acquired Images}

The study of autocorrelation and semivariance indicate that, on average, the optimal resolution of the images is situated between 6 and 7 meters (table 5.2). From examination of the field data, this size corresponds to the average crown area. With a pixel size equal to tree crown diameter it is unlikely that a tree will be covered by a single pixel. A better approach might be to use a higher spatial resolution, perhaps using a pixel size of approximately 2 meters or less, or about one-third of the pixel size derived from the study, as Woodcock and Strahler (1987) suggested. 
Table 5.2- Research methods results

\begin{tabular}{|l|c|c|}
\hline \multicolumn{1}{|c|}{ Method used } & Case & $\begin{array}{c}\text { Optimal spatial resolution } \\
\text { (meters) }\end{array}$ \\
\hline Method A -Autocorrelation & -- & 6.4 \\
\hline Method B - Semivariance & Rook & 6.7 \\
\hline Method B - Semivariance & Bishop & 7.0 \\
\hline Method C - Statistics from plots & -- & 6.9 \\
\hline
\end{tabular}

From the examination of the Appalachian hardwoods imagery, it can be seen that the spacing between neighboring trees is very small. From the examination of plot statistics, and after investigation of the relationship between crown diameter and DBH, it can be inferred that the measurements of autocorrelation and of semivariance could be successfully used in the regression equation 5.1 to estimate the DBH for the Appalachian Hardwood plots investigated, if the average crown diameter is known.

\subsubsection{Objective 2 - Determination of Optimal Scale of} Acquired Images

Another problem addressed was whether the accuracy of the results of a classification based on images with high spatial resolution would be similar to those using the optimal spatial resolution. From table 5.1, it can be observed that the CIR 0.44$\mathrm{m}$ original data produced the highest classification accuracy, and the species composition was very close to that obtained at ground sampling. The upscaled images performed relatively well, and the coarsest spatial resolution that allowed all the species to be detected was the $1.8 \mathrm{~m}$. When the pixels were further aggregated, some species were no 
longer detected, including sweet birch, yellow birch and yellow-poplar. These species could not be detected once the aggregated pixels size was over 1.8-m. Their signatures were practically identical to those of other species, which triggered their elimination from the classification routine. Once the pixels were aggregated, they were no longer pure because they were generated from original pixels belonging to more than one species. Consequently, the statistical information generated by the aggregated pixels was changed. Contingency tables, also called confusion matrices, also were used to test the signatures. Contingency tables compare, on a category-by-category basis, the relationship between training data and the corresponding results of an automated classification using that same data. The contingency tables at the end of the chapter (tables $5.4-5.6$ ) display the sources of error from the original CIR 0.44-m image, and also from the 1.8-m and 3.1-m aggregated images. Species with a low percent of representation in the total species composition have a tendency to be misclassified using the CIR 0.44-m imagery (table 5.4). This is especially true for sweet birch and yellow birch, which are misclassified as American basswood, black cherry or sugar maple-2 (shadowed sugar maple). On the other hand, the yellow-poplar could be detected very well in the CIR 0.44-m image, but once the pixels were aggregated the potential for misclassification increased, and the yellow-poplar could no longer be detected when pixel sizes were larger than $1.8 \mathrm{~m}$. Attempts to keep the less prevalent species in classifications of upscaled images with pixel sizes larger than 1.8-m introduced very large errors, suggesting that efforts to use their signatures would not be prudent.

In conclusion, results of this empirical method suggest that the optimal scale or spatial resolution the species classification in the study area is approximately 2 meters, 
which represents one-third the average canopy size suggested by the semivariance and the autocorrelation. Image size can also affect the image scale selected. The original image at $0.44-\mathrm{m}$ resolution required 80 Mbytes of storage space. This decreased to 4.5 Mbytes for the image with a pixel size of $1.8 \mathrm{~m}$. When hundreds of images are acquired for only one project, the scaling-up method speeds-up the classification process and frees storage space for other applications.

These findings confirm that the spatial information is better preserved when images are acquired with highest resolution possible and later scaled up, rather than being acquired at a coarser resolution.

As can be observed in tables 5.1 and 5.3, the composition derived from the classification of the scaled-up image with 1.8 -m resolution was extremely close to the "control" composition estimated from ground plot data. Also, the classification statistics for the $1.8-\mathrm{m}$ resolution image were very close to the statistics of the CIR 1-m image, the imagery originally acquired with 1-m resolution. However, the number of species correctly identified in the CIR 1-m resolution image was smaller then the number of species correctly identified in the scaled-up CIR 0.44-m resolution images (tables 5.1 and $5.3)$. 
Table 5.3- Percentage of area occupied by species from the classification of original and upscaled CIR images

\begin{tabular}{|l|r|r|r|r|r|r|r|r|r|r|r|r|}
\hline $\begin{array}{l}\text { Species/ Pixel } \\
\text { Resolution }\end{array}$ & $\begin{array}{c}\text { AB } \\
\%\end{array}$ & $\begin{array}{c}\text { BAS } \\
\%\end{array}$ & $\begin{array}{c}\text { BC } \\
\%\end{array}$ & $\begin{array}{c}\text { NRO } \\
\%\end{array}$ & $\begin{array}{c}\text { RM \&YB } \\
\%\end{array}$ & $\begin{array}{c}\text { SM } \\
\%\end{array}$ & $\begin{array}{c}\text { YP } \\
\%\end{array}$ & $\begin{array}{c}\text { OTH } \\
\%\end{array}$ & $\begin{array}{c}\text { CC/P } \\
\text { CUT } \\
\%\end{array}$ & $\begin{array}{c}\text { ROADS } \\
\%\end{array}$ & $\begin{array}{c}\text { Total } \\
\%\end{array}$ \\
\hline $\begin{array}{l}\text { Ground data } \\
\text { (control) }\end{array}$ & 6 & 9 & 11 & 10 & 13 & 3 & 23 & 3 & 6 & 14 & 2 & 100 \\
\hline $0.44-m$ (original) & 12 & 6 & 9 & 13 & 12 & 5 & 19 & 2 & -- & 20 & 2 & 100 \\
\hline $1.8-m$ (aggregated) & 7 & 7 & 6 & 16 & 11 & 5 & 18 & 6 & -- & 22 & 2 & 100 \\
\hline $\begin{array}{l}1-\mathrm{m}(\text { ORIGINAL } \\
\text { IMAGE) }\end{array}$ & 8 & 11 & 5 & 18 & 8 & -- & 15 & 5 & -- & 26 & & 100 \\
\hline
\end{tabular}

Table 5.4- Contingency table for classification of CIR - 0.44-m image using Maximum Likelihood classifier

\begin{tabular}{|c|c|c|c|c|c|c|c|c|c|c|c|c|}
\hline $\begin{array}{c}\text { Classified } \\
\text { Data } \\
\text { pixels })\end{array}$ & BAS & $\begin{array}{c}\text { SB \& } \\
\text { YB }\end{array}$ & NRO & Roads & CC/Shade & BC & SM1 & SM2 & YP & RM & AB & $\begin{array}{c}\text { Row } \\
\text { Total }\end{array}$ \\
\hline BAS & 73 & 64 & 78 & 10 & 21943 & 10 & 6 & 59 & 1 & 177 & 87 & 22508 \\
\hline SB \& YB & 7 & 38 & 36 & 0 & 3005 & 8 & 1 & 92 & 0 & 78 & 93 & 3358 \\
\hline NRO & 1 & 4 & 2041 & 5 & 1255 & 6 & 6 & 13 & 8 & 35 & 69 & 3443 \\
\hline Roads & 0 & 0 & 0 & 7873 & 5657 & 0 & 0 & 0 & 1 & 76 & 0 & 13607 \\
\hline CC/Shade & 12 & 6 & 6 & 251 & 64200 & 0 & 1 & 45 & 0 & 46 & 110 & 64677 \\
\hline BC & 6 & 62 & 113 & 4 & 788 & 191 & 2 & 324 & 0 & 65 & 163 & 1718 \\
\hline SM1 & 0 & 3 & 182 & 356 & 22 & 0 & 266 & 0 & 0 & 246 & 2 & 1077 \\
\hline SM2 & 2 & 39 & 13 & 11 & 4008 & 20 & 2 & 349 & 0 & 38 & 231 & 4713 \\
\hline YP & 0 & 1 & 226 & 68 & 100 & 0 & 0 & 0 & 272 & 50 & 0 & 717 \\
\hline RM & 2 & 78 & 205 & 134 & 5230 & 0 & 192 & 64 & 5 & 1207 & 43 & 7160 \\
\hline AB & 0 & 5 & 119 & 0 & 262 & 19 & 7 & 98 & 0 & 5 & 587 & 1102 \\
\hline Column & 103 & 300 & 3019 & 8712 & 106470 & 254 & 483 & 1044 & 287 & 2023 & 1385 & 124080 \\
Total & & & & & & & & & & & & \\
\hline
\end{tabular}


Table 5.5- Contingency table for classification of aggregated image with 1.8-m pixel resolution using Maximum Likelihood classifier

\begin{tabular}{|c|c|c|c|c|c|c|c|c|c|c|c|c|}
\hline $\begin{array}{c}\text { Classified } \\
\text { data } \\
\text { (pixels) }\end{array}$ & $\mathrm{AB}$ & BAS & BC & NRO & $\mathrm{RM}$ & $\begin{array}{c}\text { SB } \\
\& \\
\text { YB }\end{array}$ & SM-1 & SM-2 & YP & $\begin{array}{l}\mathrm{CC} / \mathrm{P} \\
\mathrm{CUTS}\end{array} \mid$ & ROADS & $\begin{array}{l}\text { Row } \\
\text { Total }\end{array}$ \\
\hline $\mathrm{AB}$ & 20 & 0 & 0 & 2 & 9 & 0 & 1 & 8 & 3 & 281 & 0 & 324 \\
\hline BAS & 4 & 9 & 2 & 10 & 0 & 8 & 0 & 4 & 0 & 487 & 0 & 524 \\
\hline $\mathrm{BC}$ & 4 & 1 & 13 & 11 & 2 & 4 & 0 & 10 & 3 & 4 & 0 & 52 \\
\hline NRO & 0 & 0 & 0 & 146 & 2 & 0 & 1 & 0 & 0 & 112 & 3 & 264 \\
\hline RM & 1 & 1 & 0 & 16 & 67 & 3 & 11 & 1 & 1 & 288 & 48 & 437 \\
\hline SB\&YB & 2 & 2 & 1 & 0 & 6 & 8 & 0 & 11 & 2 & 88 & 0 & 120 \\
\hline SM-1 & 1 & 0 & 0 & 7 & 13 & 0 & 21 & 0 & 0 & 0 & 4 & 46 \\
\hline SM-2 & 11 & 0 & 5 & 3 & 2 & 4 & 4 & 23 & 0 & 68 & 0 & 120 \\
\hline $\mathrm{YP}$ & 10 & 1 & 4 & 5 & 13 & 6 & 1 & 8 & 10 & 3 & 0 & 61 \\
\hline $\begin{array}{c}\text { CC/P } \\
\mathrm{CUT} / \mathrm{S}\end{array}$ & 1 & 2 & 0 & 1 & 3 & 0 & 0 & 0 & 0 & 5432 & 29 & 5468 \\
\hline ROADS & 0 & 0 & 0 & 0 & 7 & 0 & 0 & 0 & 0 & 420 & 554 & 981 \\
\hline $\begin{array}{c}\text { Column } \\
\text { Total } \\
\end{array}$ & 54 & 16 & 25 & 201 & 124 & 33 & 39 & 65 & 19 & 7183 & 638 & 8397 \\
\hline
\end{tabular}

Table 5.6- Contingency table for classification of aggregated image with 3.1-m pixel resolution using Maximum Likelihood classifier

\begin{tabular}{|c|r|r|r|r|r|r|r|r|r|r|}
\hline $\begin{array}{c}\text { Classified } \\
\text { data } \\
\text { (pixels) }\end{array}$ & AB & BAS & BC & NRO & RM & SM-1 & SM-2 & $\begin{array}{c}\text { CC/P } \\
\text { CUTS }\end{array}$ & ROADS & $\begin{array}{c}\text { Row } \\
\text { Total }\end{array}$ \\
\hline AB & 12 & 0 & 0 & 1 & 4 & 1 & 6 & 26 & 0 & 50 \\
\hline BAS & 1 & 7 & 0 & 5 & 0 & 0 & 4 & 143 & 0 & 160 \\
\hline BC & 6 & 0 & 10 & 5 & 2 & 0 & 4 & 1 & 0 & 28 \\
\hline NRO & 1 & 0 & 0 & 58 & 2 & 0 & 0 & 28 & 0 & 89 \\
\hline RM & 4 & 1 & 0 & 7 & 32 & 4 & 1 & 113 & 21 & 183 \\
\hline SM-1 & 0 & 0 & 0 & 2 & 2 & 6 & 0 & 1 & 1 & 12 \\
\hline SM-2 & 3 & 0 & 1 & 1 & 0 & 2 & 16 & 20 & 0 & 43 \\
\hline CC/P CUTS & 1 & 2 & 0 & 0 & 2 & 2 & 0 & 1928 & 13 & 1948 \\
\hline ROADS & 0 & 0 & 0 & 0 & 3 & 0 & 0 & 146 & 202 & 351 \\
\hline $\begin{array}{l}\text { Column } \\
\text { Total }\end{array}$ & 28 & 10 & 11 & 79 & 47 & 15 & 31 & 2406 & 237 & 2864 \\
\hline
\end{tabular}




\section{CHAPTER 6. SPECIATION OF A CENTRAL APPALACHIAN HARDWOOD FOREST USING AIRBORNE REMOTELY SENSED DIGITAL IMAGES}

\subsection{INTRODUCTION}

Manual interpretation has traditionally been employed to extract data from images for forest classification. In recent years, the modern digital computer has assisted the human interpreter by removing camera distortions and other spatial anomalies, enhancing details, modifying the tonal range and producing new color displays. The best analysis may be obtained, at least from images originally obtained digitally, by digital extraction of the desired information. Modern image sensors, such as the ADAR 1000 system, produce digital data that allows this processing.

Classification is the process whereby an image is converted into a thematic map, in which regions with similar properties are identified. At the simplest level this involves identifying pixels with a similar range of digital numbers (DNs), which we assume implies that the corresponding areas of the surface are also similar to each other. The objective of image classification is to replace visual analysis of the image with quantitative techniques for automating the identification of features in a scene. When we use spectral radiances observed in the data, we refer to the classification process as spectral pattern recognition. In contrast, when we use geometric shapes, sizes and patterns present in the image we are speaking about spatial pattern recognition. In general, we can say that classification of an image is an exercise in pattern recognition, 
whether or not the pattern includes spatial information or just radiometric (spectral) information conditions (Lillesand and Kiefer, 1994).

If every possible surface material had a unique, known and invariable spectral signature and if we could construct a noiseless sensor that could measure this spectrum over all wavelengths, correcting the data for incidence and scattering angle effects, atmospheric attenuation and scattering, there would be no fundamental problem in identifying by remote sensing the contents of any homogenous resolution element. Multispectral classification attempts to solve problems caused by the failure of real systems and materials to meet these conditions (Lillesand and Kiefer, 1994).

The production of thematic maps can be inefficient, lenghty and, most importantly, requires highly-trained technicians with domain knowledge able to visually differentiate multiple shades of color and texture. Automated techniques using 9"x 9" color-infrared aerial photographs have produced unsatisfactory results (Neese, 1998). One of the main reasons for using the ADAR 1000 system was the acquisition of images in a digital format, which provides opportunities to georeference, mosaick and classify data using sophisticated image processing software.

One objective of this part of the study was to identify the tree species in the study area using a supervised approach. The supervised approach requires that the analyst "train" the computer on samples selected from known forest species. The statistics gathered from the training samples are then used to classify the remaining pixels in the mosaicked image. The classification procedure will perform relatively well if the training classes are representative and have significantly different spectral signatures. If the classes are very similar, the classification procedure probably will not produce accurate 
results. Another objective was to evaluate classification accuracy using tools available in the image processing software to compare species composition estimated from ground sampling data to that produced through image classification.

\subsection{TRAINING DATA AND SPECTRAL SIGNATURES ACQUISITION}

The imagery used for this study was acquired on two different dates in the fall of 1998. The sets of images used for this part of the study were:

- visible color (VIS), 0.5-m resolution, acquired on October 21, 1998;

- color infrared (CIR), 0.5-m resolution, acquired on October 23, 1998; and

- $\quad$ CIR, 1-m resolution, acquired on October 23, 1998.

In this part of the Appalachian region, peak fall colors generally occurs during two weeks in October. Specific time of image acquisition to capture the peak coloration must be determined through close observation of the areas of interest; images should be acquired when leaf coloration peaks. Certainly, there are other constraints, such as weather conditions and plane and personnel availability that affect flight timing; however, every effort should be made to collect images at the peak of fall coloration. When the imagery was acquired, the tree foliage were a week past peak fall coloration and some of the tree species had lost their leaves. One day after the imagery was acquired, samples of leaves were collected. Color was qualitatively assessed and leaf area indices (LAI), the ratio of the total area of all leaves on the trees to the area of ground 
covered by the trees, for all species found in the study area were estimated quantitatively. Species that did not lose their leaves had a LAI of $100 \%$; values were less than $100 \%$ for the tree species that had lost some percent of their leaves (table 6.1).

Table 6.1- Leaf colors and leaf area indices (LAI) for the principal forest species identified in the study area

\begin{tabular}{|l|l|l|c|}
\hline \multicolumn{1}{|c|}{ Species } & $\begin{array}{c}\text { Mnemonic } \\
\text { notation }\end{array}$ & \multicolumn{1}{|c|}{ Leaf coloration } & $\begin{array}{c}\text { LAI } \\
(\%)\end{array}$ \\
\hline Northern red oak & NRO & Dark-green and brown & 100 \\
\hline Fraser magnolia & MAG & Green and brown & 100 \\
\hline Yellow poplar & YP & Yellow and brown & 90 \\
\hline American beech & AB & Brown & 70 \\
\hline Black cherry & BC & Whitish-green to red & 70 \\
\hline Sugar maple & SM & Yellow to red & $40-80$ \\
\hline Red maple & RM & Red to yellow & $40-50$ \\
\hline Sweet birch & SB & Yellowish-brown & $30-50$ \\
\hline Cucumber tree & CUM & Brown & 30 \\
\hline Yellow birch & YB & Yellowish-brown & 30 \\
\hline Basswood & BAS & Light-green to yellowish-brown & $20-60$ \\
\hline White ash & WA & Whitish-green & 20 \\
\hline
\end{tabular}

The species that had lost most of their leaves were sweet birch, yellow birch, white ash and cucumber tree. Leaf coloration varied within species, as did LAI. The main factors that contribute to this variability include tree position on the slope, tree age, tree health, density of surrounding trees, soil conditions, and site productivity. A phenomenon clearly observed was the reduced LAI of trees located on the tops of the ridges and higher LAI for trees situated in the valleys. The large variety of foliage colors had a negative effect on the classification results.

The training and control data were collected in the fall of 1999 , at the beginning of the senescence period. Large single trees or groups of trees of known species were 
visually identified on large printouts of the mosaicked CIR and VIS images, and they represented the training and the control sites. Their positions were recorded using a Trimble Pathfinder ProXL GPS unit. The positions of at least four training or control sites were recorded for each species identified in the study area. At least six training sites were identified for each well-represented species, such as sugar maple and northern red oak. Training data were collected on NE-SW or SW-NE transects located in selected parts of the study area. Variation in leaf coloration and LAI within and among species were noted in the training data. The differences between the collected spectral signatures belonging to all the species used for training of the CIR 0.5 -m resolution image classification are shown in figure 6.1.

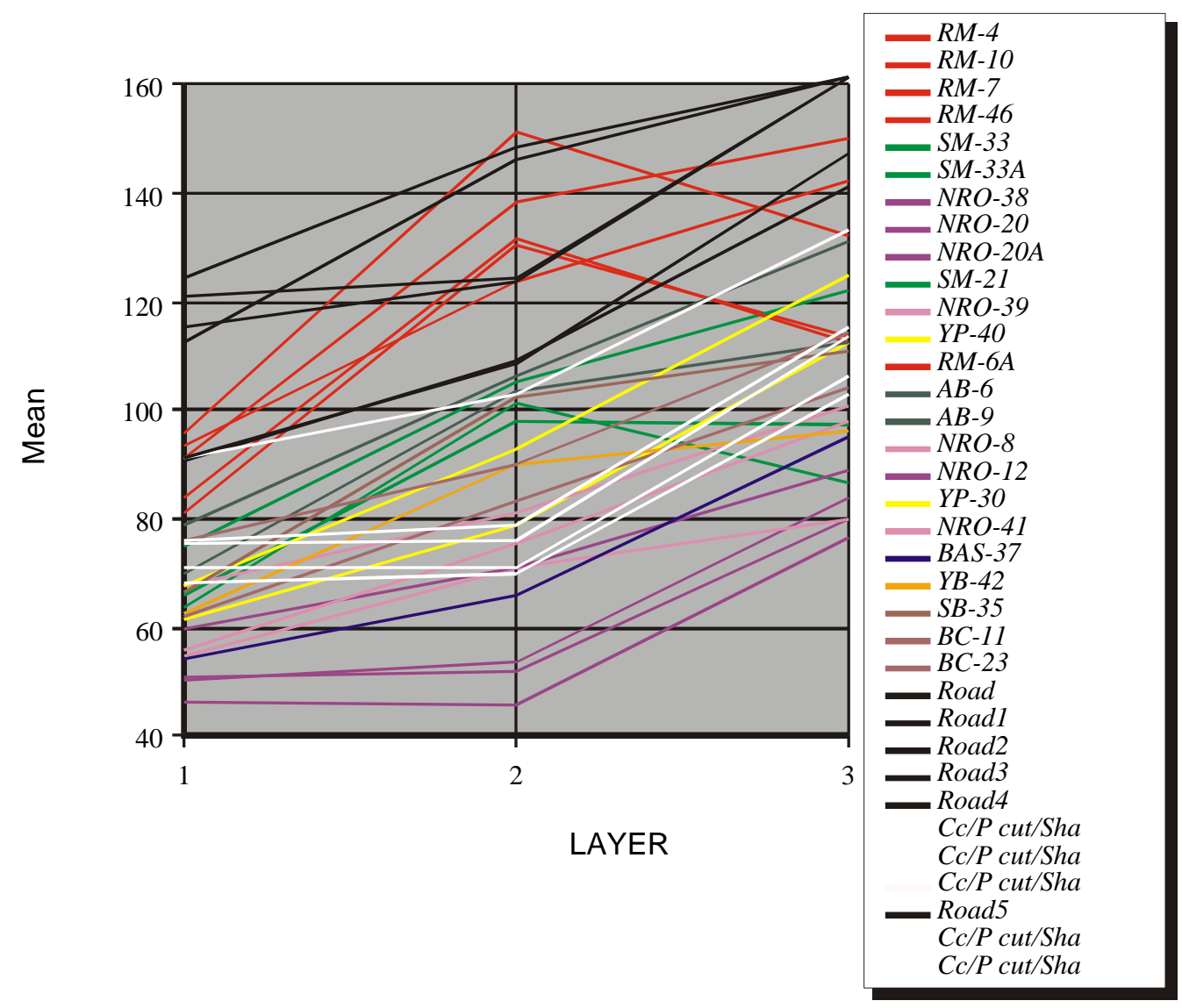

Figure 6.1- Sample plot of mean values of all the species spectral signatures used for the classification of CIR 0.5-m imagery 
The GPS positions of the training and control sites were differentially corrected and then exported as Arcview shapefiles. The Arcview files were imported into ERDAS Imagine and overlaid over the mosaicked images.

Spectral signatures from the imagery were determined by identifying the training sites in the mosaicked images, comparing their separability using several tools available in ERDAS Imagine, such as signature means plots (figure 6.1) and Jeffries-Matusita distances, and assessing the usefulness of each signature. Subsequently, within-species signatures were merged into single class statistics for each species. In order to preserve multivariate normality of the classes, when the spectral signatures of some species were different, that is, they were acquired from well-illuminated or from shaded areas, the original signatures were grouped into two distinct subclasses.

Upon merging, the signatures were tested for separability and contingency. Signature mean plots that can be used to visually assess the signature separabilities were also generated. Signature separability was tested using the Jeffries-Matusita distance, whish takes into consideration the difference between the covariance and the class means of the two classes. The Jeffries-Matusita distances were calculated as a combination of all the bands in each mosaicked image. The Jeffries-Matusita distances reported in the thesis use the ERDAS Imagine conversion of multiplying the values by 1000 and, consequently, the values range between 0 and 1414, with lower values indicating poor separability, and the values close to 1414 indicating good separability between signatures (ERDAS, 1997). Listings of signature separabilities were generated for each of the mosaicked images. If 
the Jeffries-Matusita Distance between pairs of signatures was very low, the signatures for those species were verified and collected again.

Contingency tables, also called confusion matrices, also were used to test the signatures. Contingency tables compare, on a category-by-category basis, the relationship between training data and the corresponding results of an automated classification using those same data. The contingency table is based on training data, and it can be used to evaluate the spectral homogeneity and separability of the class statistics (Lillesand and Kiefer, 1994). The contingency table and the other tools were used only as aids in the training refinement process. It should be emphasized that the contingency tables overestimate the accuracy that will be achieved in the classification of unknown pixels from other parts of the imagery, and, therefore, should not be used as an indicator of overall classification accuracy.

\subsection{IMAGE ANALYSIS METHODS}

\subsubsection{Accuracy assessment of classified images}

Data were classified using the Maximum Likelihood classifier. This method is a relative statistical method that quantitatively evaluates both the variance and covariance of the categorized spectral response patterns when classifying an unknown pixel. In order to do this, we assume that the distribution of class training data follows a Gaussian unimodal distribution. Hence, the distribution can be described by the mean vector and 
the variance-covariance matrix parameters. Given these parameters, the statistical probability of an unknown pixel belonging to a given class is calculated, and the pixel is assigned to whichever class is most likely. Alternatively, if the probability values are all below a threshold set by the analyst, the pixel is labeled unknown. There are also other methods that could be used for classification of images, such as Minimum distance-tomean or the Parallelepiped classifiers, but the Maximum Likelihood method is considered more accurate (Lillesand and Kiefer, 1994). Maximum Likelihood classification was performed on all three mosaicked images, using ERDAS Imagine.

Accuracy assessment of the classified images was performed using a combination of error matrix analysis and verification using control points recorded in the field and imported into the ACCURACY ASSESSMENT routine of ERDAS Imagine. Data from the control sites were compared to the classified images, establishing whether the site was correctly or incorrectly classified. An error matrix was generated for each of the mosaicked images, and overall accuracy, producer's accuracy, and user's accuracy were calculated using the following equations:

total number of correctly classified training sets (of pixels)

Overall accuracy $=\frac{(\text { summmed along the major diagonal) }}{\text { total number of reference training sets (of pixels) }}$ 
number of correctly classified training sets

in each category

Producer's accuracy $=\frac{\text { (on the major diagonal) }}{\text { number of training sets of pixels used for that category }}$

(the column total)

User's accuracy $=\frac{\text { number of correctly classified training sets in each category }}{\text { total number training sets (of pixels) }}$
that were classified in that category
(the row total)

The producer's accuracy indicates what proportion of the ground area of a given cover type is correctly classified on the map, and is a measure of errors of ommision. The user's accuracy indicates the probability that area classified into a given category actually represent that category on the ground, and is related to errors of commission.

The Kappa Hat $\left(\mathrm{K}^{\wedge}\right)$ statistic was used to compare the actual agreement between reference data and an automated classifier and the chance of agreement between the reference data and a random classifier. The Kappa Hat statistic is defined as:

$$
\mathrm{K}^{\wedge}=\frac{\text { observed accuracy }- \text { chance agreement }}{1-\text { chance agreement }}
$$

\footnotetext{
A Kappa Hat value of 1.00 means that there was a perfect agreement between the control data and the classification.
} 


\subsubsection{Comparison between the species composition derived from ground sampling and the classified images}

The species composition estimated from ground sampling data was compared to that derived from the classified images. The ground data were collected from 182 sample plots. Only the trees visible from overhead, with their crowns situated in the upper part of the canopy were considered. This included dominant, codominant and intermediate trees, which can be "seen" in the acquired images.

The species composition was estimated for the entire study area by extrapolating the sample ground data. In addition, the compositions of six subunits delineated within the study were determined. A DEM with $15-\mathrm{m}$ resolution provided by Westvaco Corporation was used to determine the aspect, and this information was aggregated to determine average aspect of each subunit. Six subunits, two with NE aspect, two with SE aspect, one with SW aspect, and an isolated unit that was partially cut in 1998, were delineated (figure 6.2). This approach was necessary because although the field data did not exhibit any connection between other relief characteristics, such as elevation or slope, the classification results suggested that shaded areas, i.e. slopes with NE aspect, might be erroneously classified as shade. It is important to note here that the species distribution on the slopes did not follow any pattern because partial harvesting that entailed removing the largest trees of the most commercially valuable species had occurred throughout the study area. Consequently, the species composition in the Westvaco Wildlife and Ecosystem Research Forest as a whole, and also in the study area, does not follow any 
relief-related pattern; trees of all species are intermingled at any point on the ground. For example, $400-\mathrm{m}^{2}$ ground plots included up to seven to ten of the fifteen different species identified in the study area.

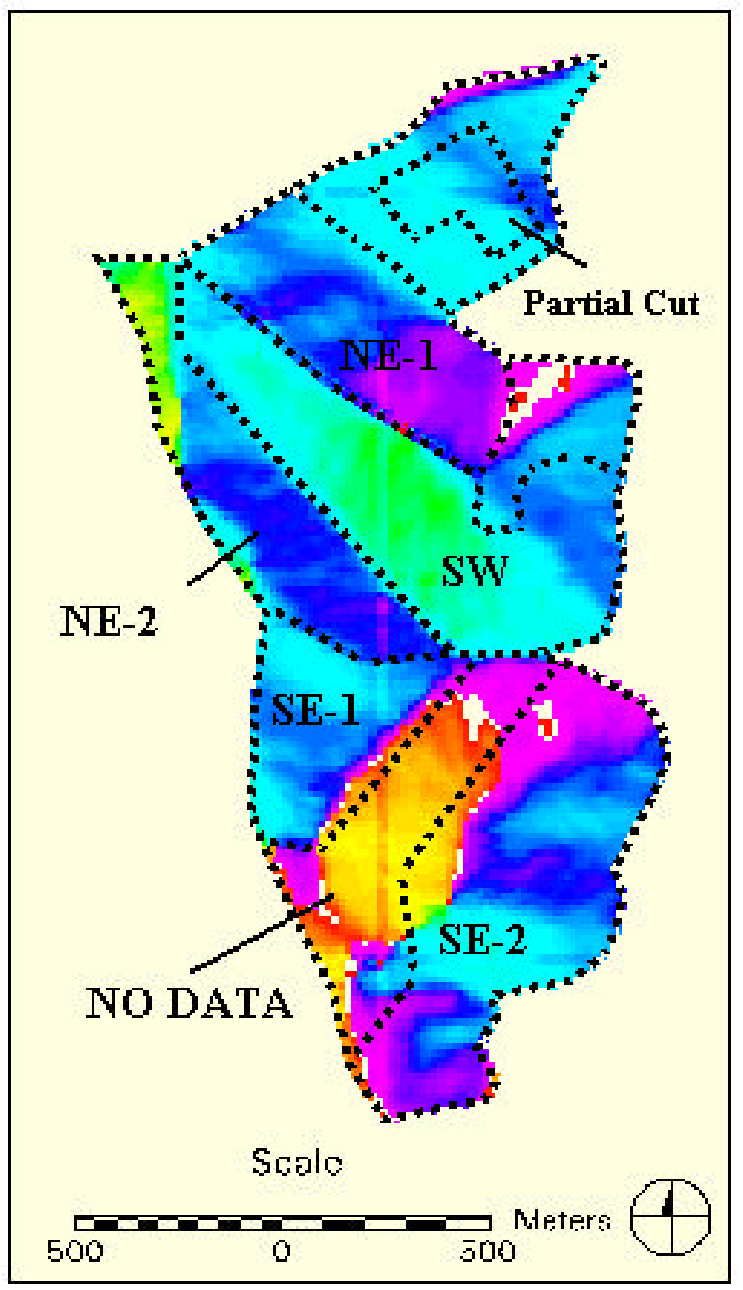

Figure 6.2- Aspect-based subunits of the study area (no data were collected in part of the southern end of the study area that was scheduled for clearcutting in 1998) 
The ground sampling plots were further grouped by subunit, and the statistics derived from the plots exhibited acceptable error in the estimation of basal area and, subsequently, species composition (table 6.2). Maximum percent error in estimating the species composition from the ground data varied between $10 \%$ and $15 \%$; therefore, estimates made using ground data were considered true values. Consequently, species composition estimated from ground data could be used with a high level of confidence in comparisons with estimates derived from the classified images. Thus, after the images were classified, the visible crown area occupied by each species was determined by subunit and compared to the "true" composition estimated from the ground data.

\section{Table 6.2- Estimated error in determination of basal area}

\begin{tabular}{|l|c|c|}
\hline \multicolumn{1}{|c|}{ Aspect-based subunit } & Number of plots & $\begin{array}{c}\text { Estimated error } \\
(\%)\end{array}$ \\
\hline NE-1 & 30 & 12.5 \\
\hline NE-2 & 30 & 13 \\
\hline SE-1 & 25 & 14 \\
\hline SE-1 & 45 & 10 \\
\hline SW & 45 & 10 \\
\hline Partial Cut & 7 & 14 \\
\hline
\end{tabular}




\subsection{RESULTS}

\subsubsection{CIR $0.5-\mathrm{m}$ resolution imagery classification}

Thirty training sites were identified for the classification of CIR 0.5-m resolution imagery. Their signatures were merged into 11 composite signatures (figure 6.3, table 6.4). Two groups of merged signatures, from shaded and illuminated sites, SM-1 and SM-2, were produced for sugar maple. Low Jeffries-Matusita distance values revealed low separabilities between pairs of signatures belonging to SM2-AB, SB\&YB-SM2, BCSM2, SB\&YB-AB, BC-AB and SM1-RM (table 6.3). Leaf colors of all the aforementioned species were very close to light green or yellow, and the resulting separabilities were low.

The contingency table for classification of the CIR 0.5-m imagery presents the number of pixels belonging to each species' training sites, and how those pixels were classified using the Maximum Likelihood classifier (table 6.4). Overall classification accuracy of the entire study area was $73.1 \%$, with an overall Kappa statistic of 0.69 (table 6.5). A total number of 26 control sites were used for the estimation of the classification accuracy. The composition derived from the whole classified image and for the subunits were plotted using pie charts (figure 6.6 - Total study area; figure 6.10 NE-1 subunit; figure 6.12 - NE-2 subunit; figure 6.13 - Partial cut subunit; figure 6.14 SE-1 subunit; figure 6.15 - SE-2 subunit; figure 6.16 - SW subunit). 


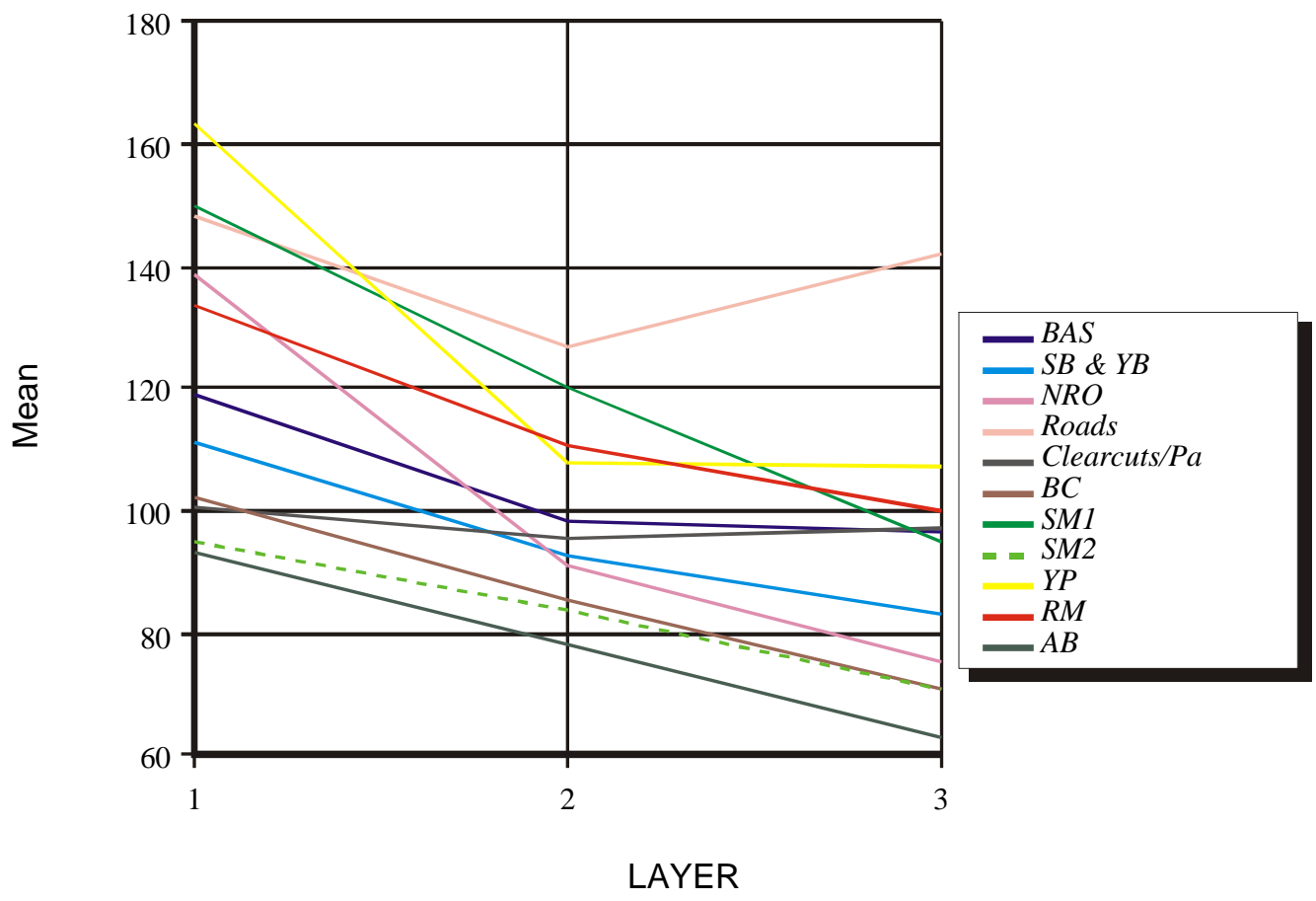

Figure 6.3- Plot of signatures used for the classification of the CIR 0.5-m imagery 
Table 6.3- Signature separability for the CIR 0.5-m imagery based on the Jefferies-Matusita distance. Colored blocks indicate pairs with low separability ${ }^{4}$

\begin{tabular}{|c|c|c|c|c|c|c|c|c|c|}
\hline \multirow[t]{9}{*}{ Bands } & \multirow[t]{9}{*}{ AVE } & \multirow[t]{9}{*}{ MIN } & \multicolumn{2}{|c|}{ Class Pairs: } & & & \multirow{2}{*}{\multicolumn{2}{|c|}{1.67}} & \multirow[b]{2}{*}{$1: 8$} \\
\hline & & & 1: 2 & $1: 3$ & $1: 4$ & $1: 5$ & & & \\
\hline & & & $1: 9$ & $1: 10$ & $1: 11$ & $2: 3$ & $2: 4$ & $2: 5$ & $2: 6$ \\
\hline & & & $2: 7$ & $2: 8$ & $2: 9$ & $2: 10$ & $2: 11$ & $3: 4$ & $3: 5$ \\
\hline & & & $3: 6$ & $3: 7$ & $3: 8$ & $3: 9$ & $3: 10$ & $3: 11$ & $4: 5$ \\
\hline & & & 4: 6 & 4: 7 & 4: 8 & 4: 9 & 4:10 & $4: 11$ & $5: 6$ \\
\hline & & & $5: 7$ & 5: 8 & 5: 9 & 5:10 & 5:11 & $6: 7$ & $6: 8$ \\
\hline & & & 6: 9 & $6: 10$ & $6: 11$ & 7: 8 & 7: 9 & 7:10 & \multirow[t]{2}{*}{$7: 11$} \\
\hline & & & 8: 9 & $8: 10$ & $8: 11$ & 9:10 & $9: 111$ & $10: 11$ & \\
\hline \multirow[t]{8}{*}{123} & \multirow[t]{8}{*}{1132} & \multirow[t]{8}{*}{462} & 827 & 1169 & 1302 & 892 & 1147 & 1222 & 1087 \\
\hline & & & 1397 & 935 & 1079 & 1096 & 1324 & 960 & 792 \\
\hline & & & 1094 & 558 & 1393 & 785 & 687 & 1360 & 1296 \\
\hline & & & 1190 & 1140 & 1164 & 1248 & 1075 & 1133 & 1179 \\
\hline & & & 1411 & 1164 & 1387 & 1379 & 1188 & 1389 & 1239 \\
\hline & & & 1200 & 1035 & 1395 & 1065 & 1024 & 1356 & 594 \\
\hline & & & 1414 & 1255 & 718 & 1253 & 1366 & 753 & \multirow[t]{2}{*}{1296} \\
\hline & & & 1409 & 1089 & 462 & 1321 & 1410 & 1172 & \\
\hline
\end{tabular}

41 BAS, 2 SB \& YB, 3 NRO, 4 ROADS, 5 CLEARCUT/PARTIAL CUT/SHADE, 6 BC,

7 SM1, 8 SM2, 9 YP, 10 RM, 11 AB 
Table 6.4- Contingency table for classification of the CIR 0.5-m imagery using the Maximum Likelihood classifier

\begin{tabular}{|c|c|c|c|c|c|c|c|c|c|c|c|c|}
\hline $\begin{array}{c}\text { Classified } \\
\text { Data } \\
\text { (pixels) }\end{array}$ & BAS & $\begin{array}{c}\text { SB \& } \\
\text { YB }\end{array}$ & NRO & Roads & $\begin{array}{c}\text { Clear cut/ } \\
\text { Shade }\end{array}$ & BC & SM1 & SM2 & YP & RM & AB & $\begin{array}{c}\text { Row } \\
\text { Total }\end{array}$ \\
\hline BAS & 73 & 64 & 78 & 10 & 21943 & 10 & 6 & 59 & 1 & 177 & 87 & 22508 \\
\hline SB \& YB & 7 & 38 & 36 & 0 & 3005 & 8 & 1 & 92 & 0 & 78 & 93 & 3358 \\
\hline NRO & 1 & 4 & 2041 & 5 & 1255 & 6 & 6 & 13 & 8 & 35 & 69 & 3443 \\
\hline Roads & 0 & 0 & 0 & 7873 & 5657 & 0 & 0 & 0 & 1 & 76 & 0 & 13607 \\
\hline CC/Shade & 12 & 6 & 6 & 251 & 64200 & 0 & 1 & 45 & 0 & 46 & 110 & 64677 \\
\hline BC & 6 & 62 & 113 & 4 & 788 & 191 & 2 & 324 & 0 & 65 & 163 & 1718 \\
\hline SM1 & 0 & 3 & 182 & 356 & 22 & 0 & 266 & 0 & 0 & 246 & 2 & 1077 \\
\hline SM2 & 2 & 39 & 13 & 11 & 4008 & 20 & 2 & 349 & 0 & 38 & 231 & 4713 \\
\hline YP & 0 & 1 & 226 & 68 & 100 & 0 & 0 & 0 & 272 & 50 & 0 & 717 \\
\hline RM & 2 & 78 & 205 & 134 & 5230 & 0 & 192 & 64 & 5 & 1207 & 43 & 7160 \\
\hline AB & 0 & 5 & 119 & 0 & 262 & 19 & 7 & 98 & 0 & 5 & 587 & 1102 \\
\hline Column & 103 & 300 & 3019 & 8712 & 106470 & 254 & 483 & 1044 & 287 & 2023 & 1385 & 124080 \\
Total & & & & & & & & & & & & \\
\hline
\end{tabular}

Table 6.5- Classification accuracy assessment report for the CIR 0.5-m resolution imagery

\begin{tabular}{|c|c|c|c|c|c|c|c|c|c|c|c|c|}
\hline $\begin{array}{c}\text { Classified } \\
\text { Data } \\
\text { control } \\
\text { sites) }\end{array}$ & SM & BAS & AB & YP & RM & BC & $\begin{array}{c}\text { SB } \\
\& \\
\text { YB }\end{array}$ & NRO & $\begin{array}{c}\text { Classified } \\
\text { Totals }\end{array}$ & $\begin{array}{c}\text { Number } \\
\text { Correct }\end{array}$ & $\begin{array}{c}\text { Producer's } \\
\text { Accuracy }\end{array}$ & $\begin{array}{c}\text { User's } \\
\text { Accuracy }\end{array}$ \\
\hline SM & 3 & 1 & 1 & 0 & 0 & 0 & 0 & 0 & 5 & 3 & $100.00 \%$ & $60.00 \%$ \\
\hline BAS & 0 & 2 & 0 & 0 & 0 & 0 & 0 & 0 & 2 & 2 & $50.00 \%$ & $100.00 \%$ \\
\hline AB & 0 & 0 & 2 & 0 & 0 & 1 & 1 & 0 & 4 & 2 & $50.00 \%$ & $50.00 \%$ \\
\hline YP & 0 & 0 & 0 & 4 & 0 & 0 & 0 & 0 & 4 & 4 & $100.00 \%$ & $100.00 \%$ \\
\hline RM & 0 & 0 & 0 & 0 & 2 & 0 & 0 & 0 & 2 & 2 & $100.00 \%$ & $100.00 \%$ \\
\hline BC & 0 & 0 & 1 & 0 & 0 & 2 & 0 & 0 & 3 & 2 & $50.00 \%$ & $66.67 \%$ \\
\hline SB \& YB & 0 & 0 & 0 & 0 & 0 & 0 & 1 & 0 & 1 & 1 & $50.00 \%$ & $100.00 \%$ \\
\hline NRO & 0 & 1 & 0 & 0 & 0 & 1 & 0 & 3 & 5 & 3 & $100.00 \%$ & $60.00 \%$ \\
\hline Column & 3 & 4 & 4 & 4 & 2 & 4 & 2 & 3 & 26 & 19 & & \\
Total & & & & & & & & & & & & \\
\hline
\end{tabular}

Overall classification accuracy $=73.08 \%$

Overall Kappa statistic $=0.6905$ 


\subsubsection{VIS $0.5-\mathrm{m}$ resolution imagery classification}

Thirty training sites (the same ones used for the classification of the CIR $0.5-\mathrm{m}$ imagery) were used to classify the VIS 0.5 -m imagery. Their signatures were merged into 12 signatures (figure 6.4, table 6.7). It was necessary to produce two different groups of signatures for red maple and northern red oak because the images were acquired on an overcast day. Eight of the acquired signatures are grouped together with spectral distance in any of the bands of less than 30 DNs (figure 6.4, table 6.6). Signature separability based on Jeffries-Matusita distances revealed relatively low separabilities between the pair of signatures belonging to $\mathrm{AB}-\mathrm{SB} \& \mathrm{YB}$ (table 6.6). All other pairs grouped around a Jeffries-Matusita distance of over 1000. The poor weather conditions during image acquisition probably account for the grouping of the Jeffries-Matusita distance values. From our experience, VIS images acquired in full illumination during peak coloration exhibit a great variety of leaf colors.

The contingency table for classification of the VIS 0.5 -m imagery presents the number of pixels belonging to each species' training sites, and how those pixels were classified using the Maximum Likelihood classifier (table 6.7). Overall classification accuracy of the entire study area was $61.5 \%$, with an overall Kappa statistic of 0.56 (table 6.8). The total number of control sites used in the estimation of classification accuracy was 26 . The compositions derived from the whole classified image and for the subunits were plotted using pie charts (figure 6.6 - Total study area; figure 6.10 - NE-1 subunit; figure 6.12 - NE-2 subunit; figure 6.13 - Partial cut subunit; figure 6.14 - SE-1 subunit; figure 6.15 - SE-2 subunit; figure 6.16 - SW subunit). 


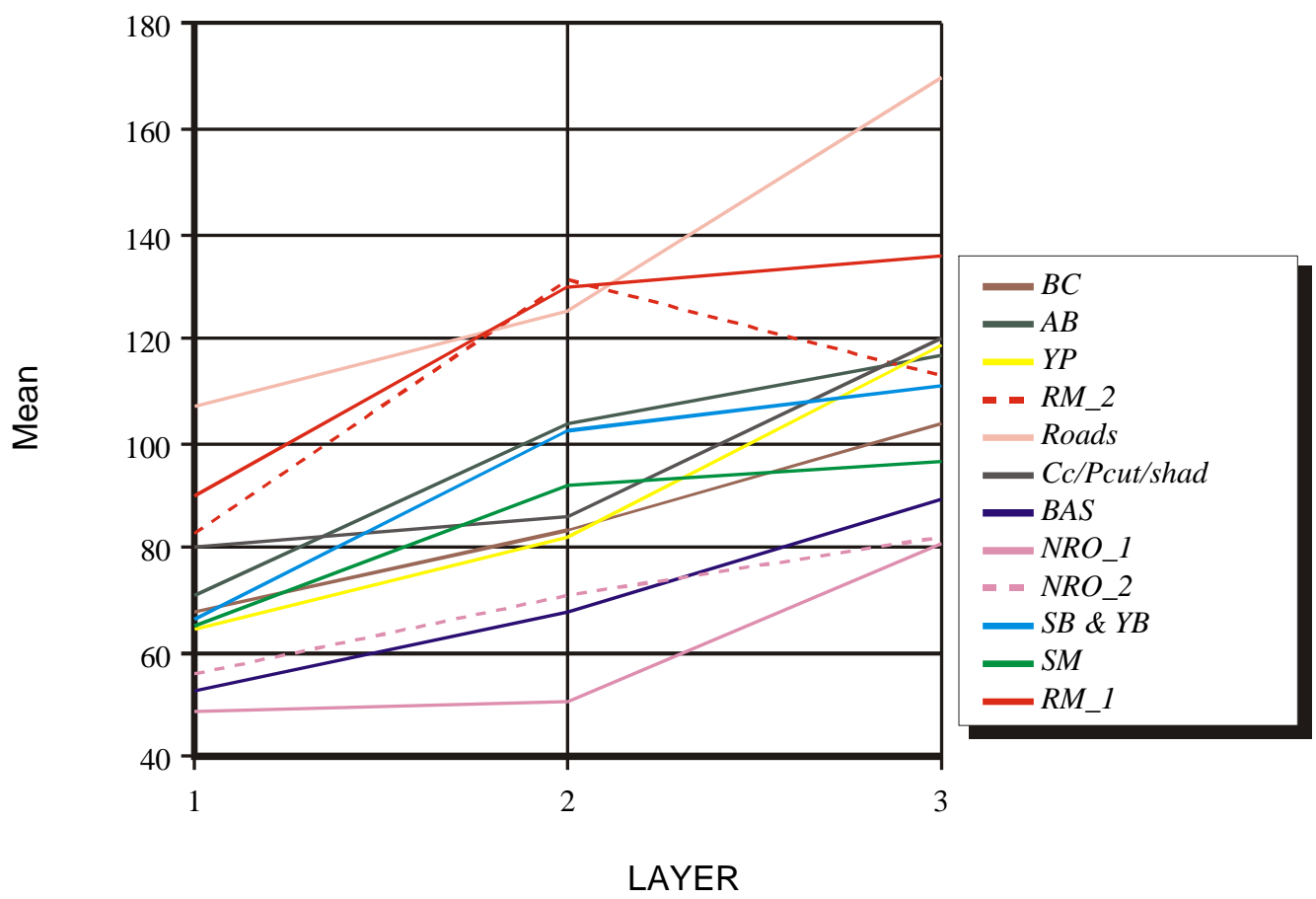

Figure 6.4- Plot of signatures used for the classification of the VIS 0.5-m imagery 
Table 6.6- Signature separability for the VIS 0.5-m imagery based on the Jefferies-Matusita distance. Colored blocks indicate pairs with low separability ${ }^{5}$

Bands AVE MIN Class Pairs:

$\begin{array}{lllllll}1: 2 & 1: 3 & 1: 4 & 1: 5 & 1: 6 & 1: 7 & 1: 8\end{array}$

$\begin{array}{lllllll}1: 9 & 1: 10 & 1: 11 & 1: 12 & 2: 3 & 2: 4 & 2: 5\end{array}$

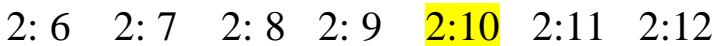

$\begin{array}{lllllll}3: 4 & 3: 5 & 3: 6 & 3: 7 & 3: 8 & 3: 9 & 3: 10\end{array}$

$\begin{array}{lllllll}3: 11 & 3: 12 & 4: 5 & 4: 6 & 4: 7 & 4: 8 & 4: 9\end{array}$

$\begin{array}{lllllll}4: 10 & 4: 11 & 4: 12 & 5: 6 & 5: 7 & 5: 8 & 5: 9\end{array}$

$\begin{array}{lllllll}5: 10 & 5: 11 & 5: 12 & 6: 7 & 6: 8 & 6: 9 & 6: 10\end{array}$

$\begin{array}{lllllll}6: 11 & 6: 12 & 7: 8 & 7: 9 & 7: 10 & 7: 11 & 7: 12\end{array}$

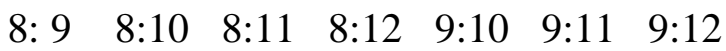

10:11 10:12 11:12

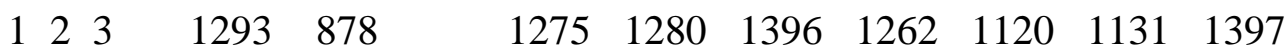

$\begin{array}{lllllll}1059 & 1293 & 1025 & 1323 & 1365 & 1329 & 1294\end{array}$

$\begin{array}{lllllll}1356 & 1413 & 1414 & 1396 & 878 & 1127 & 1221\end{array}$

$\begin{array}{llllllll}1412 & 1336 & 1248 & 1304 & 1399 & 1403 & 1402\end{array}$

$\begin{array}{llllllll}1337 & 1374 & 1394 & 1410 & 1410 & 1414 & 1401\end{array}$

$\begin{array}{llllllll}1344 & 1244 & 1018 & 1023 & 1371 & 1398 & 1360\end{array}$

$\begin{array}{lllllll}1358 & 1316 & 1084 & 1290 & 1259 & 1350 & 1403\end{array}$

$\begin{array}{lllllll}1287 & 1252 & 1227 & 1025 & 1368 & 1249 & 1404\end{array}$

$\begin{array}{lllllll}1391 & 1414 & 1397 & 1413 & 1315 & 1114 & 1388\end{array}$

$\begin{array}{lll}1130 & 1289 & 1237\end{array}$

$5 \quad 1$ BC, 2 AB, 3 YP, 4 RM_2, 5 Roads, 6 CLEARCUT/PARTIAL CUTS/SHADE, 7 BAS , 8 NRO_1, 9 NRO_2, 10 SB \& YB, 11 SM, 12 RM_1 
Table 6.7-Contingency table for classification of the VIS 0.5-m imagery using Maximum Likelihood classifier

\begin{tabular}{|l|r|r|r|r|r|r|r|r|r|r|r|r|r|}
\hline $\begin{array}{l}\text { Classified } \\
\text { Data } \\
\text { (pixels) }\end{array}$ & BC & AB & YP & RM_2 & Roads & $\begin{array}{l}\text { Cc/P Cut/ } \\
\text { Shade }\end{array}$ & & & & & & &
\end{tabular}

Table 6.8- Classification accuracy assessment report for VIS 0.5-m resolution imagery

\begin{tabular}{|c|c|c|c|c|c|c|c|c|c|c|c|c|c|c|}
\hline $\begin{array}{l}\text { Classified } \\
\text { Data } \\
\text { (control } \\
\text { sites) }\end{array}$ & RM & BAS & $\mathrm{BC}$ & $\mid \begin{array}{l}\text { NRO } \\
-1\end{array}$ & $\mathrm{AB}$ & YP & $\begin{array}{l}\text { NRO } \\
-2\end{array}$ & SM & $\begin{array}{l}\text { SB } \\
\& \\
\text { YB }\end{array}$ & $\begin{array}{l}\text { Reference } \\
\text { Totals }\end{array}$ & $\begin{array}{l}\text { Classified } \\
\text { Totals }\end{array}$ & $\begin{array}{l}\text { Number } \\
\text { Correct }\end{array}$ & $\begin{array}{l}\text { Producer's } \\
\text { Accuracy }\end{array}$ & $\begin{array}{l}\text { User's } \\
\text { Accuracy }\end{array}$ \\
\hline RM & 0 & 0 & 0 & 0 & 0 & ( & 0 & 0 & 0 & 2 & 0 & 0 & --- & --- \\
\hline BAS & 0 & 2 & 0 & 0 & 0 & ( & 0 & 0 & 1 & 3 & 3 & 2 & $66.67 \%$ & $66.67 \%$ \\
\hline $\mathrm{BC}$ & 0 & 0 & 4 & 0 & 0 & ( & 0 & 0 & 0 & 4 & 4 & 4 & $100.00 \%$ & $100.00 \%$ \\
\hline NRO_1 & 1 & 0 & 0 & 0 & 1 & T & 0 & 0 & 0 & 0 & 2 & 0 & --- & --- \\
\hline $\mathrm{AB}$ & 0 & 1 & 0 & 0 & 0 & ( & 0 & 0 & 0 & 4 & 1 & 0 & $0.00 \%$ & $0.00 \%$ \\
\hline $\mathrm{YP}$ & 0 & 0 & 0 & 0 & 0 & & 4 & 0 & 0 & 4 & 4 & 4 & $100.00 \%$ & $100.00 \%$ \\
\hline NRO_2 & 0 & 0 & 0 & 0 & 3 & ( & 0 & 0 & 1 & 4 & 7 & 3 & $75.00 \%$ & $42.86 \%$ \\
\hline SM & 1 & 0 & 0 & 0 & 0 & & 0 & 2 & 0 & 2 & 4 & 2 & $100.00 \%$ & $50.00 \%$ \\
\hline$\overline{\mathrm{SB} \& \mathrm{YB}}$ & 0 & 0 & 0 & 0 & 0 & ( & 0 & 0 & 1 & 3 & 1 & 1 & $33.33 \%$ & $100.00 \%$ \\
\hline \begin{tabular}{|l|} 
Column \\
Total
\end{tabular} & 2 & 3 & 4 & 0 & 4 & 2 & 4 & 2 & 3 & 26 & 26 & 16 & & \\
\hline
\end{tabular}

Overall classification accuracy $=61.54 \%$

Overall Kappa statistic $=0.5608$ 


\subsubsection{CIR 1-m resolution imagery classification}

Thirty training sites (the same ones used for classification of the CIR $0.5-\mathrm{m}$ and VIS 0.5-m imagery) were used to classify the CIR 1-m imagery. Their signatures were merged into 11 signatures (figure 6.5). Because of the existence of two groups of signatures belonging to American beech (shaded and illuminated sites), two groups of

merged signatures, AB-o (overstory) and AB-u (understory), were produced. Signature separability based on Jeffries-Matusita distance exhibited low separability between the pairs of signatures belonging to SM-YP, BC- AB-u and RM-YP (table 6.9).

The contingency table for classification of the CIR 1-m imagery presents the number of pixels belonging to each species training sites, and the way those pixels were classified using the Maximum Likelihood classifier (table 6.10). Overall classification accuracy of the entire study area was $50 \%$, with an overall Kappa statistic of 0.41 (table 6.11). The total number of control sites used in the estimation of the classification accuracy was 20. The composition derived from the whole classified image and for the subunits were plotted using pie charts (figure 6.6 - Total study area; figure 6.10 - NE-1 subunit; figure 6.12 - NE-2 subunit; figure 6.13 - Partial cut subunit; figure 6.14 - SE-1 subunit; figure 6.15 - SE-2 subunit; figure 6.16 - SW subunit). 


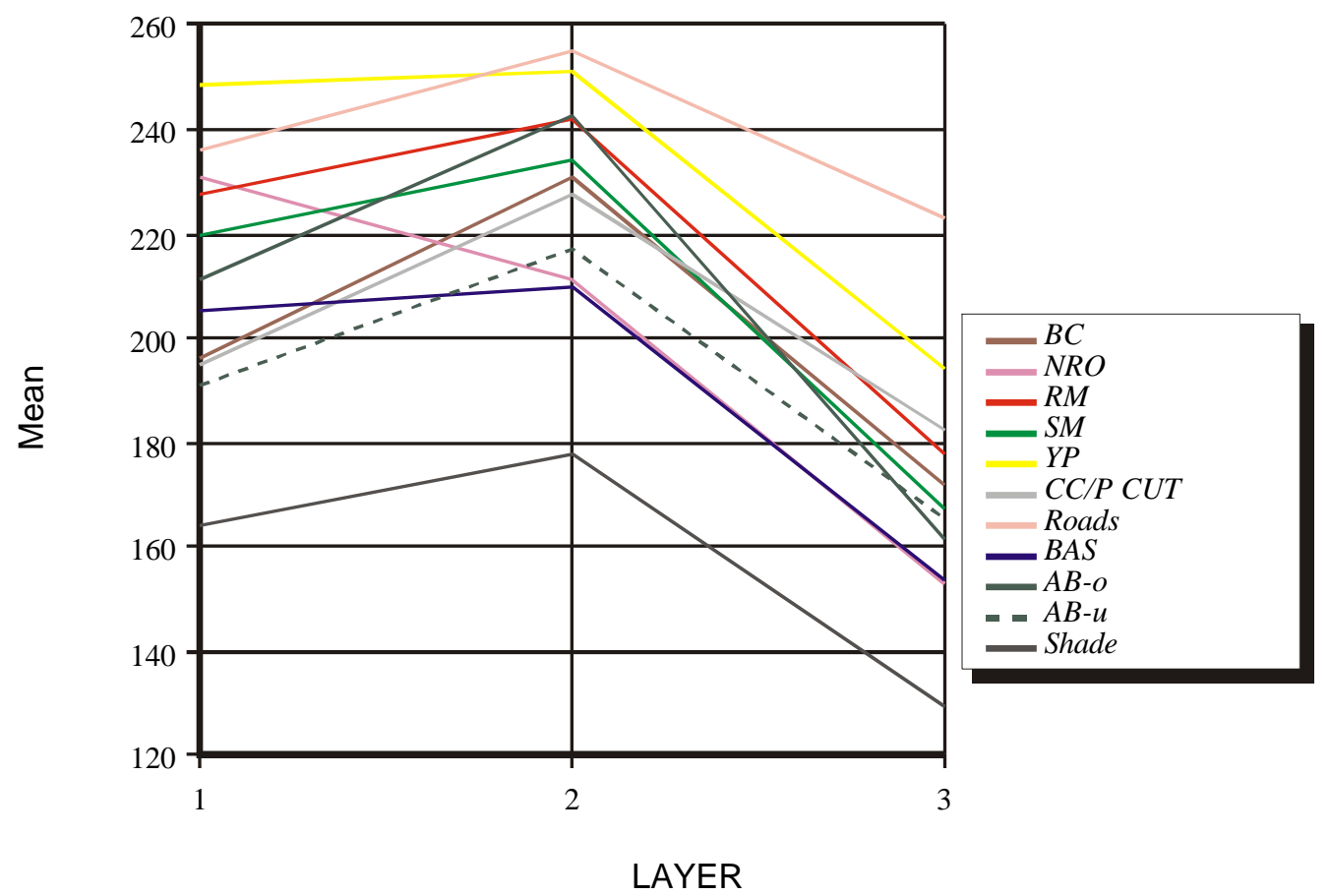

Figure 6.5- Plot of signatures used for the classification of the CIR 1-m imagery 
Table 6.9- Signature separability for the CIR 1-m imagery based on the Jefferies-Matusita distance. Colored blocks indicate pairs with low separability ${ }^{6}$

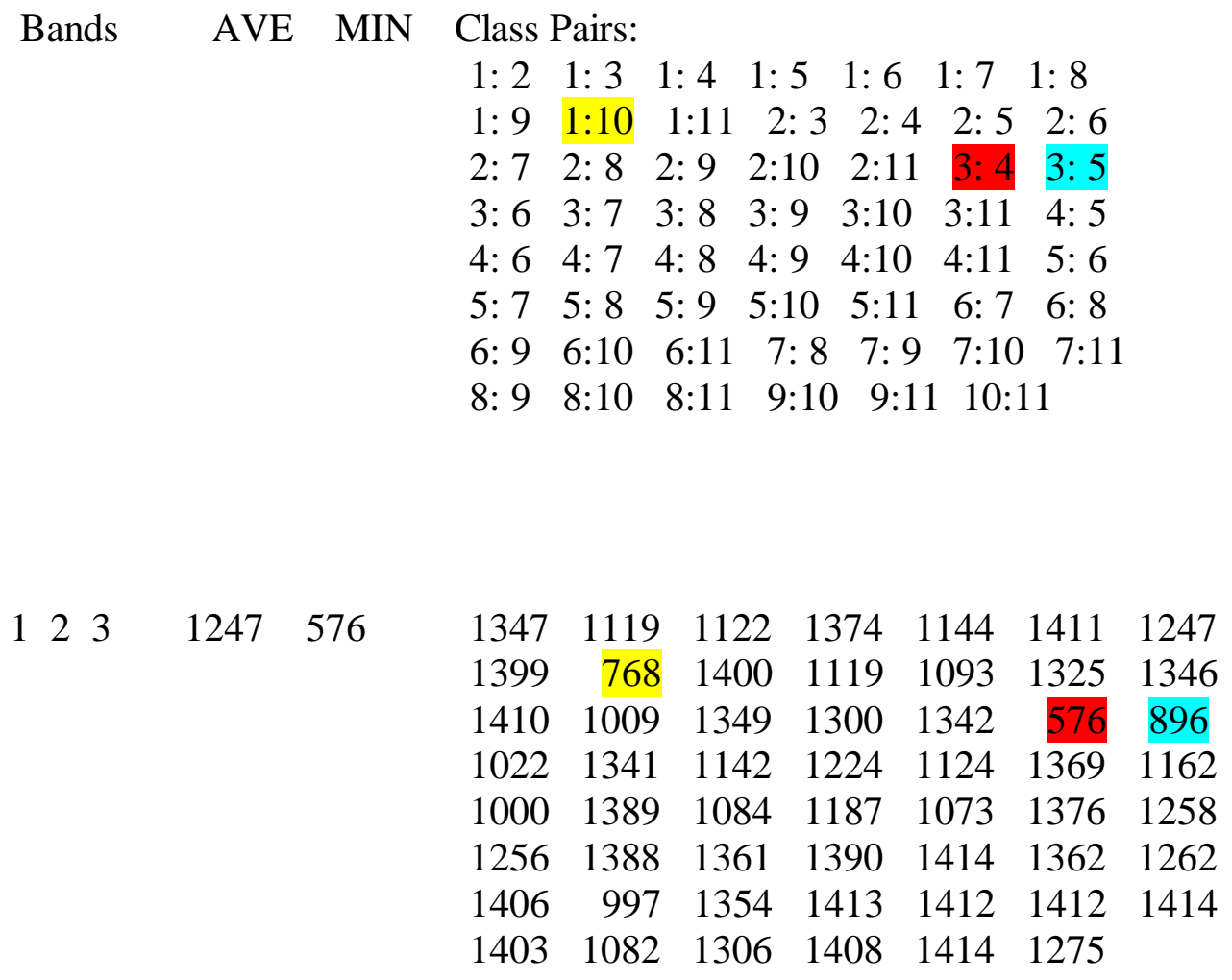

61 BC, 2 NRO, 3 RM, 4 SM, 5 YP, 6 CC/PARTIAL CUT, 7 ROADS, 8 BAS, 9 AB-overstory, 10 ABunderstory, 11 SHADE 
Table 6.10- Contingency table for classification the of CIR 1-m imagery using the Maximum Likelihood classifier

\begin{tabular}{|c|c|c|c|c|c|c|c|c|c|c|c|c|}
\hline $\begin{array}{c}\text { Classified } \\
\text { Data } \\
\text { (pixels) }\end{array}$ & AB-o & AB-u & BAS & BC & NRO & RM & SM & YP & $\begin{array}{c}\text { CC/P } \\
\text { CUT }\end{array}$ & Roads & Shade & $\begin{array}{c}\text { Row } \\
\text { Total }\end{array}$ \\
\hline AB-o & 17 & 0 & 0 & 0 & 14 & 26 & 23 & 0 & 3 & 0 & 0 & 83 \\
\hline AB-u & 0 & 35 & 9 & 8 & 7 & 15 & 32 & 0 & 387 & 0 & 2 & 495 \\
\hline BAS & 0 & 2 & 96 & 2 & 80 & 25 & 50 & 0 & 200 & 0 & 2 & 457 \\
\hline BC & 0 & 16 & 2 & 53 & 7 & 67 & 31 & 3 & 438 & 0 & 0 & 617 \\
\hline NRO & 0 & 0 & 9 & 0 & 498 & 4 & 12 & 0 & 65 & 0 & 0 & 588 \\
\hline RM & 0 & 0 & 0 & 1 & 17 & 79 & 42 & 3 & 241 & 5 & 0 & 388 \\
\hline SM & 0 & 1 & 2 & 1 & 35 & 63 & 99 & 0 & 40 & 0 & 0 & 241 \\
\hline YP & 0 & 0 & 0 & 0 & 7 & 186 & 29 & 34 & 210 & 40 & 0 & 506 \\
\hline CC/P CUT & 0 & 1 & 2 & 2 & 1 & 49 & 19 & 0 & 4179 & 1 & 0 & 4254 \\
\hline Roads & 0 & 0 & 0 & 0 & 0 & 16 & 3 & 12 & 747 & 1405 & 0 & 2183 \\
\hline Shade & 0 & 1 & 2 & 0 & 9 & 16 & 0 & 0 & 84 & 0 & 63 & 175 \\
\hline $\begin{array}{c}\text { Column } \\
\text { Total }\end{array}$ & 17 & 56 & 122 & 67 & 675 & 546 & 340 & 52 & 6594 & 1451 & 67 & 9987 \\
\hline
\end{tabular}

Table 6.11- Classification accuracy assessment report for the CIR 1-m resolution imagery

\begin{tabular}{|l|r|r|r|r|r|r|r|r|r|r|r|r|r|r|r|}
\hline $\begin{array}{l}\text { Classified } \\
\text { Data } \\
\text { control } \\
\text { sites }\end{array}$ & AB & BAS & BC & NRO & RM & SM & YP & $\begin{array}{l}\text { CC/P } \\
\text { CUT }\end{array}$ & Roads & $\begin{array}{l}\text { Shade } \\
\text { Refe- }\end{array}$ & $\begin{array}{l}\text { Classif. } \\
\text { rence } \\
\text { Totals }\end{array}$ \\
Totals
\end{tabular}

Overall classification accuracy $=50.00 \%$

Overall Kappa statistic $=0.4118$ 


\subsection{DISCUSSION}

The best statistical results of the classification were produced using the CIR 0.5-m resolution image. The worst statistical results were produced using the CIR 1-m resolution imagery, which could be used to identify correctly only 9 classes (table 6.12).

Table 6.12 - Statistical results of the image classification

\begin{tabular}{|c|c|c|c|c|}
\hline Image set & $\begin{array}{c}\text { Number of classes } \\
\text { correctly identified }\end{array}$ & $\begin{array}{c}\text { Overall } \\
\text { classification } \\
\text { accuracy }\end{array}$ & $\begin{array}{c}\text { Overall Kappa } \\
\text { statistic }\end{array}$ & Comments \\
\hline CIR 0.5-m & 10 & $73.1 \%$ & 0.69 & Best results \\
\hline VIS 0.5-m & 10 & $61.5 \%$ & 0.56 & \\
\hline CIR 1-m & 9 & $50.0 \%$ & 0.41 & \\
\hline
\end{tabular}

The results of the classification of the CIR 0.5-m imagery were the most accurate, with the highest overall accuracy and the highest Kappa statistic. The compositions derived from each of the classified images were plotted using pie charts (figures 6.6 6.16). Species composition for the entire study area is closer to the "true" composition when the CIR 0.5-m imagery is the basis for classification. It should be emphasized that the classification results are also closer to the "true" composition for each of the aspectbased subunits, although the areas classified as clearcut/partial cut/shade are very high on the shaded slopes, occupying as much as $31 \%$ of the entire NE-1 subunit.

The results of the classification of the CIR 1-m imagery were the most inaccurate, with lowest accuracy and lowest Kappa statistic. Species composition derived for the entire study area based on the CIR 1-m resolution imagery is second best when compared to the "true" composition estimated from the ground data. The classification results are also closer to the "true" composition for each of the aspect-based subunits, although the 
areas classified as clearcut/partial cut /shade are higher than those produced by the CIR $0.5-\mathrm{m}$ imagery, occupying as much as $32 \%$ of the entire NE-1 subunit.

The results of the classification of the VIS 0.5-m imagery were the second best, with values of accuracy and Kappa statistic, situated between those of the CIR 0.5-m and CIR 1-m images. Species composition of the whole classified area is the most inaccurate when compared to the "true" composition estimated from the ground data. The poor results using the VIS 0.5-m imagery were evident in the results obtained for the whole study area and for each of the aspect-based subunits. One explanation for the results is that the images were acquired during low illumination conditions. Even so, substantial information is contained in the images and they could be useful in forest management applications. The VIS 0.5-m resolution images included the lowest amount of shade, and they could be very useful for visual identification of features like roads and streams.

A serious problem in the image classification was the high percent of shade in the CIR images. For the entire study area, the percentage shaded or occupied by clearcuts and partial cuts in the CIR $0.5-\mathrm{m}$ resolution images was $20 \%$, which is $6 \%$ higher than the "true" area occupied by those classes. The percent shaded or harvested in the CIR 1-m resolution image was $26 \%$, which is $12 \%$ higher than the "true" area occupied by clearcuts/partial cuts or shade. The shading altered the compositions derived from each classified image, but if the percent shade is distributed relative to the proportion of each species in the general species composition, the results would be close to reality. As indicated previously, the VIS 0.5 -m resolution imagery was not affected by shading.

Overall, the CIR 0.5-m resolution imagery produced the best results and the compositions derived from the classified image were very close to the "true" composition 
of each of the aspect-based subunits. However, the subunits with a northern aspect, NE-1 and NE-2, had the highest percent of shade; one third of each subunit's area was shaded (figure 6.10 and figure 6.12). Shading was minimal on subunits with a southern aspect, and predicted species composition was very close to that estimated using the ground plot data (figures 6.13 - 6.16). The CIR 1-m resolution imagery was only slightly more shaded, and the results for the aspect-based subunits were very similar to those from the CIR 0.5-m imagery. Consequently, even if shading altered the individual species percentages derived from the CIR images, the overall results were representative and accurately reflected the ground data.

Finally, the classified images contained relatively low pixelation (salt-and-pepper aspect); that is, the pixels belonging to different classes were not scattered randomly in the image (figures $6.7-6.9,6.11$, and 6. 17). The pixels belonging to different tree species or to other classes (clearcuts, roads, etc.) were clumped together, and the classified image did not require a "smoothing" routine to eliminate scattered pixels. 
Composition from ground data (true)

Roads AB

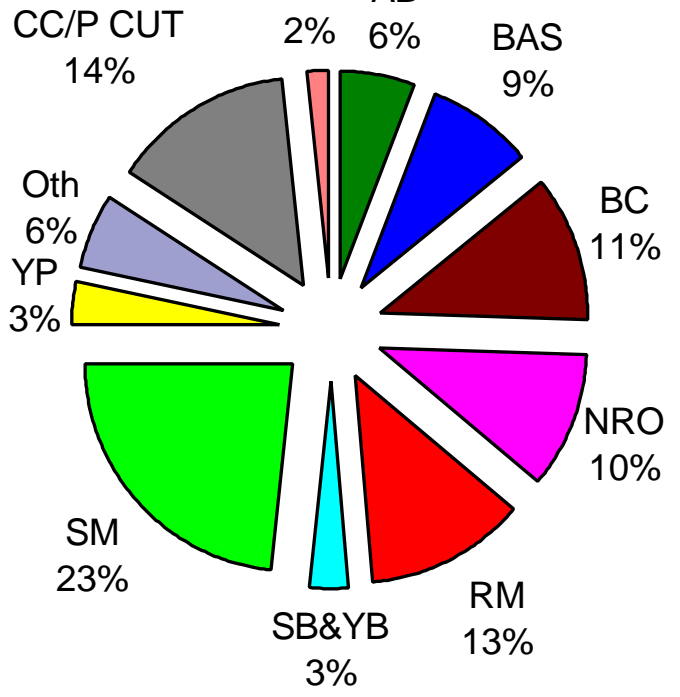

Composition from VIS $0.5-\mathrm{m}$ imagery

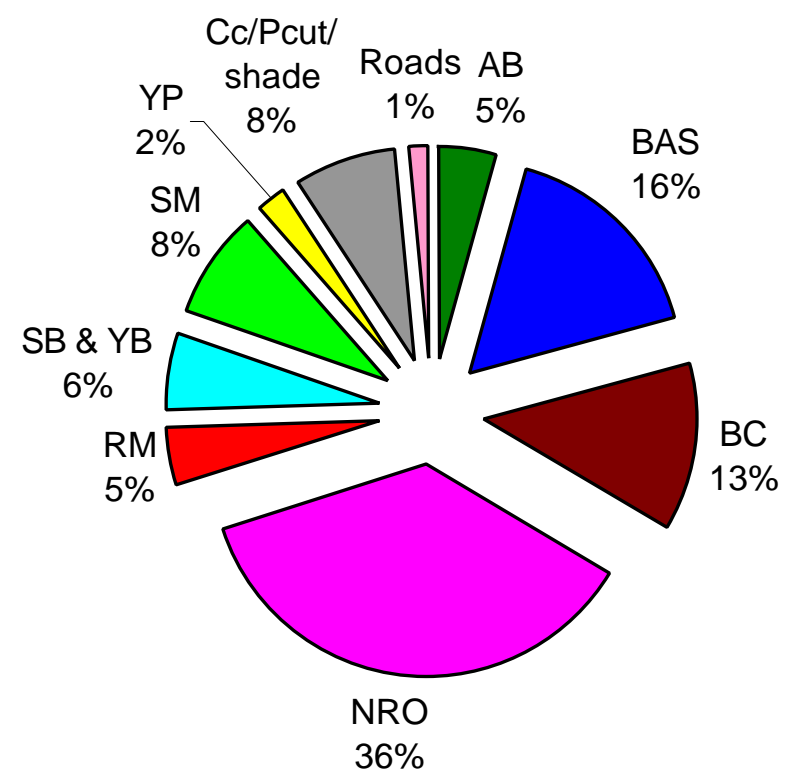

Composition from CIR $0.5-\mathrm{m}$ imagery

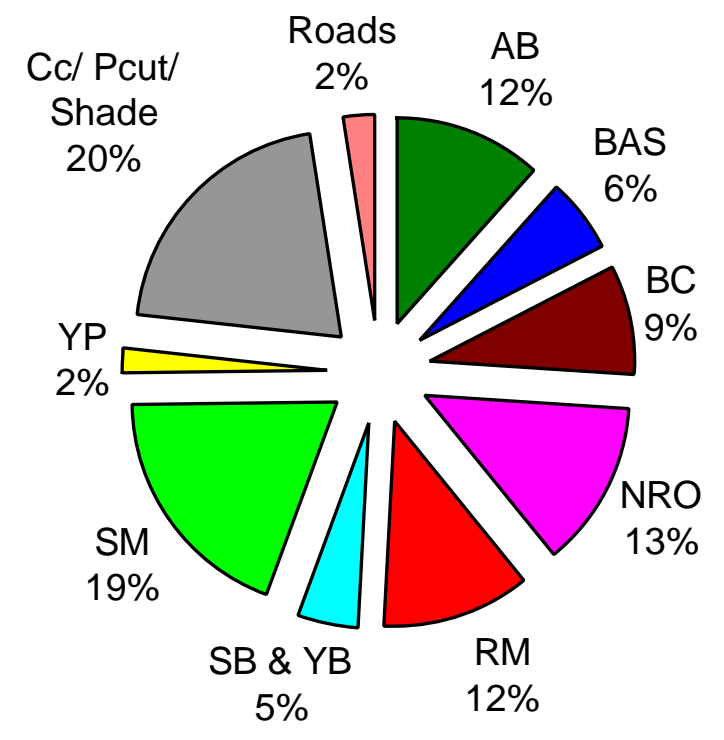

Composition from CIR 1-m imagery

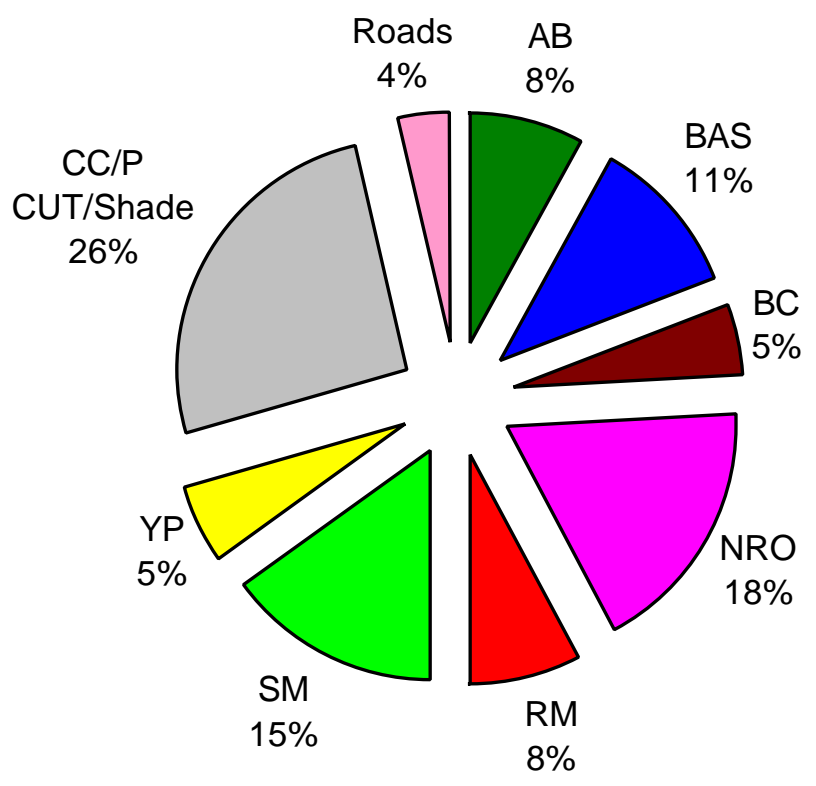

Figure 6.6- Total study area species composition derived from various sources 


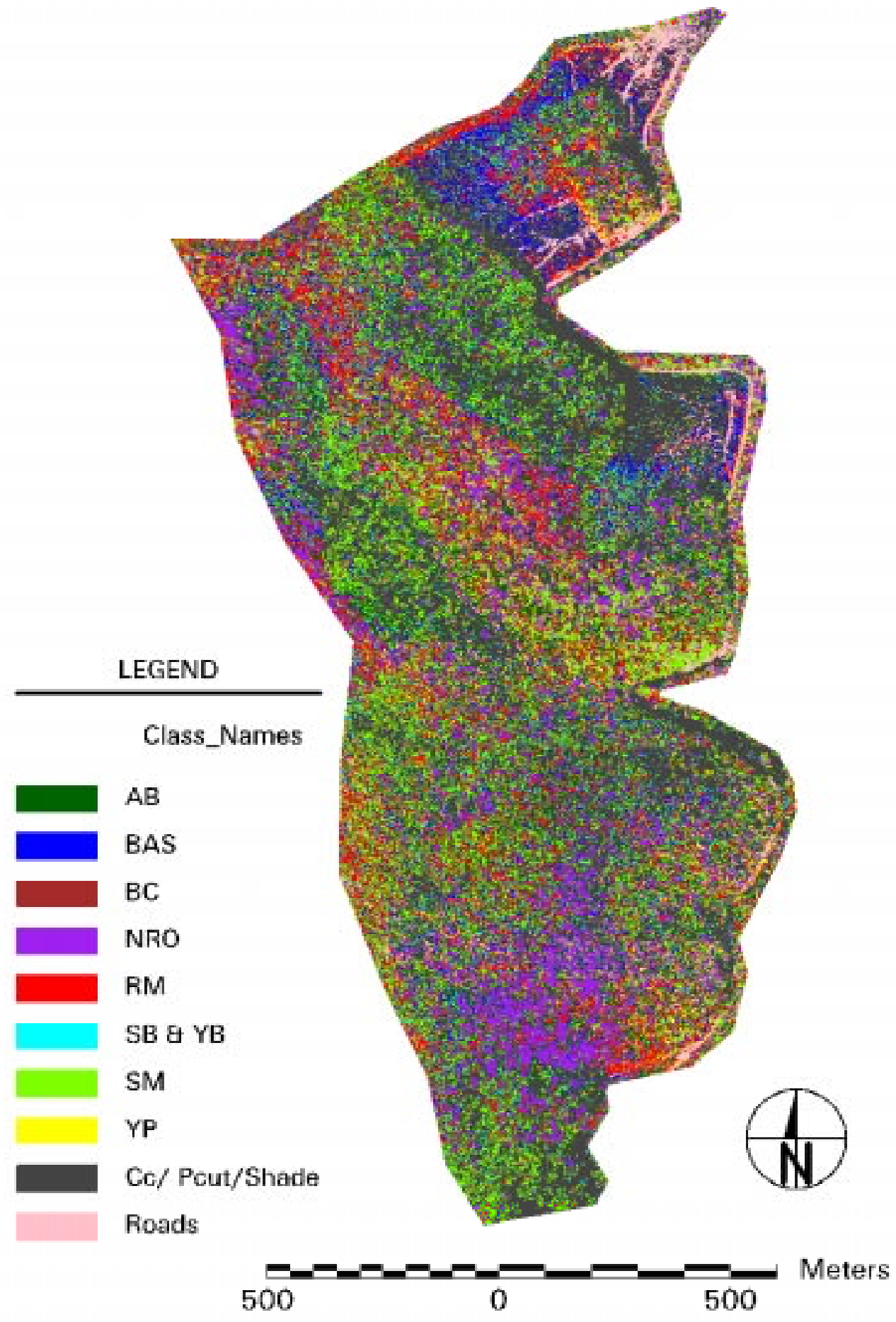

Figure 6.7- Classified image of the entire study area derived from CIR 0.5-m resolution imagery 


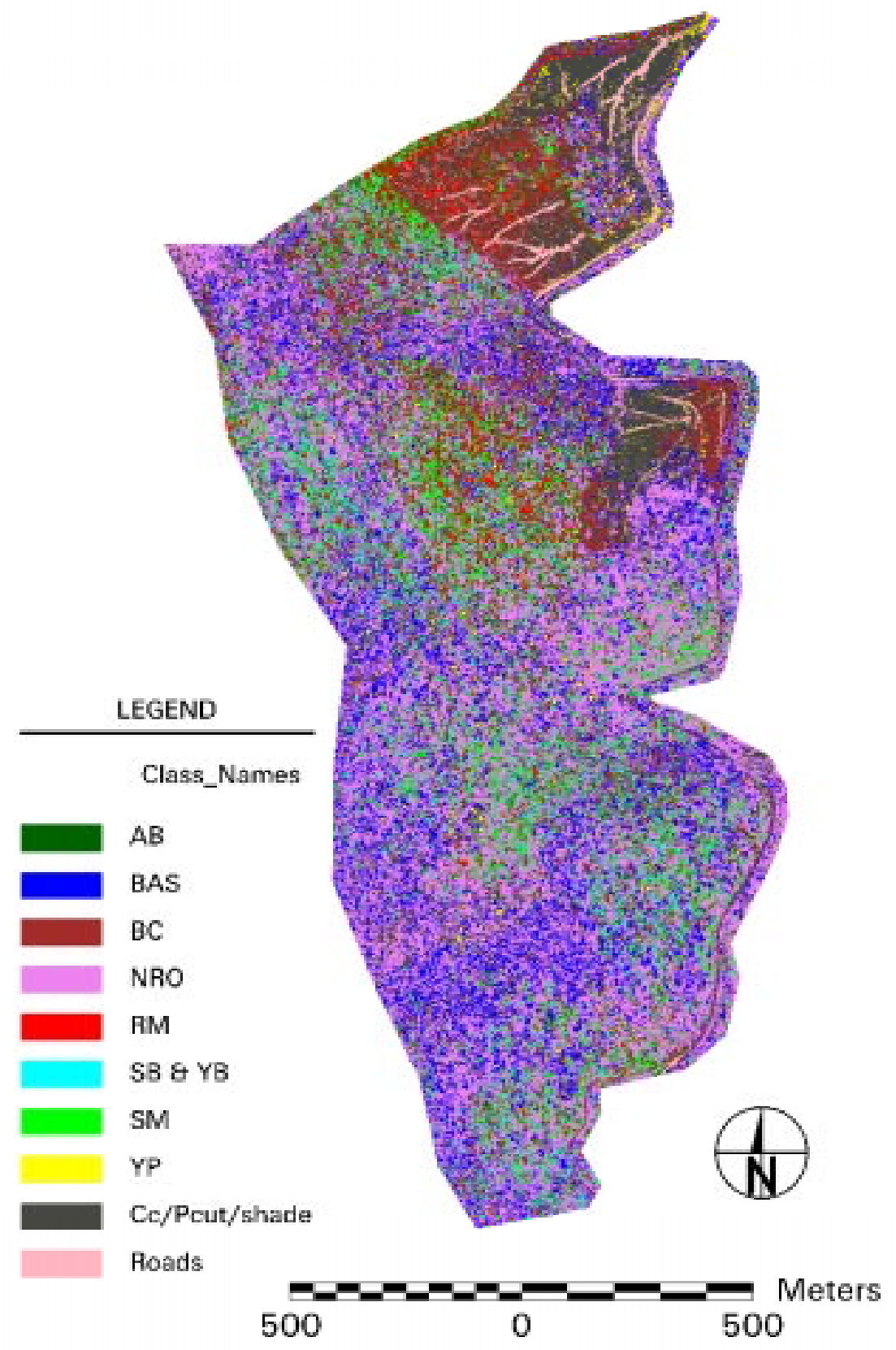

Figure 6.8- Classified image of the entire study derived from VIS 0.5-m resolution imagery 


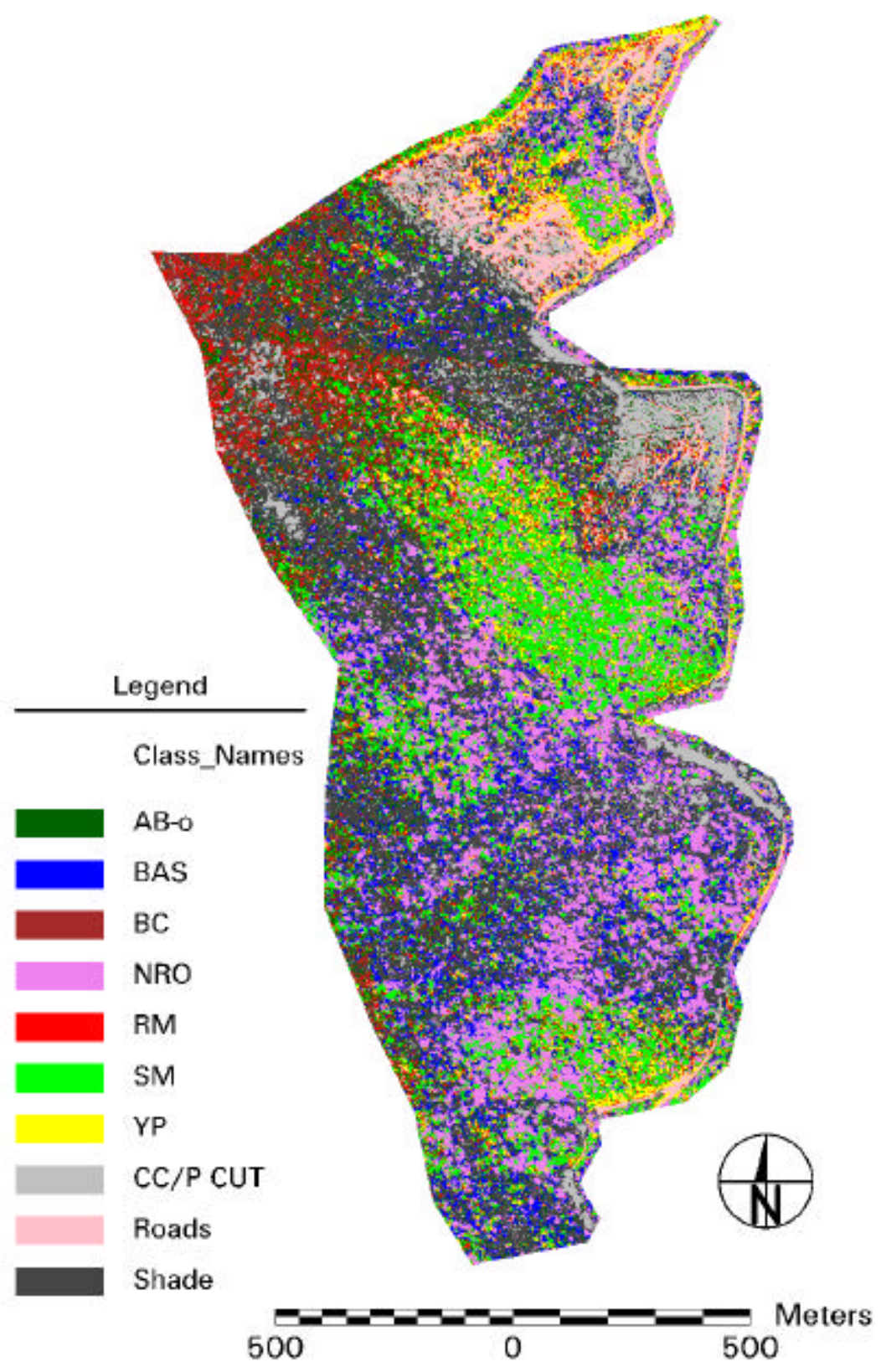

Figure 6.9- Classified image of the entire study derived from CIR 1-m resolution imagery 


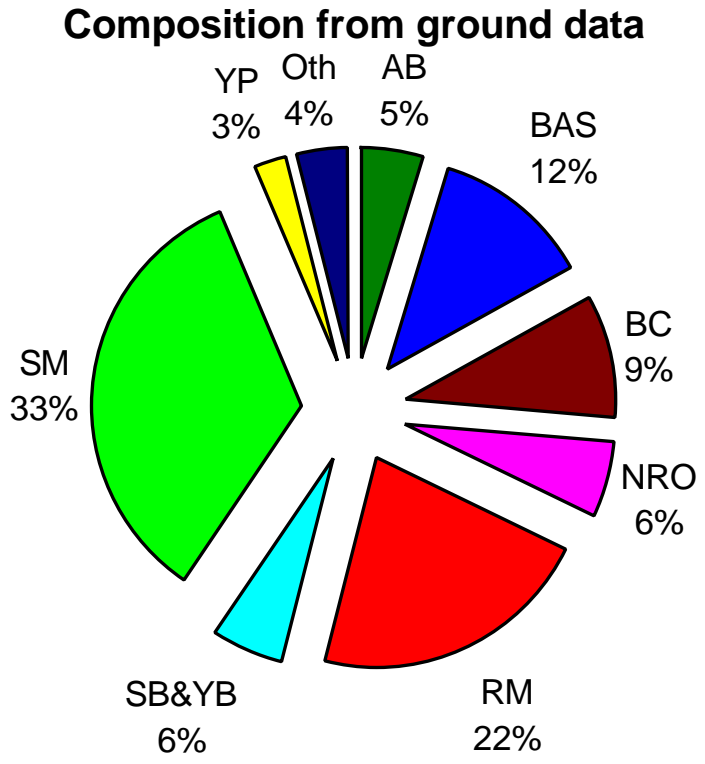

Composition from VIS $0.5-\mathrm{m}$ imagery

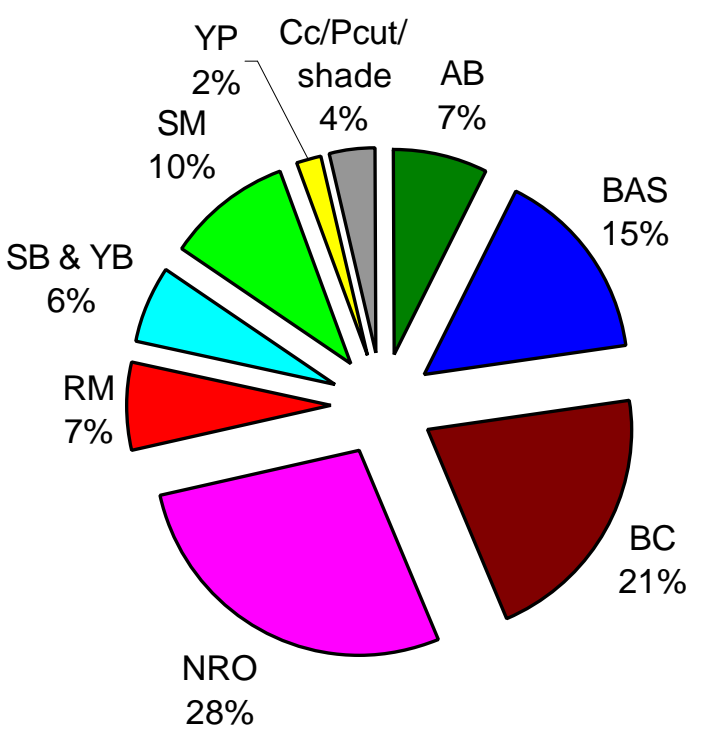

\section{Composition from CIR-0.5m imagery}

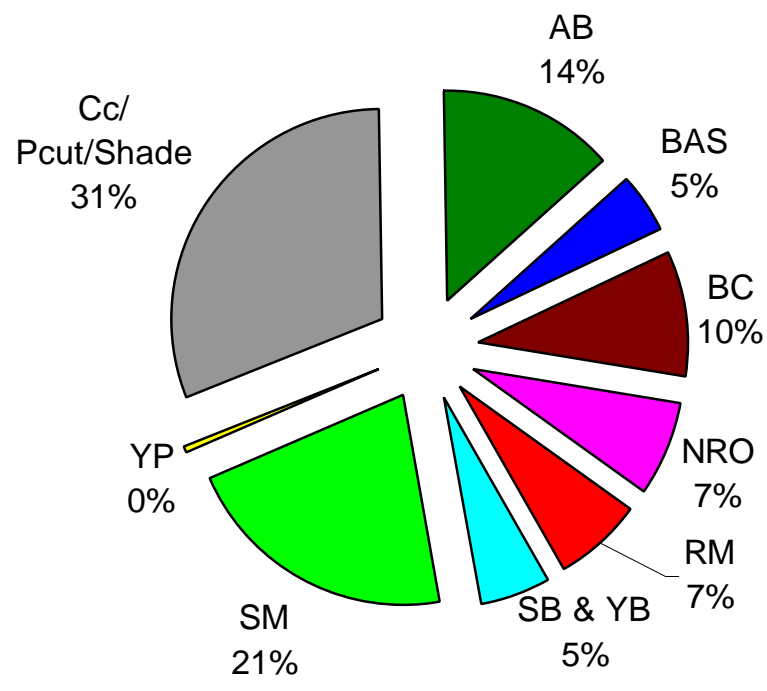

Composition from CIR 1-m imagery

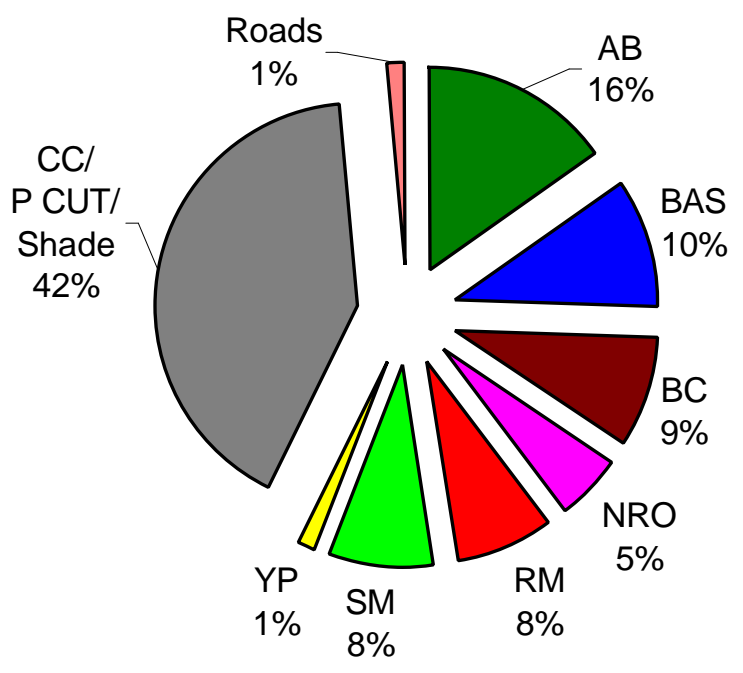

Figure 6.10- NE-1 subunit species composition derived from various sources 


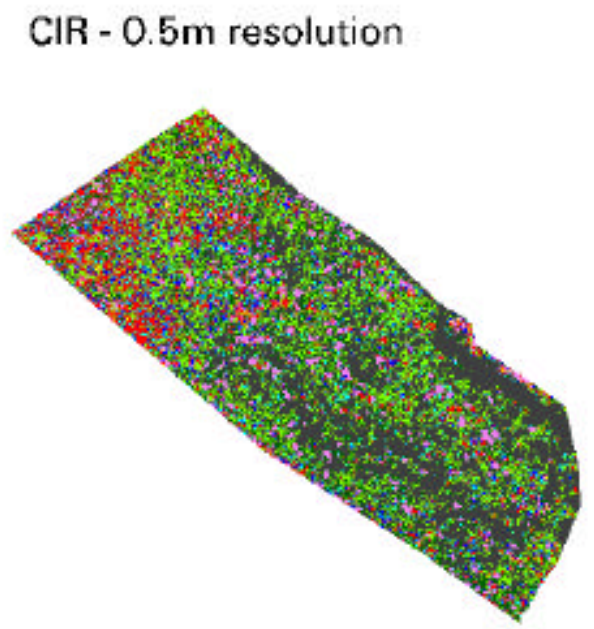

$$
\text { CIR }-1 \mathrm{~m} \text { resolution }
$$
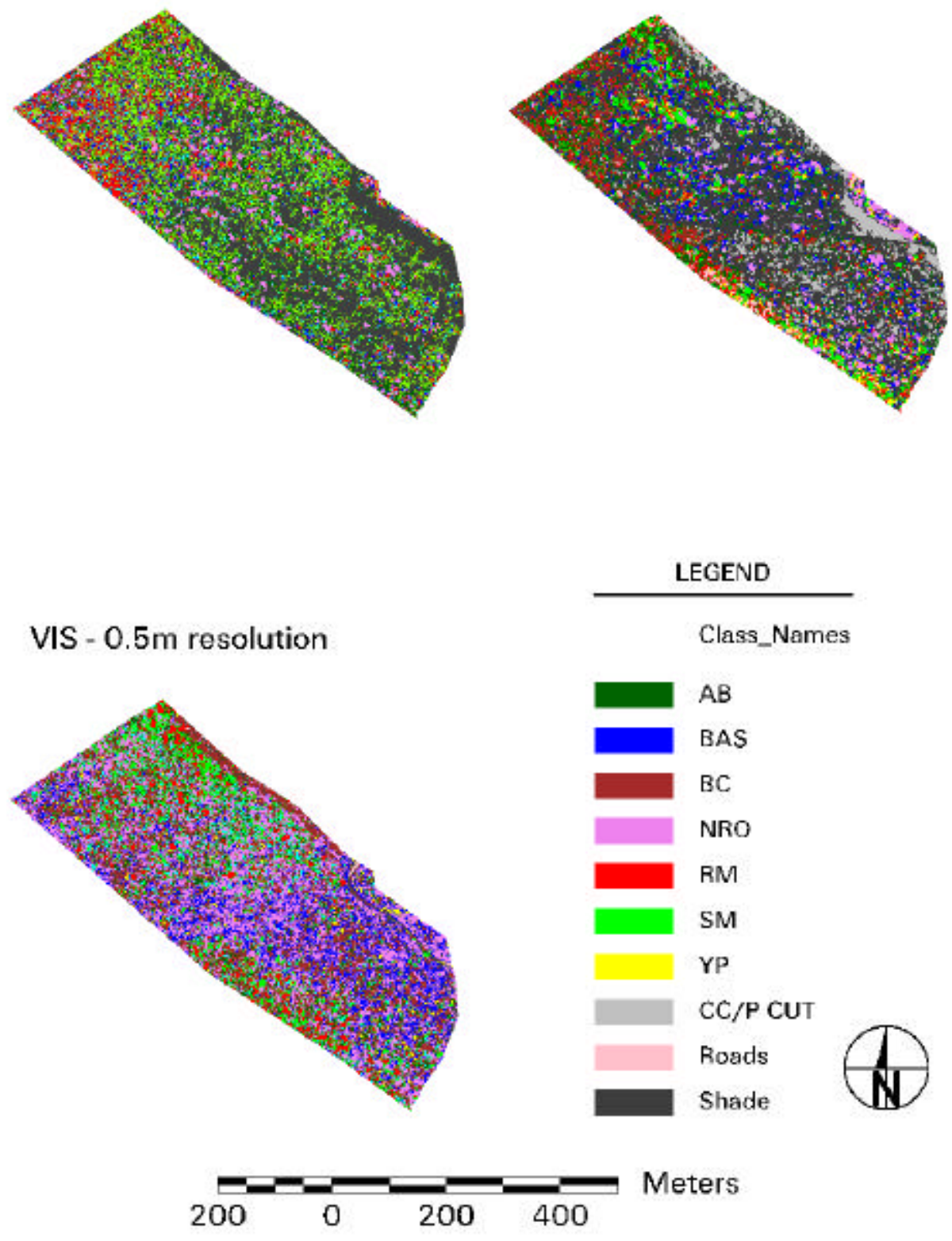

Figure 6.11- NE-1 subunit classification derived from different images 
Composition from ground data (true)

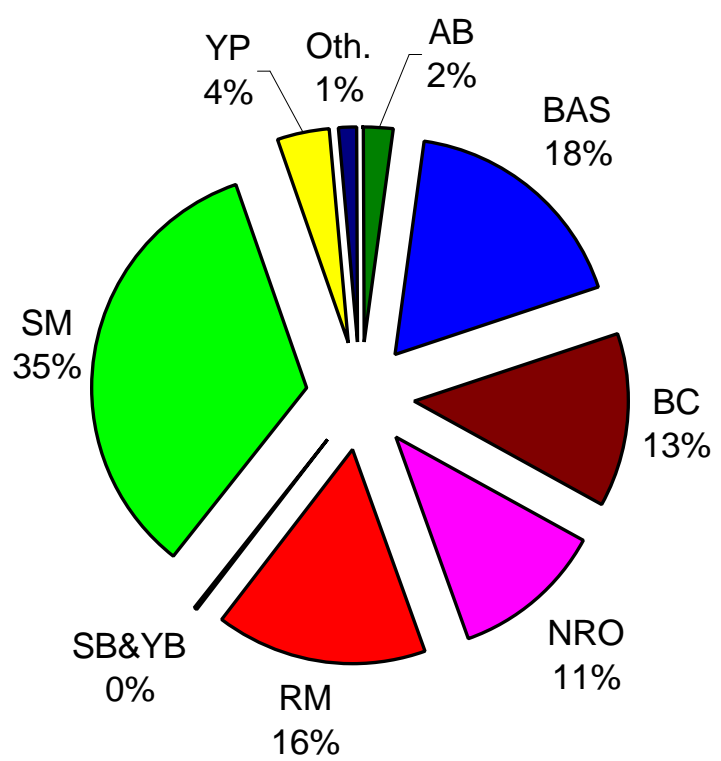

\section{Composition from VIS-0.5m imagery}

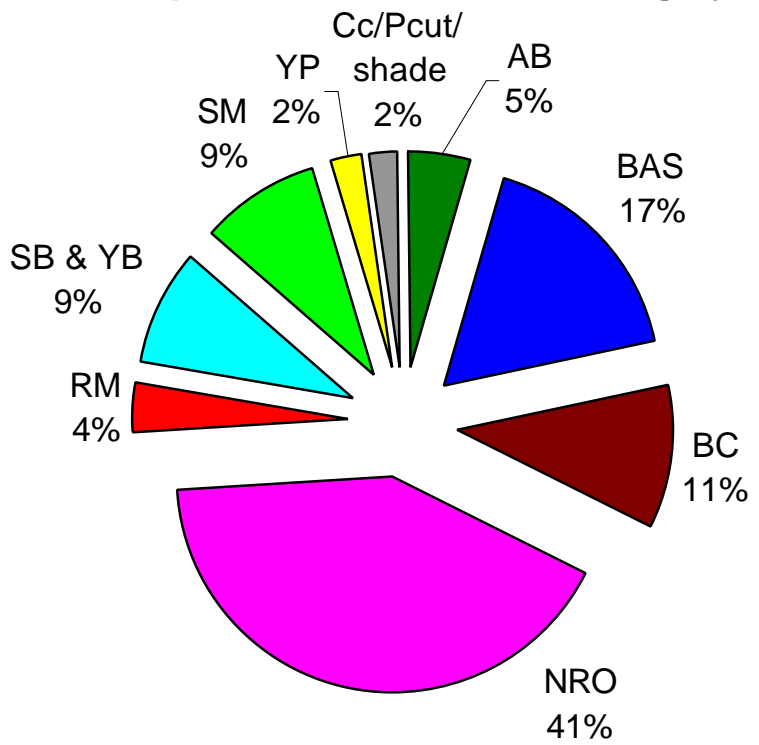

Composition from CIR 0.5-m imagery

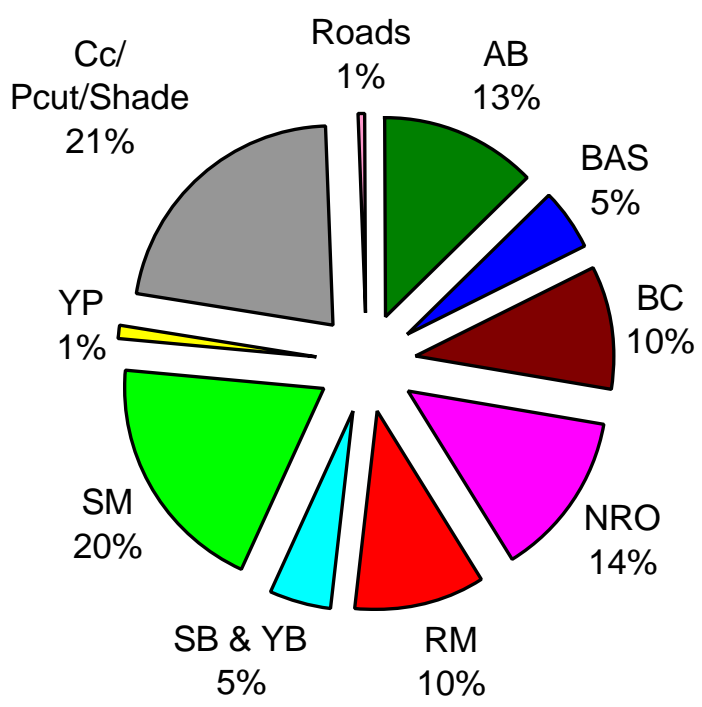

\section{Composition from CIR 1-m imagery}

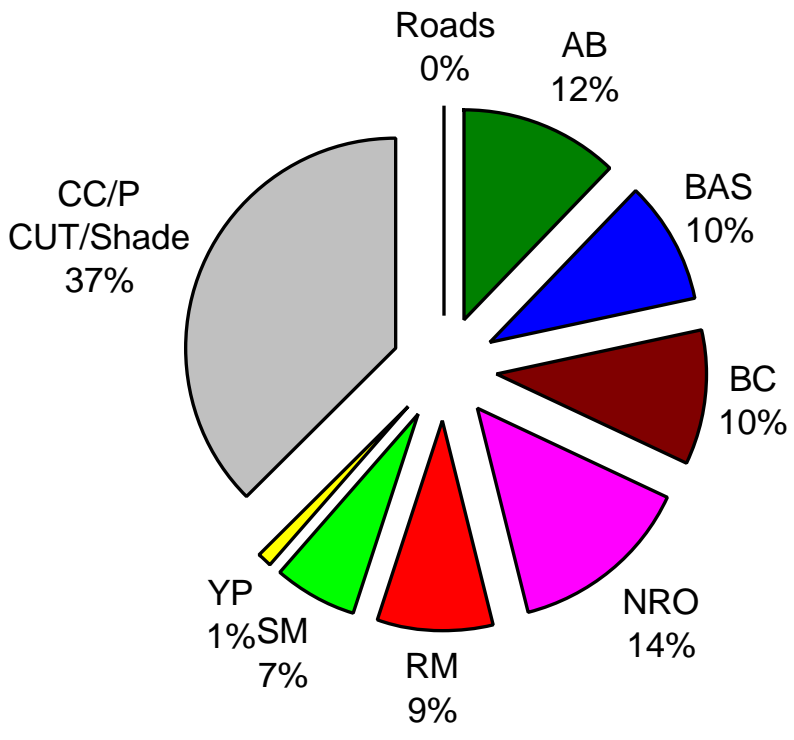

Figure 6.12- NE-2 subunit species composition derived from various sources 


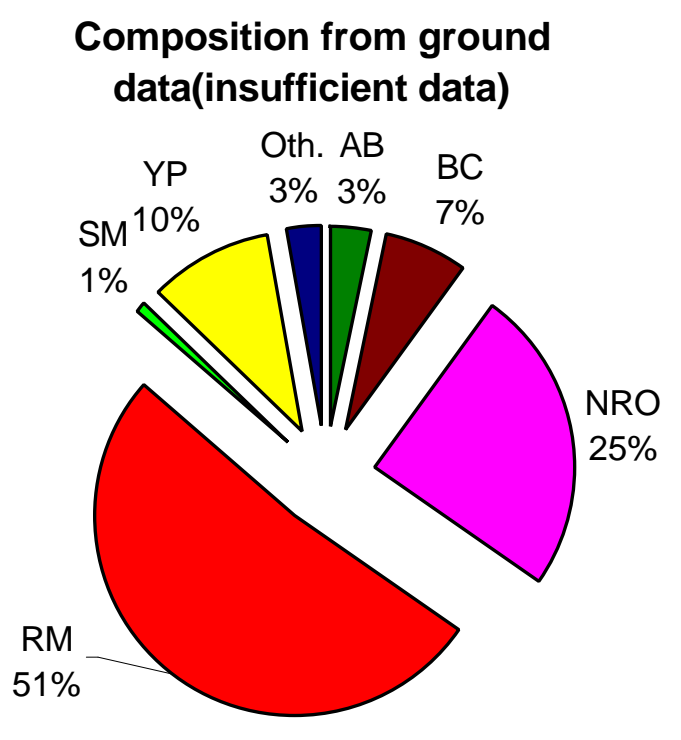

Composition from $\mathrm{ClR}$ 0.5-m resolution

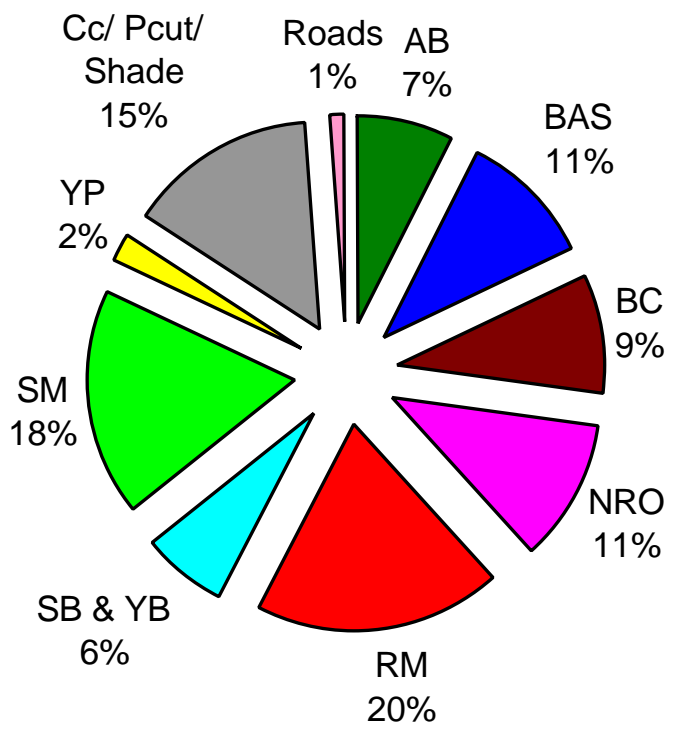

Composition from VIR $0.5-\mathrm{m}$ imagery
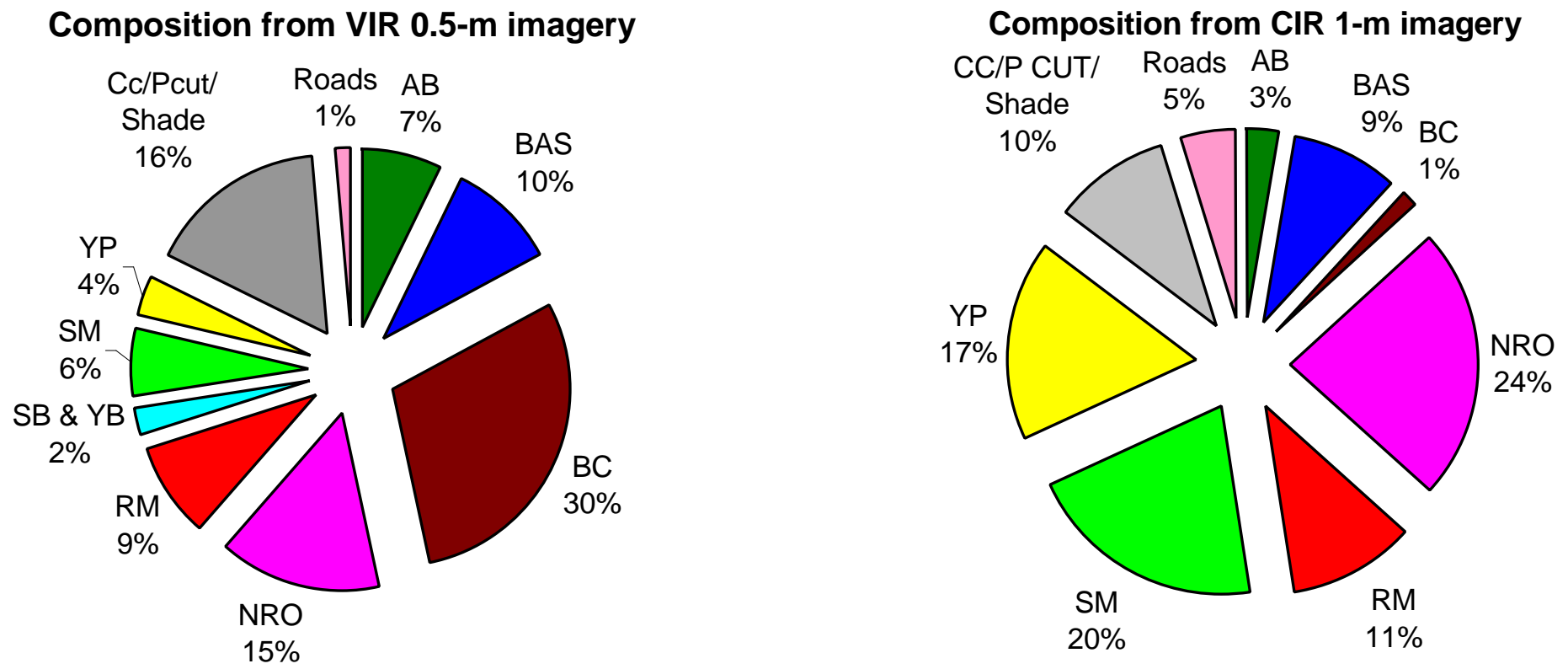

Figure 6.13- Partial Cut subunit species composition derived from various sources 
Composition from ground data (true)

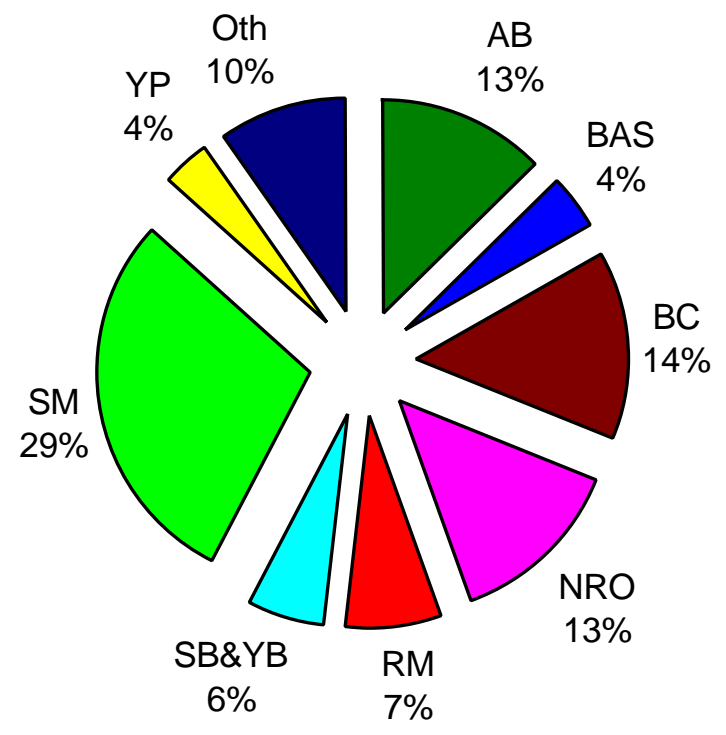

Composition from VIS 0.5-m imagery

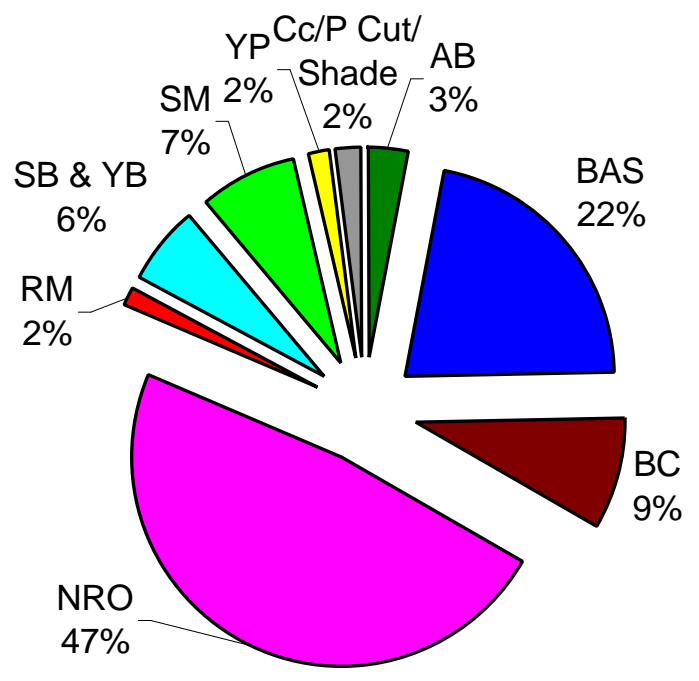

\section{Composition from CIR 0.5-m imagery}

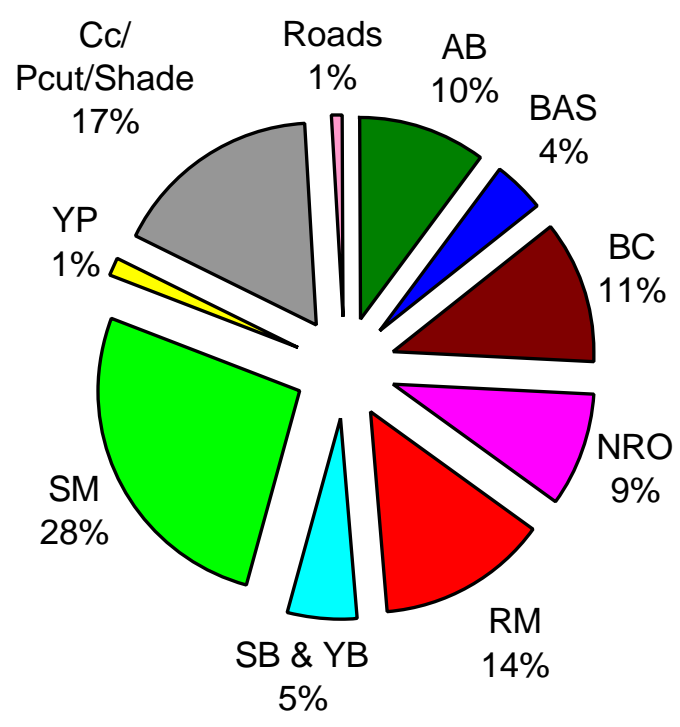

Composition from CIR 1-m imagery

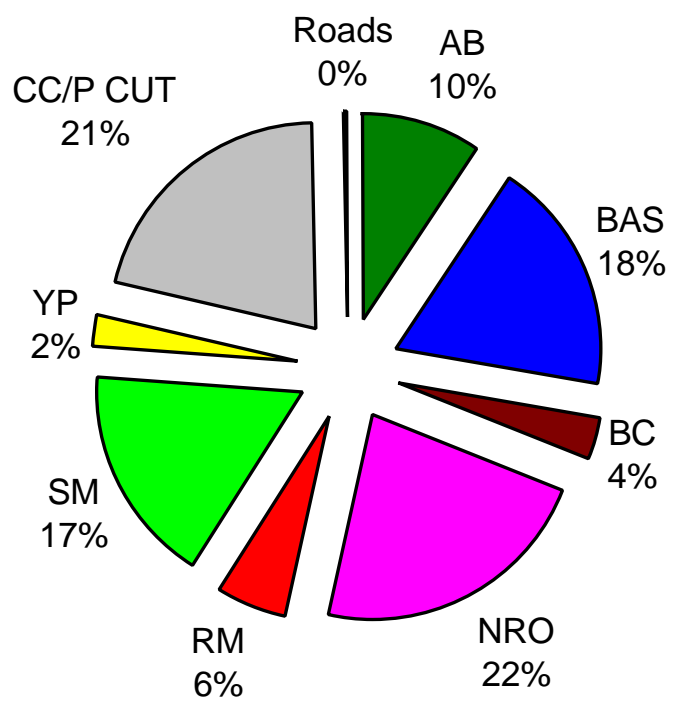

Figure 6.14- SE-1 subunit species composition derived from various sources 
Composition from ground data (true)

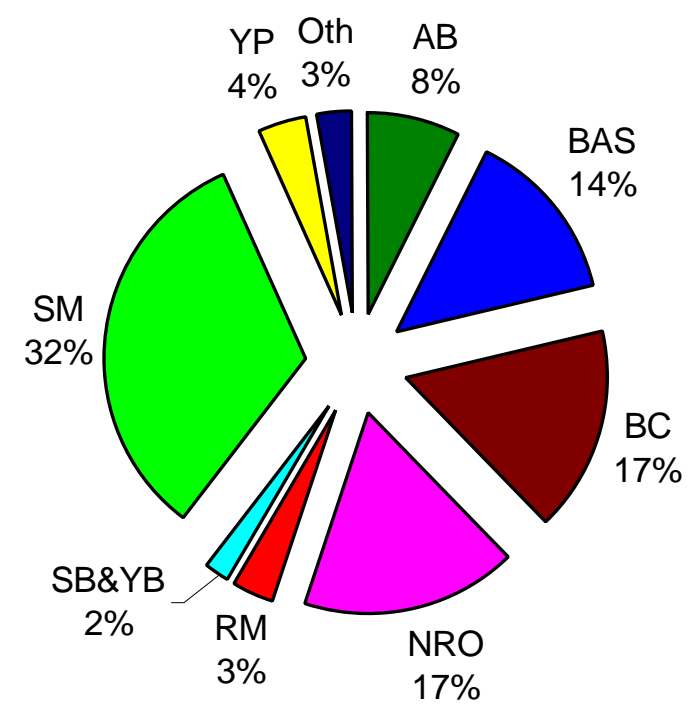

Composition from VIS 1-m imagery

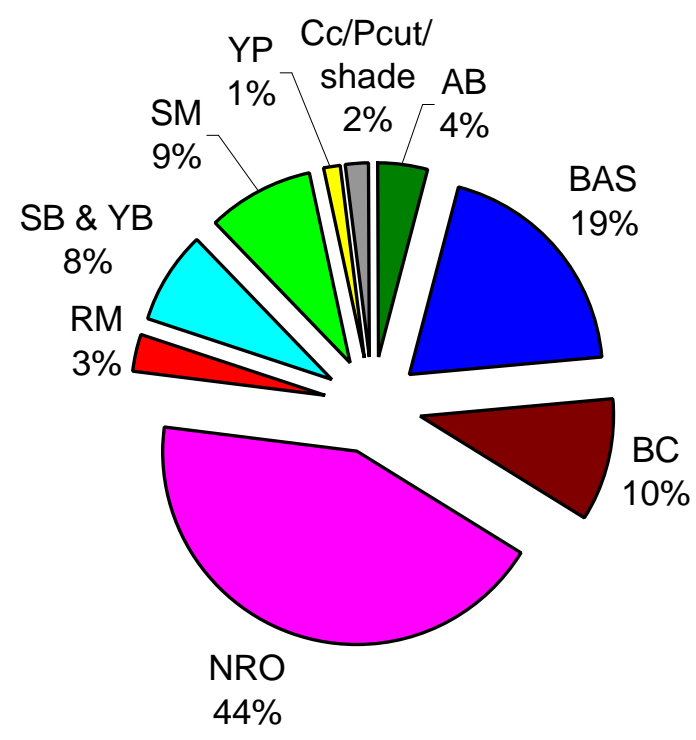

Composition from CIR 0.5-m imagery

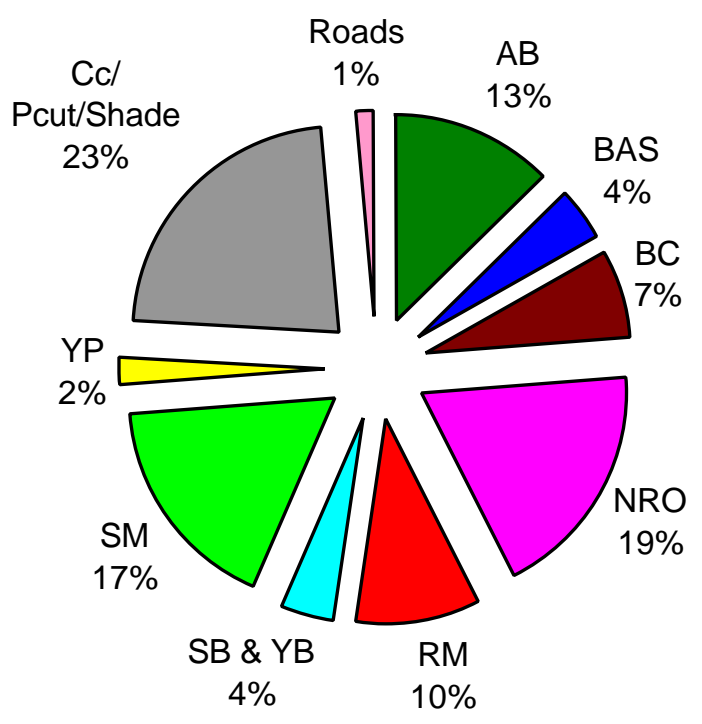

Composition from CIR 1-m imagery

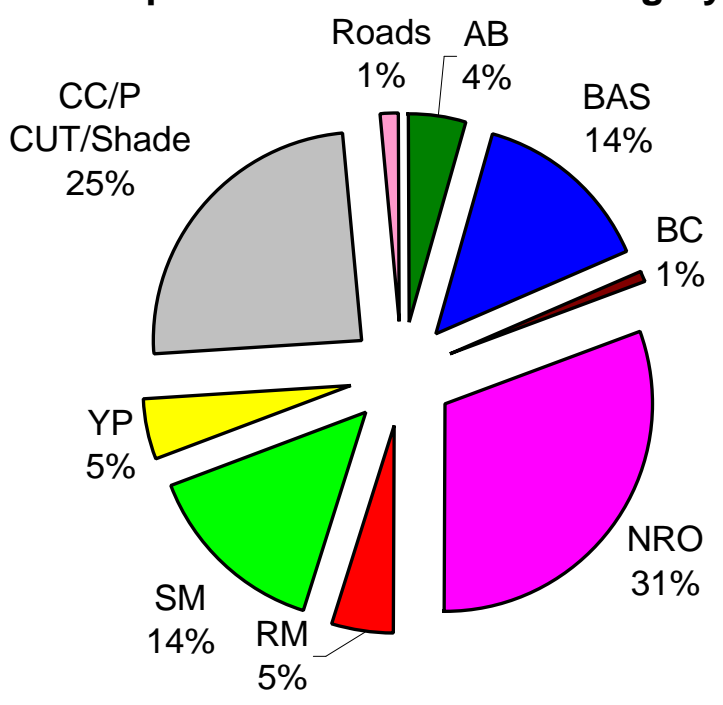

Figure 6.15- SE-2 subunit species composition derived from various sources 
Composition from ground data (true)

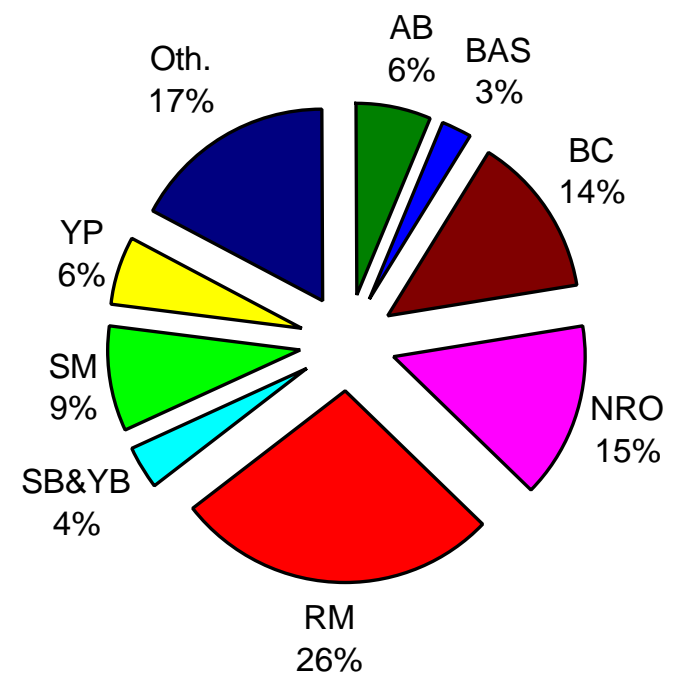

Composition from VIS 0.5-m imagery

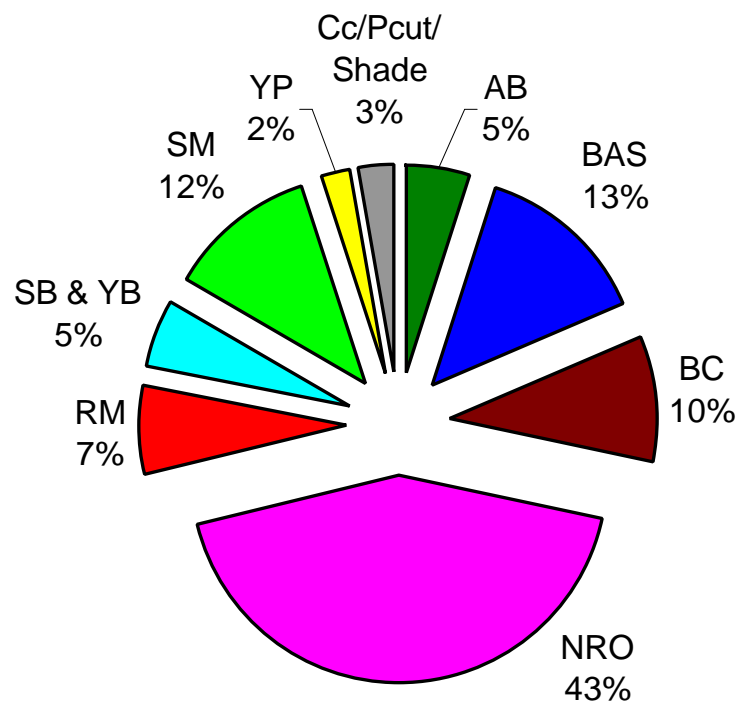

Composition from CIR $0.5-\mathrm{m}$ imagery

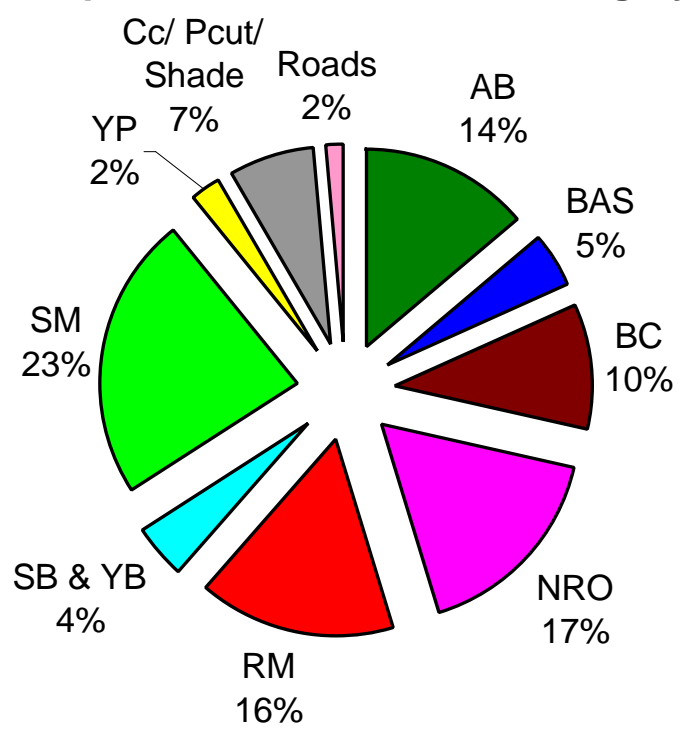

Figure 6.16- SW subunit species composition derived from various sources 
CIR $-0.5 m$ resolution

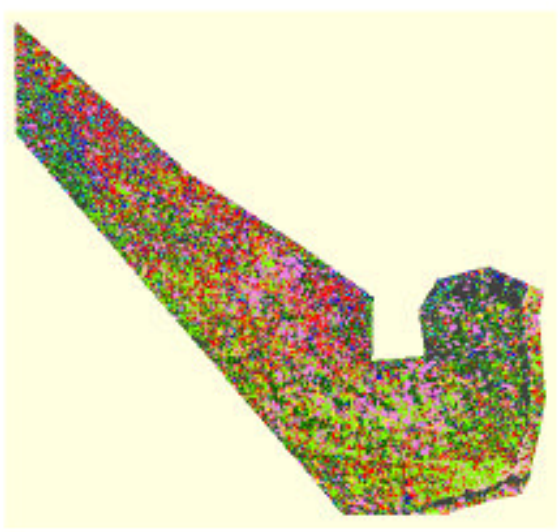

VIS $-0.5 m$ resolution
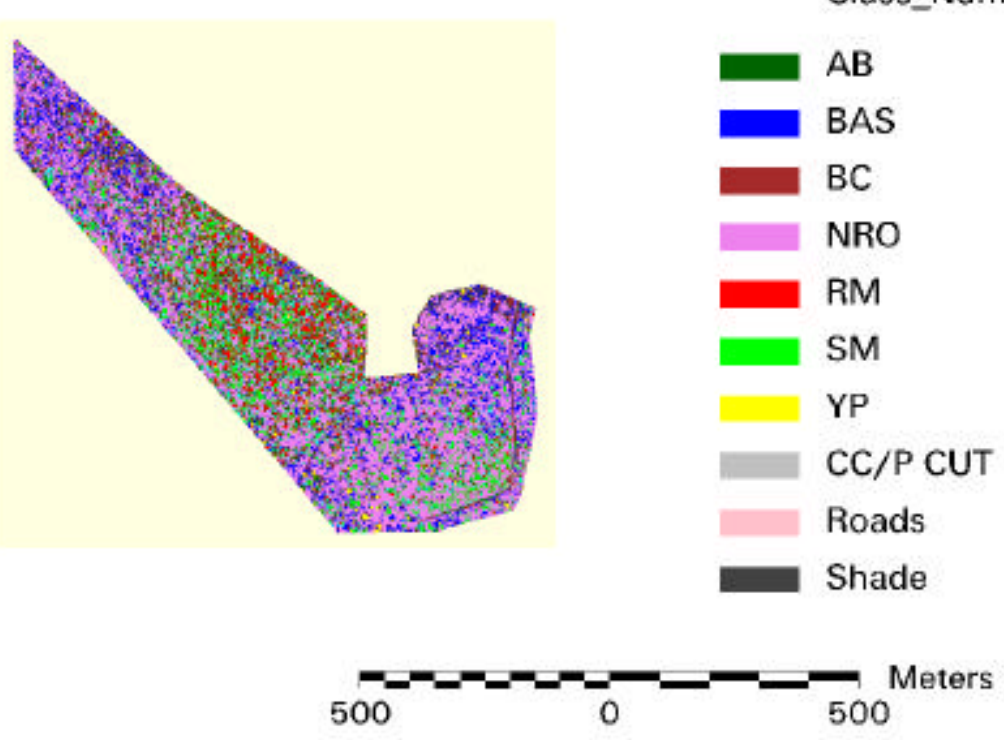

CC/P CUT

Roads
CIR $-1 \mathrm{~m}$ resolution

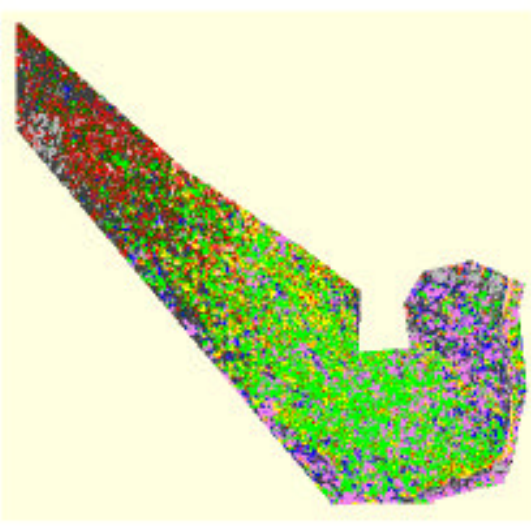

LEGEND

Class_Names

aB

BAS

BC

NRO

RM

SM

YP

Shade

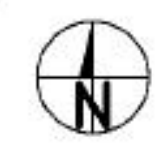

Figure 6.17- SW subunit classification derived from different images 


\section{CHAPTER 7. CONCLUSION}

Airborne digital cameras are poised to displace conventional cameras in aerial photography by offering all the advantages of direct digital images. The future digital cameras will be computer-controlled and will incorporate real-time DGPS. Even if current sensor CCD arrays are limited to about 4000x3000 pixels and, therefore, have a limited swath width, new cameras will have up to 9000x7000 elements, and it is conceived that they will match the 230 -mm (9-inch) aerial photographs.

Pitt et al. (1997) estimated that commercial digital cameras for commercial mapping are five years distance, and that, in time, the conventional aerial cameras potentially will be displaced for many forest vegetation management applications, as the cost of these higher resolution solid-state CCD array cameras declines.

The main conclusion of the study is that the imagery acquired with the ADAR 1000 system has great potential for use in various forest management applications. Both CIR and VIS images are extremely useful for classification purposes and determination of species composition. Even though the VIS images acquired for the study did not perform as expected, the species composition derived from the classified images may be useful. It also should be taken into consideration that the VIS images were acquired in completely overcast dimly lit conditions; nevertheless, the information extracted from the imagery proved to be useful. If the VIS images are acquired in normal lighting conditions, the potential of such images for forest management purposes could be very high. 
The ADAR 1000 system is more flexible than satellite imagery, because the images can be acquired when necessary, under diverse lighting conditions, and they can be used immediately after acquisition. Also, the ADAR 1000 system is more efficient when compared with standard aerial photography because the images are acquired in digital format. Authors who have used scanned aerial photos emphasized that the scanning process is time consuming and error prone, but that classification based on such images can differentiate some forest species such as yellow-poplar, scarlet oak (Quercus coccinea), chestnut oak (Quercus prinus) and northern red oak (Neese, 1998). However, the forest cover type classification errors based on such imagery can be very high, up to 70\%. The classification accuracy based on ADAR 1000 digital images was much higher. Not only could the forest cover type be correctly identified, but accurate the identification of individual tree species and species composition is possible. In addition, association of a GPS location with each image center should prove useful in automated mosaicking, reducing the number of required ground control points. 


\section{REFERENCES}

American Society of Photogrammetry (ASP), 1983. Manual of remote sensing, Volume $1,2^{\text {nd }}$ ed., ASP, Falls Church, VA, $1232 \mathrm{pp}$.

Avery, T.E. and Burkhart, H.E., 1994. Forest Measurements, 4th Edition. McGraw-Hill, New York, NY. 408 p.

Bannari, A., Gibson, J.R. and Morin, D., 1996. The necessity of exterior orientation parameters for the geometric correction of MEIS-II airborne digital images. Proceedings of the Second International Airborne Remote Sensing Conference and Exhibition, San Francisco, USA, June 24-27, Environmental Research Institute of Michigan, Vol. III, p.37-52.

Benkelman, C., Nguyen, A.T., Stow, D.A. and Hope, A.S., 1996. A simple method for vignette correction of airborne digital camera data. Proceedings of the Second International Airborne Remote Sensing Conference and ExhibitionSan Francisco, USA, June 24-27, Environmental Research Institute of Michigan, Vol. III, p.102-111.

Bian, L. 1997. Multiscale nature of spatial data in scaling up environmental models, in Scale in remote sensing and GIS, Quatrocchi, D.A. and Goodchild, M.F., Eds. CRC Lewis Publishers, Boca Raton, FL, 406p.

Bian, L. and Butler, R., 1999. Comparing effects of aggregation methods on statistical and spatial properties of simulated spatial data. Photogrammetric Engineering and Remote Sensing, 65 (1) : 73-84.

Bobbe, T., 1997. Applications of a color infrared digital camera system as a remote sensing tool for natural resource management. Technical papers of The $1^{\text {st }}$ American Symposium on Small Format Aerial Photography Cloquet, MN, Oct. 14-17, pp.71-79.

Campbell, W.G. and Mortensen, D.C., 1989. Ensuring the quality of geographic information system data: a practical application of quality control.

Photogrammetric Engineering \& Remote Sensing55(11) : 1613 - 1618.

Cao, C. and Lam, N. S-N., 1997. Understanding the scale and resolution effects in remote sensing and GIS, in Scale in remote sensing and GIS, Quatrocchi, D.A. and Goodchild, M.F., Eds. CRC Lewis Publishers, Boca Raton, FL, 406p.

Congalton, R.G., 1988. Using spatial autocorrelation analysis to explore the errors in maps generated from remotely sensed data. Photogrammetric Engineering \& Remote Sensing, 54 (5) : 587-592. 
Curran, P.J., 1988. The semivariogram in remote sensing: an introduction. Remote Sensing of Environment, 24 : 493-507.

Davis, J.C., 1986. Statistics and data analysis in geology. Wiley \& Sons, New York, 646 $\mathrm{pp}$.

Dean, C., Warner, T.A. and McGraw, J.B., 1999. Suitability of aerial imagery from a DCS460c color digital camera for deciduous forest tree delineation and species identification. ISPRS Journal of Photogrammetry and Remote Sensing Submitted.

Deckert, C. and Bolstad, P.V., 1995. Forest canopy, terrain and distance effects on global positionig system point accuracy. Photogrammetric Engineering and Remote Sensing, 62 (2) : 317-321.

D'Eon, S.P., 1996. Accuracy and signal reception of a hand-held Global Positioning System (GPS) receiver. The Forestry Chronicle, 71 (2) : 192-196.

Erdas Inc., 1997. Erdas Field guide, $4^{\text {th }}$ edition, Atlanta, Georgia, 656 p.

Frank, T.D., 1987. Mapping dominant vegetation communities in the Colorado Rocky Mountain Front Range with Landsat Thematic Mapper and digital terrain data. Photogrammetric Engineering \& Remote Sensing 54 (12): 1727 - 1734.

Franklin, J. and Woodcock, C.E., 1997. Multiscale vegetation data for the mountains of Southern California : Spatial and categorical resolution, in Scale in remote sensing and GIS, Quatrocchi, D.A. and Goodchild, M.F., Eds. CRC Lewis Publishers, Boca Raton, FL, 406p.

Geolink, 1996- GeoLink for Windows 95, 98 and NT 4.0. User Manual, v.5.6. GeoResearch, Inc., 100p.

Haddow, K.A., King, D.J. and Pitt, D.G., 1999. Regeneration assessment using high resolution CIR digital imaging. Proceedings of the Fourth International Airborne Remote Sensing Conference and Exhibition $/ 21^{\text {st }}$ Canadian Symposium on Remote Sensing. Ottawa, Canada, 21-24 June, Environmental Research Institute of Michigan, Vol. II, p. 147-154.

Hay, G.J., Niemann, K.O. and Goodenough, D.G., 1997. Spatial thresholds, imageobjects, and upscaling: a multiscale evaluation. Remote Sensing of the Environment, $62: 1-19$.

Hodgson, R.F., Caddy, F. and Pairman, D., 1981. A solid-state airborne sensing system for remote sensing, Photogrammetric Engineering and Remote Sensing 47 : 177 182. 
Hofmann-Wellenhoff, B., Liechtenegger, H. and Collins, J., 1994. Global Positioning System: Theory and Practice. 3rd revised ed., New York: Springer-Verlag, 355 p.

Holm, M., Lohi, A., Rantasuo, M., Vaatainen, S., Hoyhtya, T., Puumalainenen, J., Sarkeala, J. and Sedano, F., 1999. Creation of large mosaics of airborne digital camera imagery. Proceedings of the Fourth International Airborne Remote Sensing Conference and Exhibition/2 $f^{t}$ Canadian Symposium on Remote Sensing. Ottawa, Canada, 21-24 June, Environmental Research Institute of Michigan, Vol. II, p. 520-526.

Http://www.midstatelab.com/infrared.html - Agricultural and industrial testing, 1999.

Hyppanen, H., 1997. Spatial autocorrelation and optimal spatial-resolution of optical remote sensing data in Boreal forest environment. International Journal of Remote Sensing, 17 (17) : 3441-3452.

Jupp, D.L.B., Strahler, A.H. and Woodcock, C.E., 1988. Autocorrelation and regularization in digital images. I. Basic theory. IEEE Transactions on Geoscience and Remote Sensing,26 (4) : 463-473.

Jupp, D.L.B., Strahler, A.H. and Woodcock, C.E., 1989. Autocorrelation and regularization in digital images. II. Simple image models. IEEE Transactions on Geoscience and Remote Sensing, 27 (3) : 247-258.

King, D.J., 1995. Airborne Multispectral Digital Camera and Video Sensors: A Critical Review of System Designs and Applications. Canadian Journal of Remote Sensing, 21 (3) : 245-273.

King, D.J., 1997. Low cost multispectral digital camera for forest modeling and topographic mapping. Proceedings of the Third International Airborne Remote Sensing Conference and Exhibition, Copenhagen, Denmark, 1997, Environmental Research Institute of Michigan.

King, D.J., Armenakis, C. and Chicagov, A., 1995. Comparison of elevation modelling using scanned air photos and airborne digital camera imagery: A case study in natural terrain. Proceedings of the $15^{\text {th }}$ Biennial Workshop on Videography and Color Photography in Resource Management, Terre Haute, IN, 1-3 May, 280287.

Levesque, J. and King, D.J., 1995. The use of airborne digital camera semivariance in the evaluation of forest damage at an acid mine drainage. Proceedings, $15^{\text {th }}$ Biennial Workshop on Color Photography and Videography in Resource Assessment,Terre Haute, Indiana, May 1-3, ASPRS, p. 270-279.

Lillesand, T. M. and Kiefer, R. W., 1994. Remote sensing and image interpretation John Wiley and Sons, NY, 750 pp. 
Liu, C.J., 1993. GPS Accuracy: Can GPS fill the need for GIS? The Compiler, 11 (3) : $18-27$.

Lowe, J.L., Oswald, B.P., Coleman, T.L., Tadesse, W,.Everitt, J.H., Escobar, D.E. and Davis, M.R., 1995. Comparison of conventional ground sampling and remote sensing techniques for mapping forest vegetation. Proceedings of $15^{\text {th }}$ Biennial Workshop on Videography and Color Photography in Resource Assessmen, Terre Haute, IN, 1-3May, 31-35.

Mao, C., Grace, J. and Draper, K., 1994. Design and implementation of a real-time digital airborne CCD camera system. Proceedings of the International Society of Optical Engineers (SPIE), Airborne Reconnaissance XVIII,Vol. 2272, p. 203-212.

Marceau, D.J., Howarth, P.J. and Gratton, D.J., 1994a. Remote sensing and the measurement of geographical entities in a forested environment. 1. The scale and spatial aggregation problem. Remote Sensing of the Environment 49 : 93-104.

Marceau, D.J., Howarth, P.J. and Gratton, D.J., 1994b. Remote sensing and the measurement of geographical entities in a forested environment. 2. The optimal spatial resolution. Remote Sensing of the Environment 49 : 105-117.

Marceau, D.J., Howarth, P.J. and Gratton, D.J., 1994c. Etude du contenu spectral et spatial d'images numeriques et de l'impact sur la classification automatisee d'un couvert forestier, in Outils Micro-informatiques et Teledetection de l'Evolution des Milieux(J.-M. Dubois, Editor), Les Presses de L'Universite de Quebec, Quebec, pp. 365-384.

Mason, S., Ruther, H. and Smit, J., 1997. Investigation of the Kodak DCS460 digital camera for small-area mapping. ISPRS Journal of Photogrammetry and Remote Sensing. 52 : 202-214.

McDonald, K., 1999. Opportunity knocks: will GPS modernization open doors? GPS World, 10 (9) : 36-46.

McNab, W.H. and Avers, P.E., 1994. Ecological subregions of the United States of America: Section descriptions. USDA Forest Service Publications WO-WSA5.

Monday, H.M., Urban, J.S., Mulawa, D. and Benkelman, C.A.1994. City of Irving utilizes high resolution multispectral imagery for N.P.D.E.S. compliance. Photogrammetric Engineering and Remote Sensing 60 : 411-416.

Neale, C.M.U. and Crowther, B.G., 1994. An airborne multispectral video/radiometer remote sensing system: development and calibration. Remote Sensing of Environment, 49 : 187-194. 
Neese, C., 1998. Error in computer-assisted classification of Appalachian forest cover types. M.Sc. Thesis, Morgantown, WVU, pp. 80.

Pellika, P.K.E., 1994.Geometric and radiometric corrections for Airborne Video Imagery for Land Cover Classification Applications. Proceedings of the First International Airborne Remote Sensing Conference and ExhibitionStrasbourg, France, Sept. 11-15, Environmental Research Institute of Michigan, Vol. II, p.273-283.

Pitt, D.G., Wagner, R.G., Hall, R.J., King, D.J., Leckie, D.G. and Runneson, U., 1997. Use of remote sensing for forest vegetation management: a problem analysis. The Forestry Chonicle, 73 (4) : 459-477.

Positive Systems, 1998. ADAR System 1000 Users Manual, v.5.7, Whitefish, MT, 21p.

Seed, E.D., King, D.J. and Pellika, P.K.E., 1999. Multivariate analysis of low cost airborne CIR imagery for the determination of forest canopy structure. Proceedings of the Fourth International Airborne Remote Sensing Conference and Exhibition/2 $1^{\text {st }}$ Canadian Symposium on Remote Sensing. Ottawa, Canada, 21-24 June, Environmental Research Institute of Michigan, Vol. II, p. 139-147.

Slater, P. 1980. Remote sensing: optics and optical systems. Don Mills, ON, AddisonWesley, 575 p.

Society of American Foresters, 1980. Forest cover types of the United States and Canada. F.H.Eyre, edit., Washington, D.C., 148p.

Stow, D., Hope, A., Nguyen, A.T., Phinn, S. and Benkelman, C.A., 1996. Monitoring detailed land surface changes using an Airborne Multispectral Digital Camera System. IEEE Transactions on Geoscience and Remote Sensing,34 (5) : 11911203.

Thom, C. and Jurvillier, I., 1994.Geometrical and radiometrical calibrations of a large format aerial digital camera designed for photogrammetry. Proceedings of the First International Airborne Remote Sensing Conference and Exhibition Strasbourg, France, Sept. 11-15, Environmental Research Institute of Michigan, Vol. II, p.237-248.

Townshend, J.R.G., 1980. The spatial resolving power of earth resources satellites: A review. Progress in Physical Geography, 5 : 32-55.

United States Department of Agriculture, 1982. Soil surveys of Randolph County Area, West Virginia, 167 pages + maps.

Walsh, S.J., Moody, A., Allen, T.R. and Brown, D.G., 1997. Scale dependence of NDVI and its relationship to mountainous terrain, in Scale in remote sensing and GIS, 
Quatrocchi, D.A. and Goodchild, M.F., Eds. CRC Lewis Publishers, Boca Raton, FL, 406p.

Woodcook, C.E. and Strahler, A.H., 1987. The factor of scale in remote sensing. Remote Sensing of Environment, 21 : 311-332.

Wulder, M., Mah, S. and Trudeau, D., 1996. Mission planning for operational data acquisition campaign with the casi. Proceedings of the Second International Airborne Remote Sensing Conference and Exhibition San Francisco, USA, June 24-27, Environmental Research Institute of Michigan, Vol. III, p.53-61.

Yuill, C.B., 1999. Personal communication. 


\section{APPENDIX 1 \\ RECOMMENDATIONS}

\subsection{IMAGE ACQUISITION ISSUES}

\subsubsection{Illumination considerations}

Once the area to be imaged is selected, the user must decide how to best position the flight lines over the area to optimize the application and to take the best advantage of sun/surface/sensor geometry. In order to collect overlapping imagery suitable for mosaicking (with both end and side overlaps of 50\%), the flight lines should be calculated taking into consideration the height of flight and the time interval between the consecutive images.

Further, the flight lines can be edited in $\mathrm{ArcView}^{7}$ and used as a navigation map in Geolink (see 4.3 - Global Positioning System and its use for data acquisition and image preprocessing). The images should be acquired flying the flight lines in the same direction, which will improve their geometry and the illumination conditions.

\subsubsection{The timing for image acquisition}

The time for acquisition of digital airborne images must be chosen by keeping under close observation the areas that need to be remotely sensed. The best time for

\footnotetext{
${ }^{7}$ ArcView is a trade mark of ESRI, Redlands, CA
} 
image acquisition is when fall leaf coloration is at its peak, when the spectral information is the highest possible for all Central Appalachian hardwood species. Certainly, there are other factors that need to be considered, such as weather conditions, and plane and personnel availability, but from our experience it is highly recommended that every effort be made to acquire images when leaves are at the peak of fall coloration.

\subsubsection{Mosaicking and geometric correction}

Image mosaicking of airborne data can prove to be problematic because the reduced ground area of high-resolution imagery may result in few easily identifiable ground control points. The level of accuracy desired for a particular mission will dictate the emphasis on geocorrection accuracy. The lack of natural tie points may be rectified through the use of highly reflective markers. Ground markers are a feasible option only when the resolution is high enough to lay out markers that exceed the image resolution. Some authors (Wulder et al., 1996) have shown that white plastic house-wrap is very good as a marker on high-resolution imagery. House-wrap is used as a layer between foam insulation and siding in modern home construction and comes in rolls approximately $3 \mathrm{~m}$ wide and $50 \mathrm{~m}$ long. Once the temporary markers are positioned, survey of the makers with high accuracy GPS results in excellent ground control points. 


\subsection{GROUND AND TRAINING DATA ACQUISITION}

The ground data should be acquired on large plots, preferably square so they can be easily mapped and used for training and control. The ground plots should be located using high accuracy GPS, i.e. Trimble Pathfinder ProXL, and the positions of the corners of the plots should be located on easily identifiable features, such as crossroads, large trees, clearcuts, large gaps in the canopy, etc. Ground plots should be from $25 \times 25 \mathrm{~m}$ up to 50x50m, which will allow correct mapping of all the trees in the upper layer of the canopy. Also, groups of trees to be used for training and control points should be located inside the plots because then can be easily tied to the corners of the plot. 


\title{
DORU PACURARI
}

\author{
\#203, 395 Newton Avenue \\ Morgantown, WV \\ Zip code 26505 \\ (304) $293-8985$
}

E-mail:doru@csee.wvu.edu

\section{EDUCATION}

Jan. 2000 - present

\author{
West Virginia University, Morgantown, WV \\ Department of Computer Science \\ Master of Science program
}

Jan.1998 - Dec.1999

\author{
West Virginia University, Morgantown, WV \\ M.Sc., Division of Forestry, GPA 3.9 \\ Thesis title: Evaluation of the Use of Remotely Sensed \\ Images to Speciate Mixed Appalachian Forests

\section{Coursework:} \\ - Introductory and Advanced GIS \\ - GIS Technical Issues \\ - GIS Database Design \\ - Advanced Remote Sensing \\ - Quantitative Methods \\ - Applied Statistics and Regression Analysis \\ - Forest Stand Dynamics
}

Sept.1984 -July 1989

\author{
University of Brasov, Romania \\ Master of Science in Forestry \\ Graduating on the second position among 80 students \\ (average mark of 9.33 out of 10)
}

\section{SOFTWARE EXPERIENCE}

Operating Systems - Windows 95, NT, UNIX;

GIS - Arc/Info (Arcedit, Arcplot, Grid, Tables/Info), ArcView (Spatial Analyst, 3D Analyst);

Remote Sensing/Image Processing - ERDAS Imagine, IDRISI; 
Programming - Ada95, C, Java, Visual Basic, Quick Basic, Arc/Info AML, HTML;

Databases - Fox Pro, MS Access;

Word Processing - MS Word, Word Perfect 5.1;

Spreadsheets - MS Excel;

Others - Eudora, Netscape, MS Front Page;

GPS - Pathfinder, Geolink, Trimble;

\section{TRAINING}

1995 and 1996 Post-graduate training in Sustainable Development and Ecology with teachers from Germany, France and Netherlands University of Suceava, Department of Forestry, Romania

1995 Post-graduate training in computers, timber sales and forest management Centre National de Formation Forestiere, Nancy, France

$1990 \quad$ Post-graduate training in forest monitoring Training Centre for Forestry Personnel, Busteni, Romania

\section{WORK EXPERIENCE}

- Working experience with GIS programs (ArcInfo, ArcView);

- Working experience on Timber Supply Analysis;

- Working experience on human disturbances of Boreal Forests.

1995 - 1996 Assistant Professor, Department of Forestry University of Suceava, Suceava, Romania

- Taught Management Planning and Forestry Estimations full time course and seminars to undergraduate students (70 staff);

- Planned, implemented and tested courses

- Practical works in the field with students on Management Planning and Silviculture disciplines. 
- Taught foreign summer students from Germany, France and Netherlands with the field research on Romanian wildlife, vegetation and habitat

1995 -1996 Working with Harvard Institute for International Development on a research program about the Transaction Analysis of Stumpage Auctions in District of Suceava, Romania

- Collecting data from the field regarding the stumpage auctions from 450,000 hectares, consisting in pine, spruce and hardwoods;

- Created and maintained numerous databases in FoxPro 2.5 and did preliminary processing of the data;

- Provided detailed reports on all of my work.

\section{9 -1995 Head of Forest Resources Section}

Breaza Forest Division of Romanian Forest Service

Suceava District, Romania

- Forest Resources Management;

- Coordinated and controlled the silviculture and reforestation works;

- Negotiated and executed contracts (Timber licenses) with the logging companies;

- Approved and supervised logging activities;

- Forest protection against diseases, winds, fires, water;

- Forest monitoring;

- Coordinated and organized the privatization of forests process in Breaza Forest Division;

- Budget management;

- Trained and supervised up to 30 staff regarding operations and safety.

LANGUAGES

INTERESTS

REFERENCES
Fluent in French and Romanian

Arts, music and sports

Available upon request 


\section{RECENT PUBLICATIONS}

Pacurari, D., Gribko, L. S., Warner, T. A., Wilson, T. H., Yuill C. B., 1999. Optimal spatial resolution for Appalachian Hardwood forest images, Presented at the Fourth International Airborne Remote Sensing Conference and Exhibition $/ 21^{\text {st }}$ Canadian Symposium on Remote Sensing, Ottawa, Ontario, Canada, 21-24 June.

Pacurari, D., 1999. The optimal spatial resolution for Central Appalachian Hardwood Forest images. Presented at the Annual WESTVACO Conference Morgantown, January 13-15.

Abrudan, I., Pacurari, D., 1996. Reflection of the Non-Market Benefits of Forests in the Forest Policy of countries in transition - A case study: Romanian Forest Policy. Presented at the International Symposium on the Non-Market Benefits of Forestry Forestry Commission, Edinburgh, Scotland, June 23-29. 